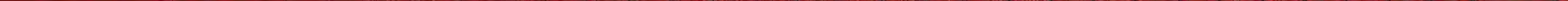




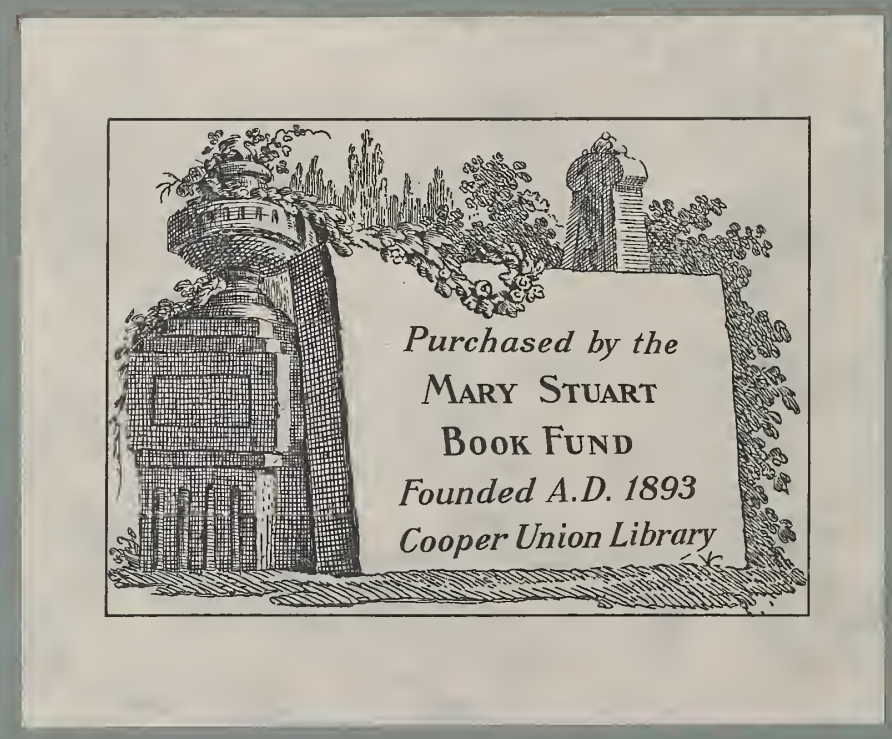


$k$ 


\section{Scènes Comiques}

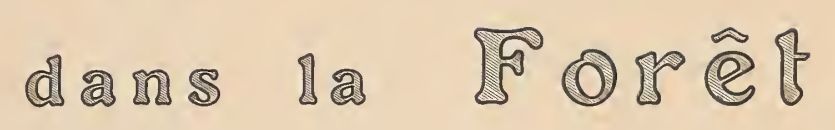




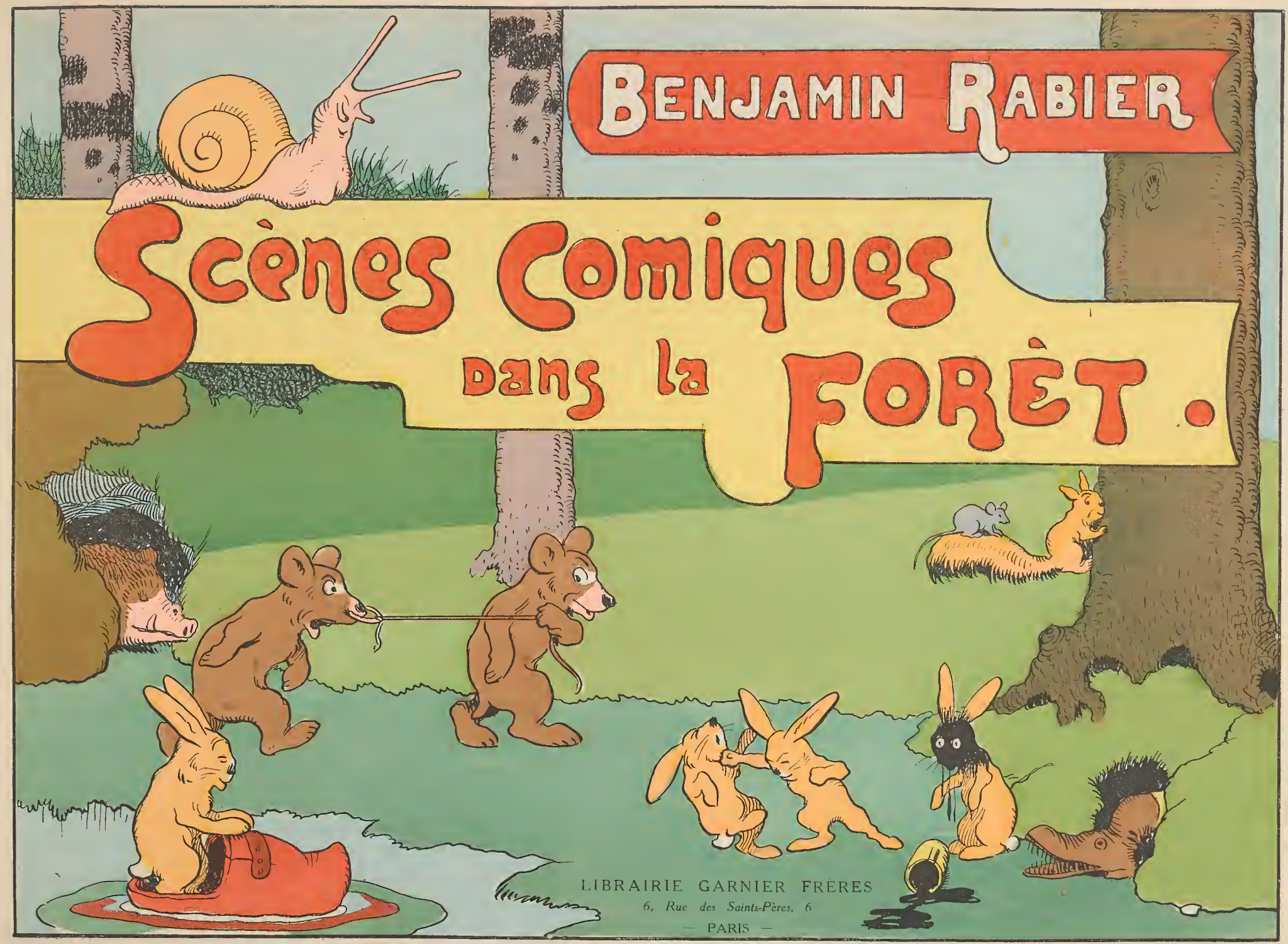




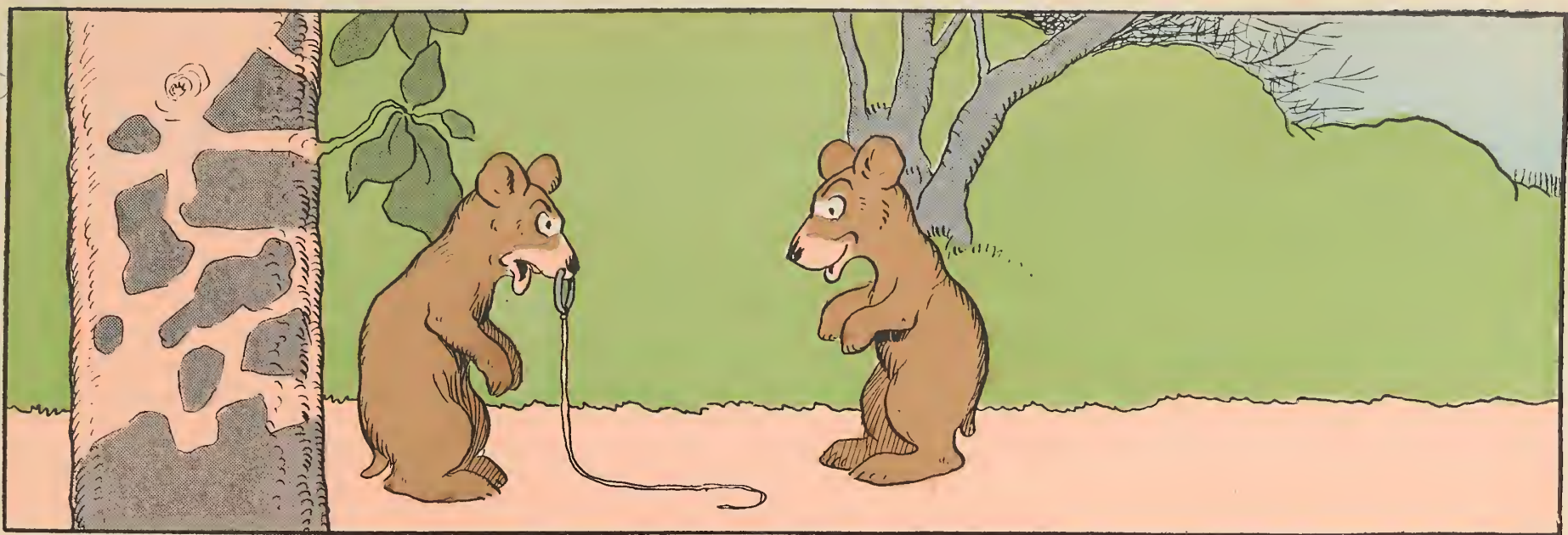

- Oui, mon chéri : j’ai été pris par des bohémiens. Ils m’ont mis un anneau dans le nez...

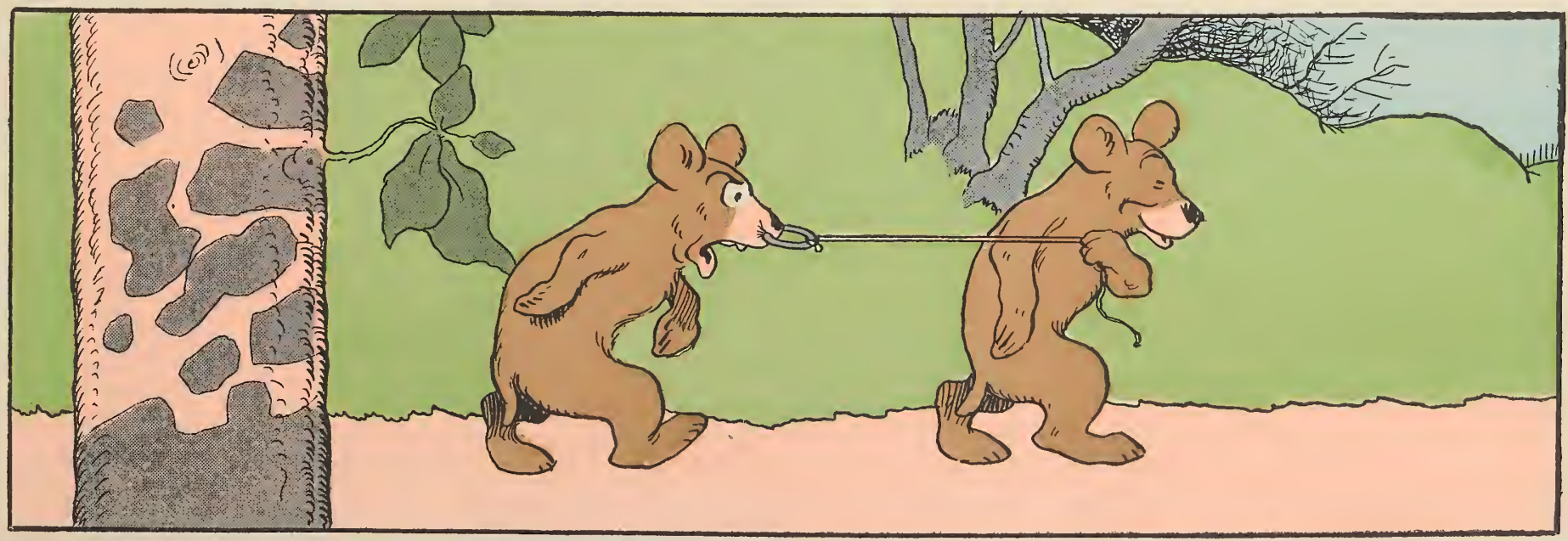

- Ça c'est une bonne affaire. Maintenant je vais pouvoir mener ma femme par le bout du nez ! 


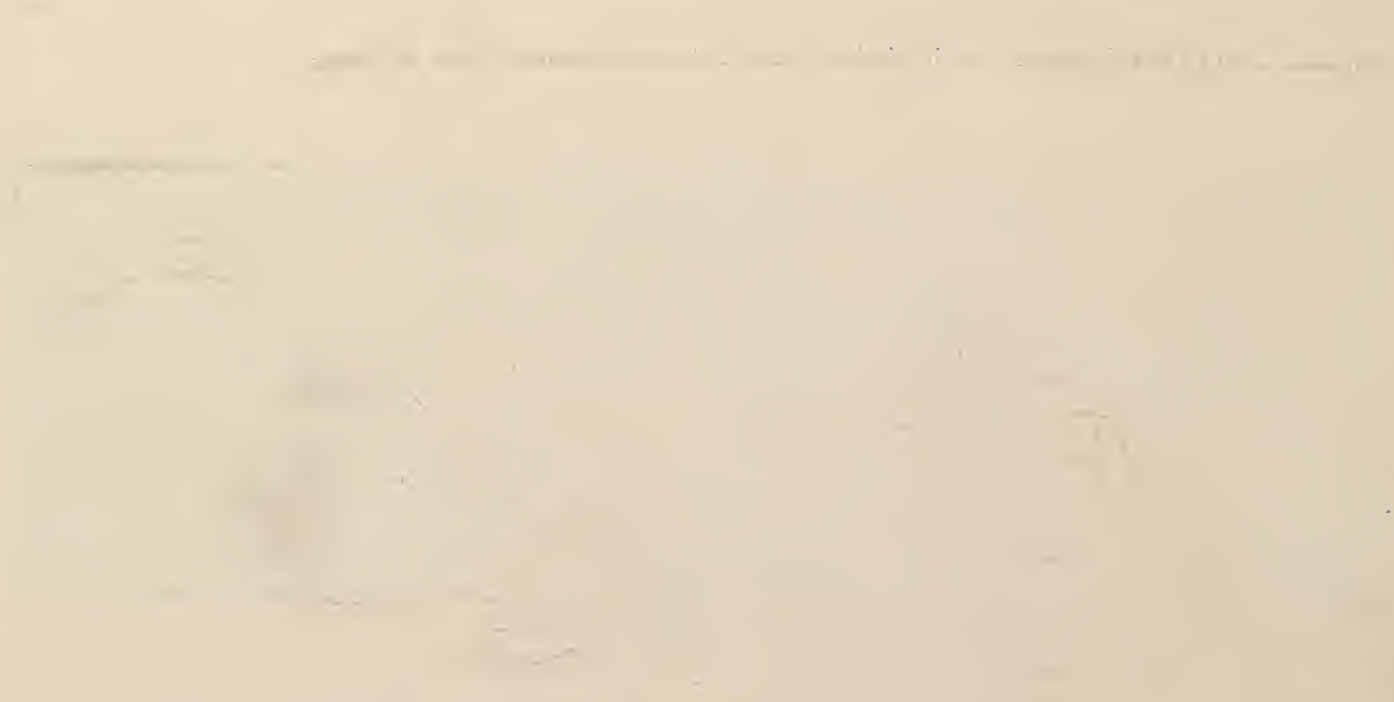




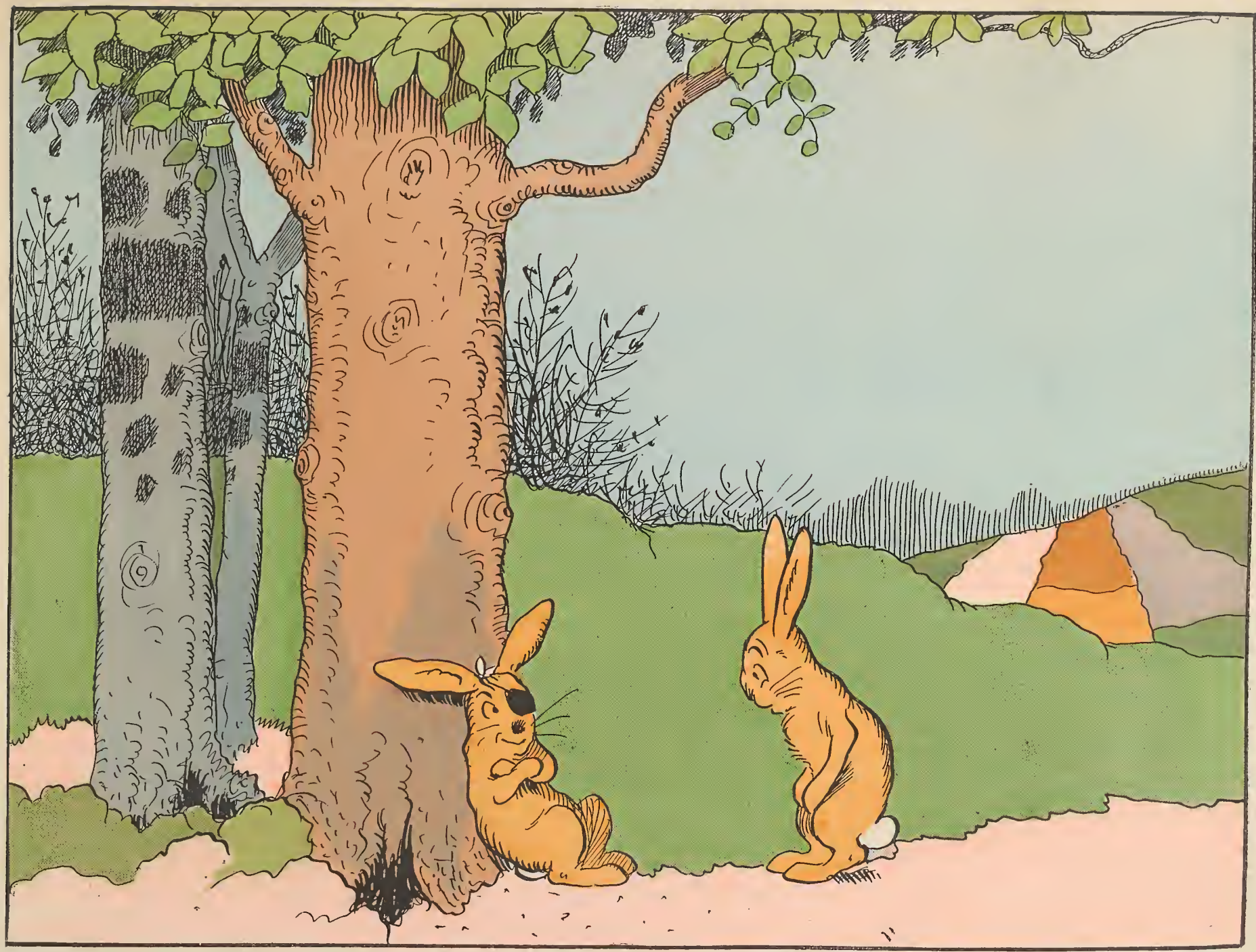

- Oui, j'ai eu un œil crevé le jour de l'ouverture de la chasse.

- Si tu sommeilles au pied de cet arbre, tu vas te faire crever l'autre !

- Sois tranquille, je ne dors que d'un œil. 


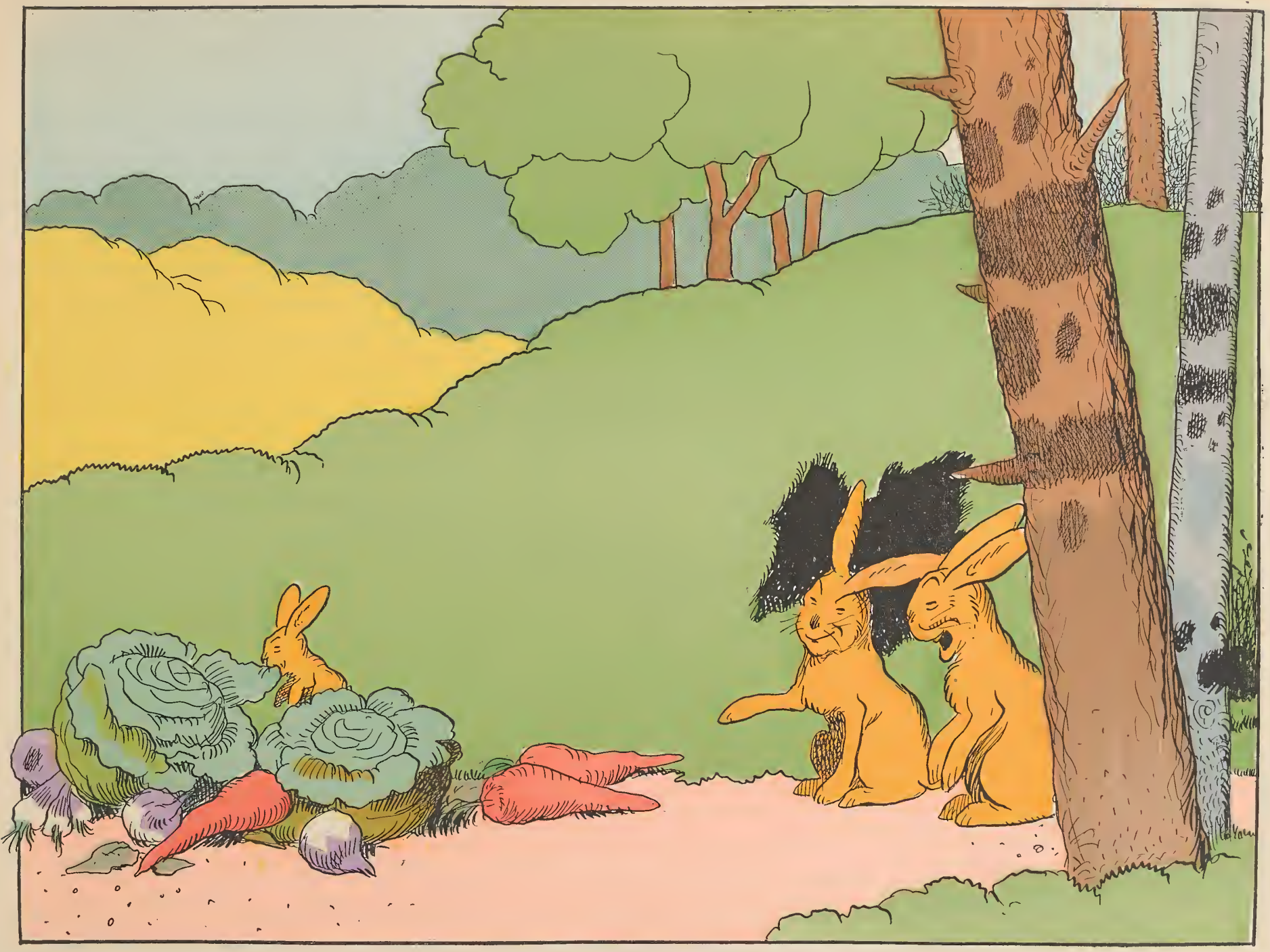

- Il est bien fier, notre fils?

- Dame ! depuis qu'il est dans les grosses légumes ! 
LE BOIS INONDE

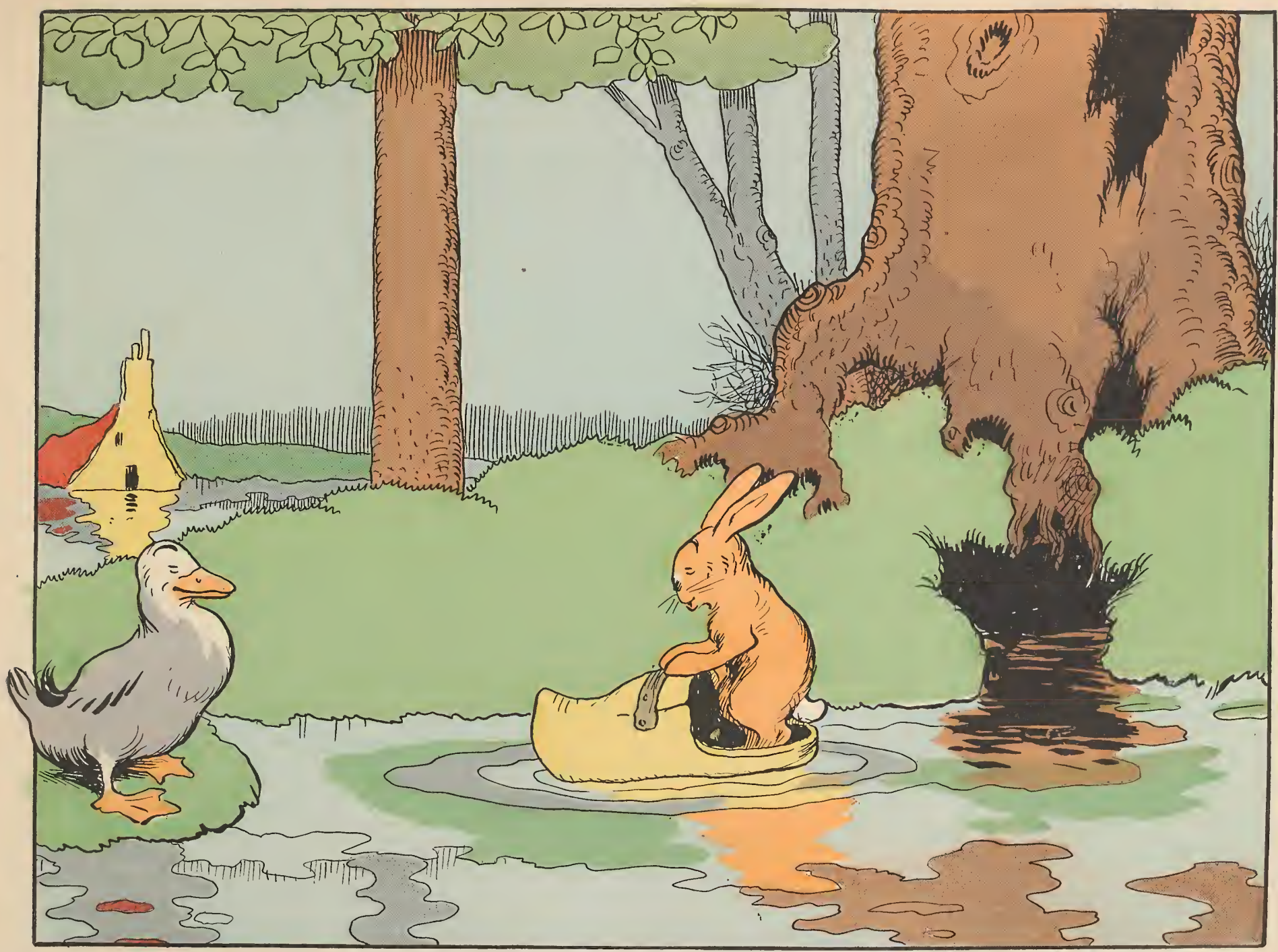

LE CANARD. - Bravo ! Tu as trouvé le moyen de sortir en bateau de ton terrier... Tu es dégourdi, toi. LE LAPIN. - Oui, je n'ai pas les deux pieds dans le même sabot! 

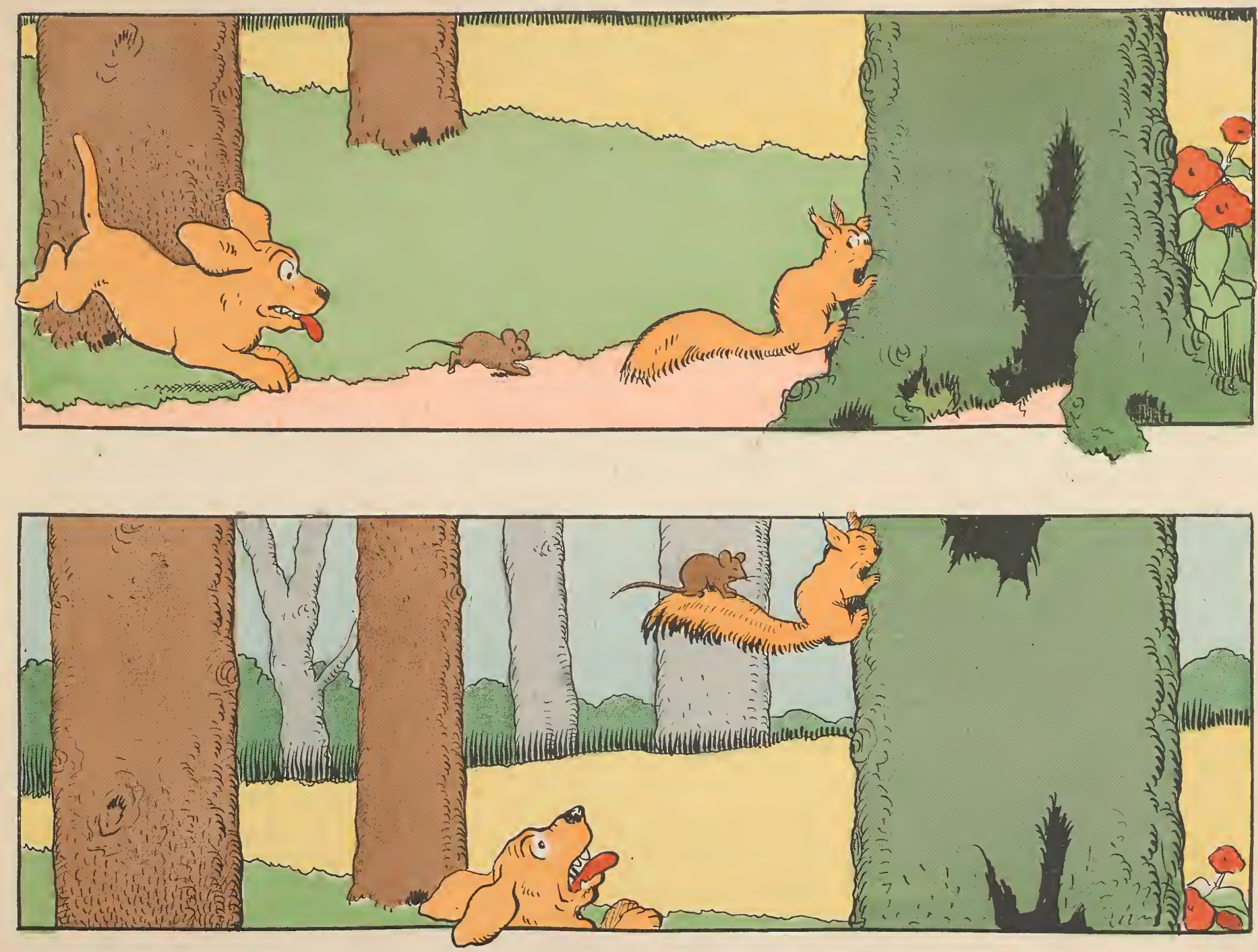

Ou 1'ascenseur improvisé. 


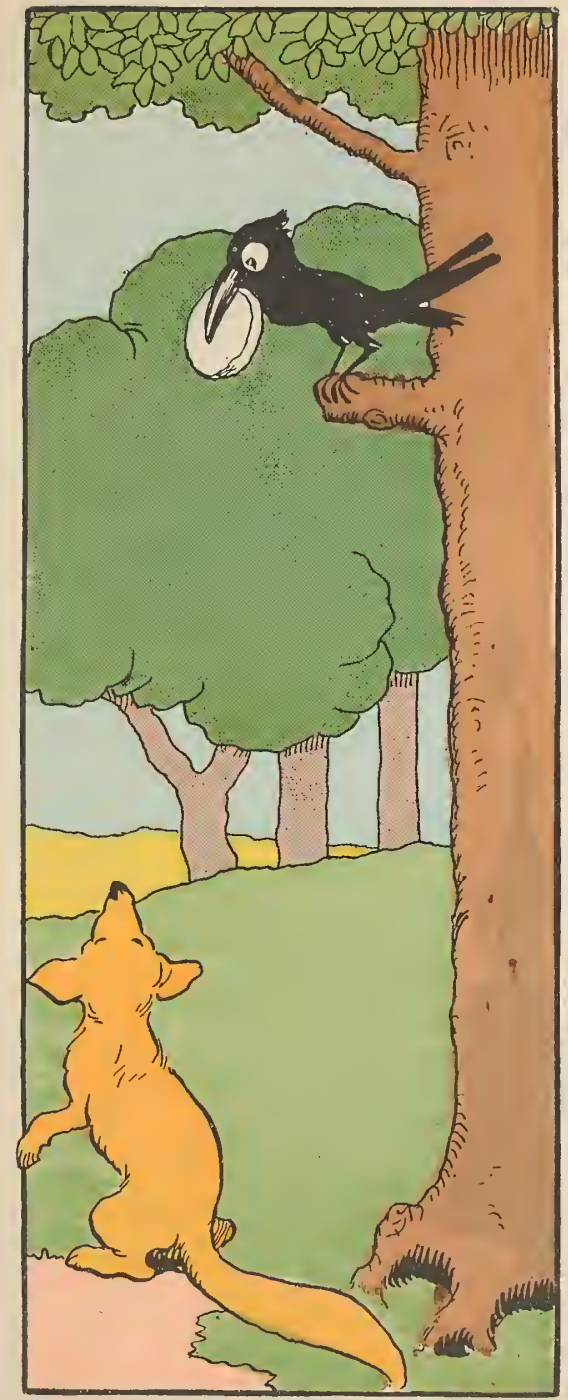

LE RENARD. - Bonjour, monsieur du Corbeau $\mathrm{Si}$ votre ramage ressemble à votre plumage, Vous êtes le phénix des hôtes de ces bois.

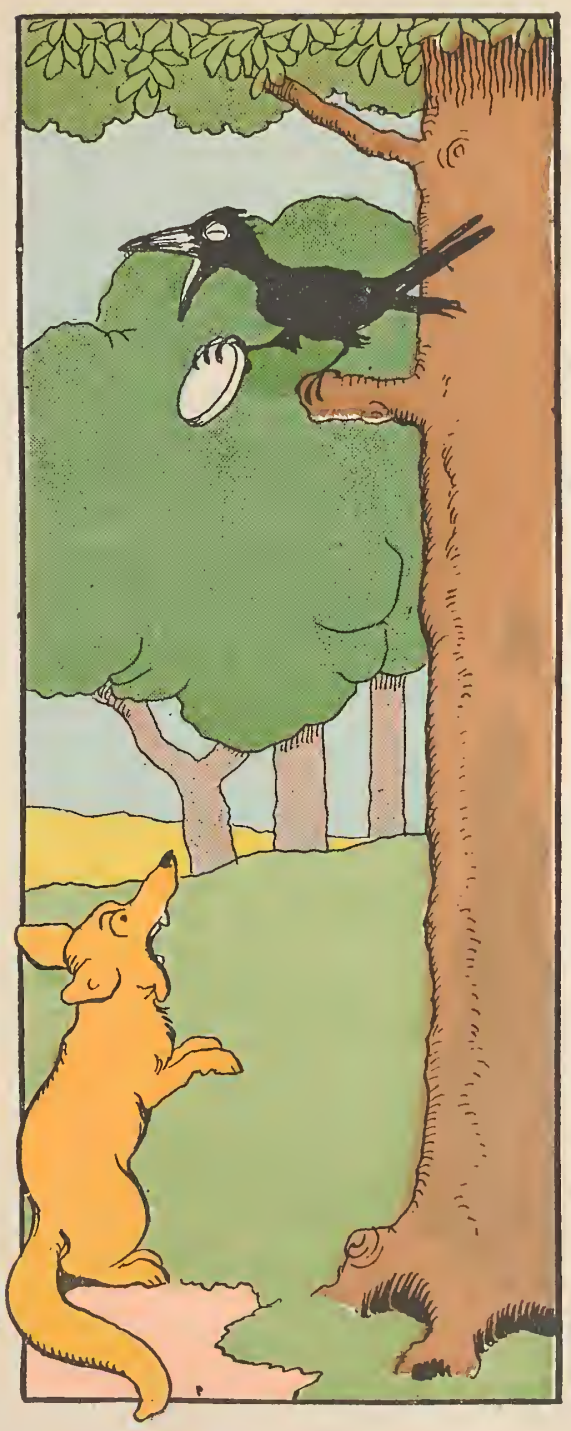

Le corbeau prend le fromage dans sa patte et se met à chanter.

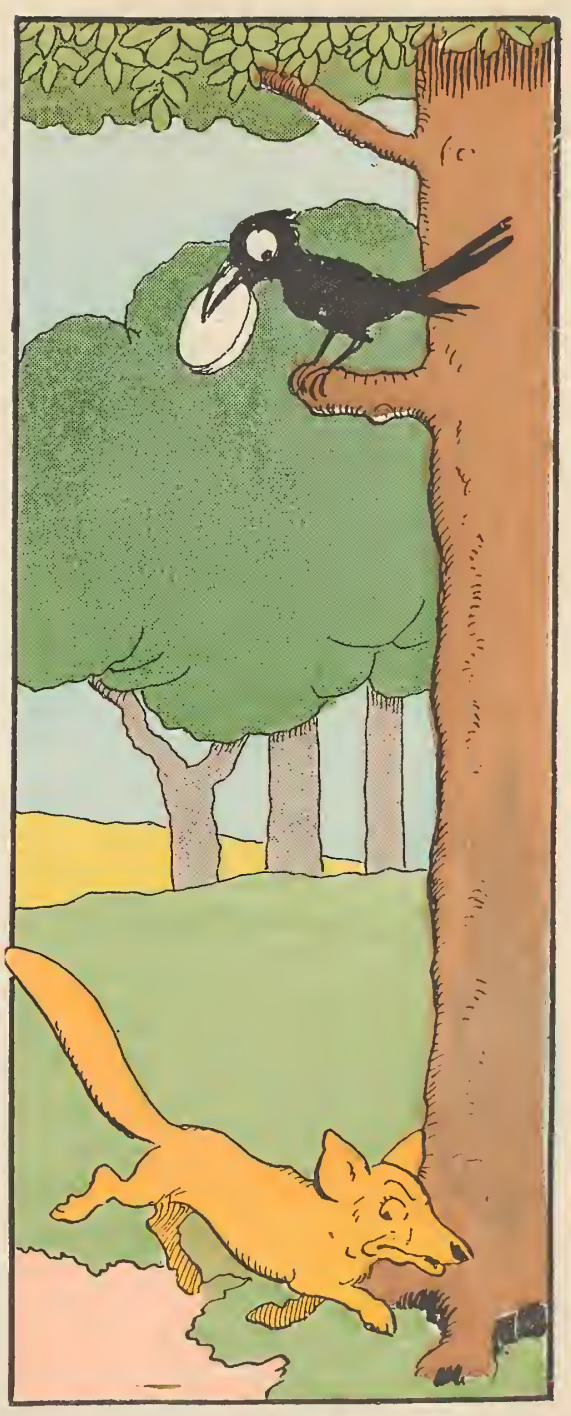

LE RENARD. - Zut !... Il a lu $\mathrm{L}_{\text {a }}$ Fontaine !!! 


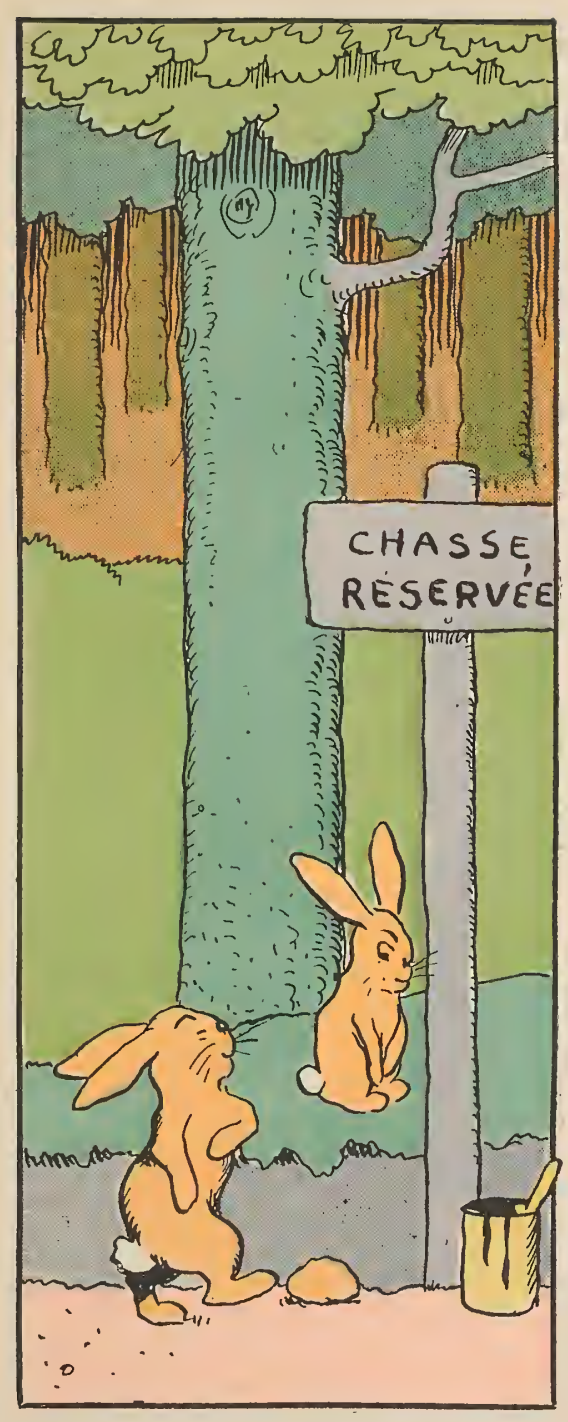

- J'ai une santé admirable, malgré_mon âge...

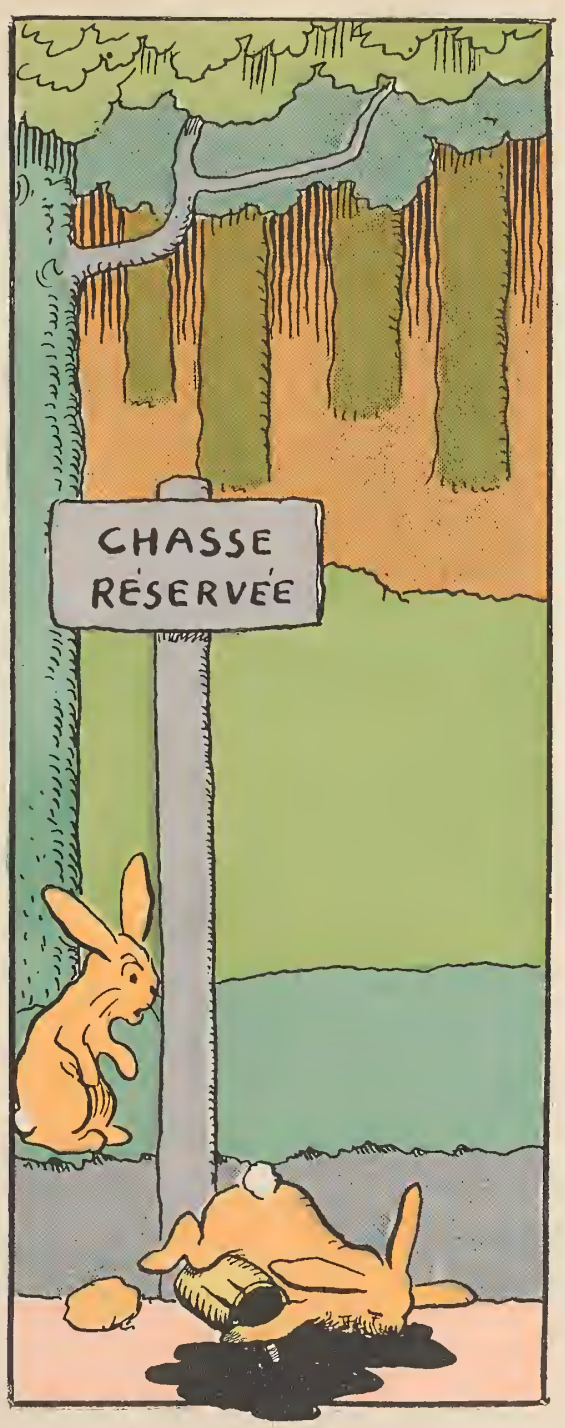

- Je suis...

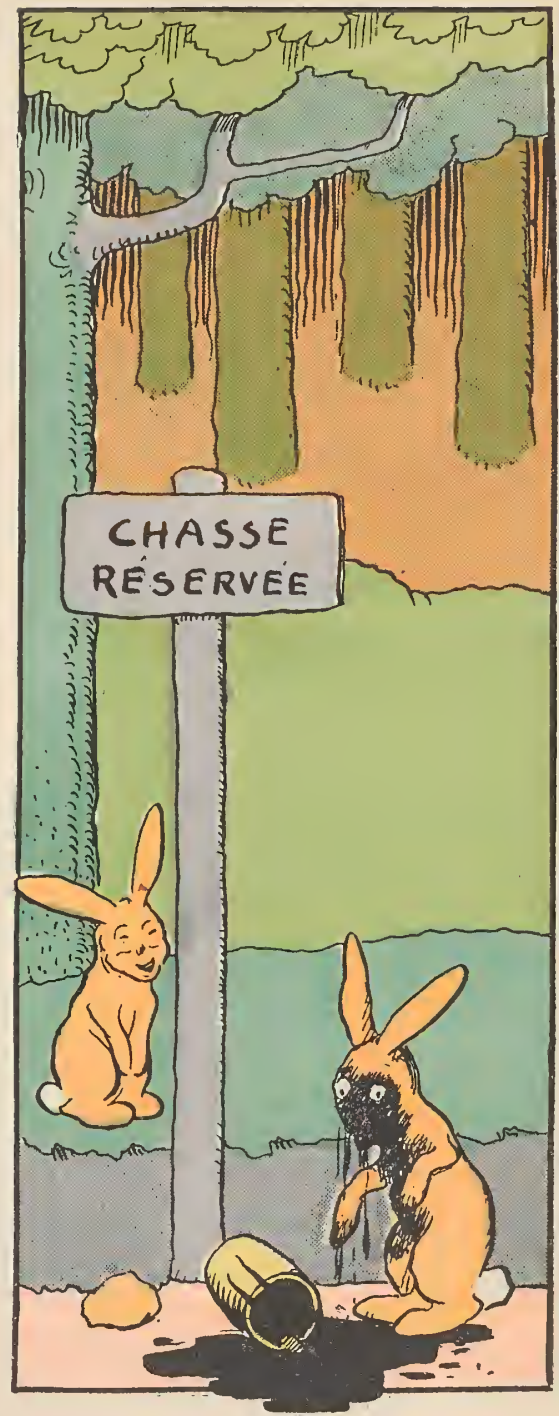

- ... encore très vert. 


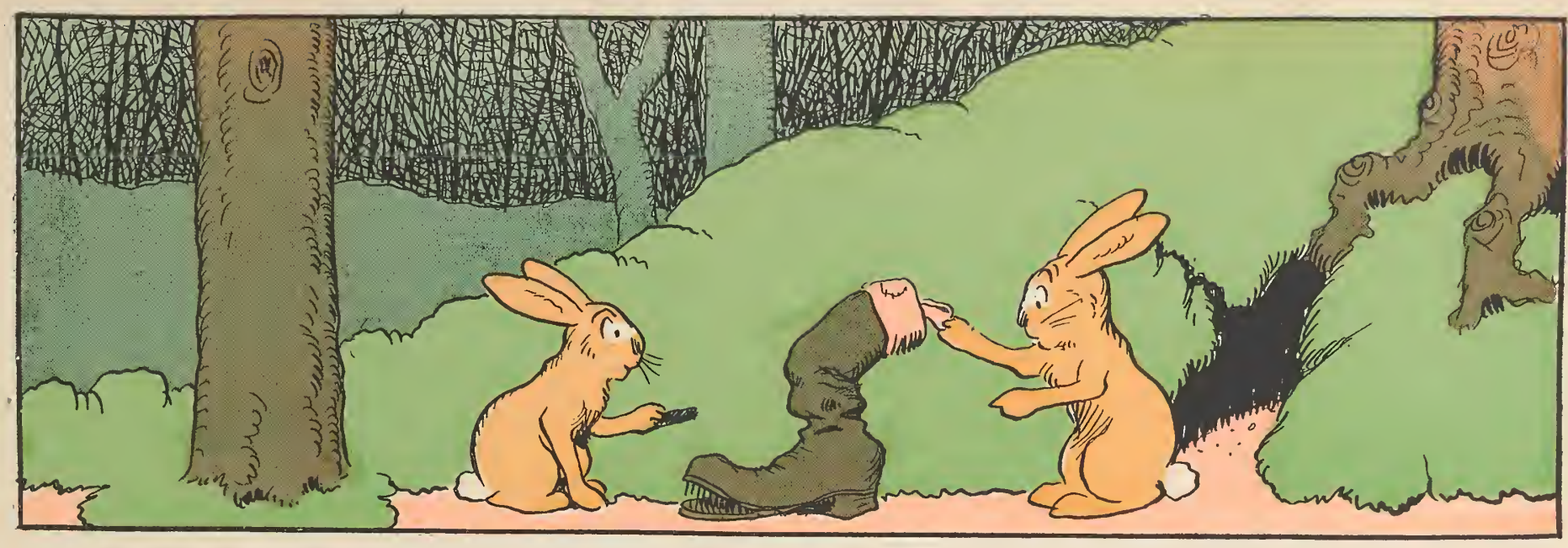

— Avec ton morceau de charbon, toi qui sais dessiner, tu vas dessiner un œil sur cette botte et faire quelques taches.

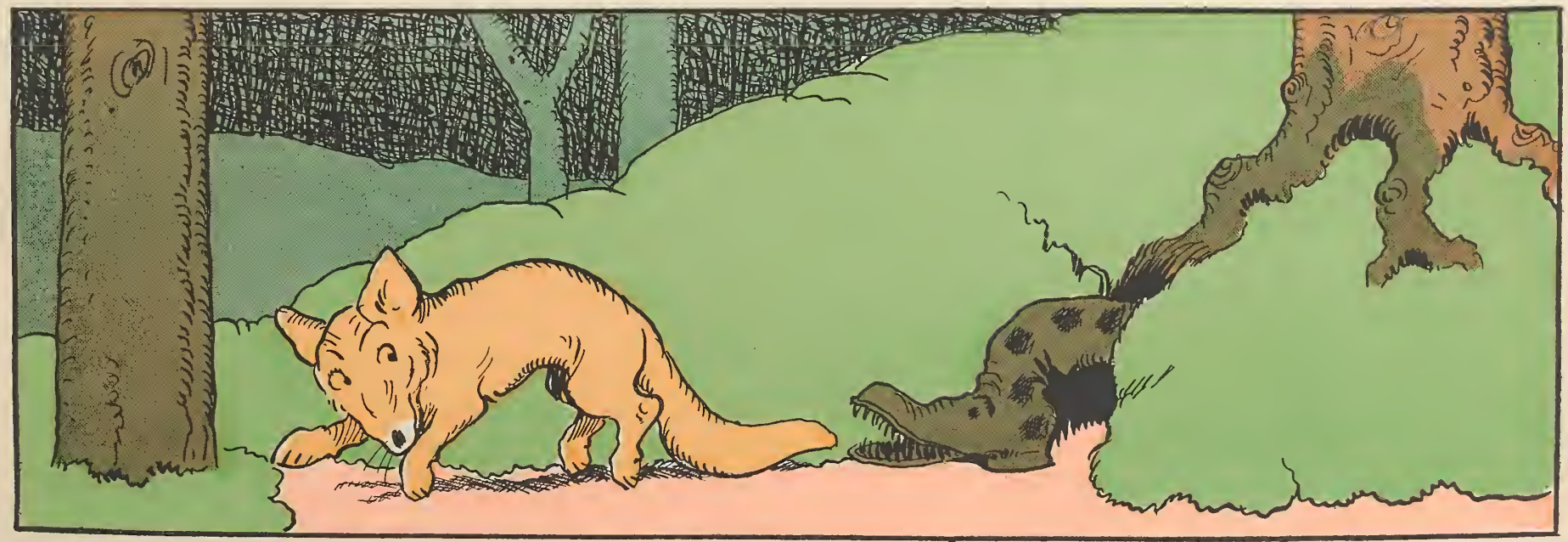

- A merveille... maintenant nos ennemis peuvent rôder près du terrier. 


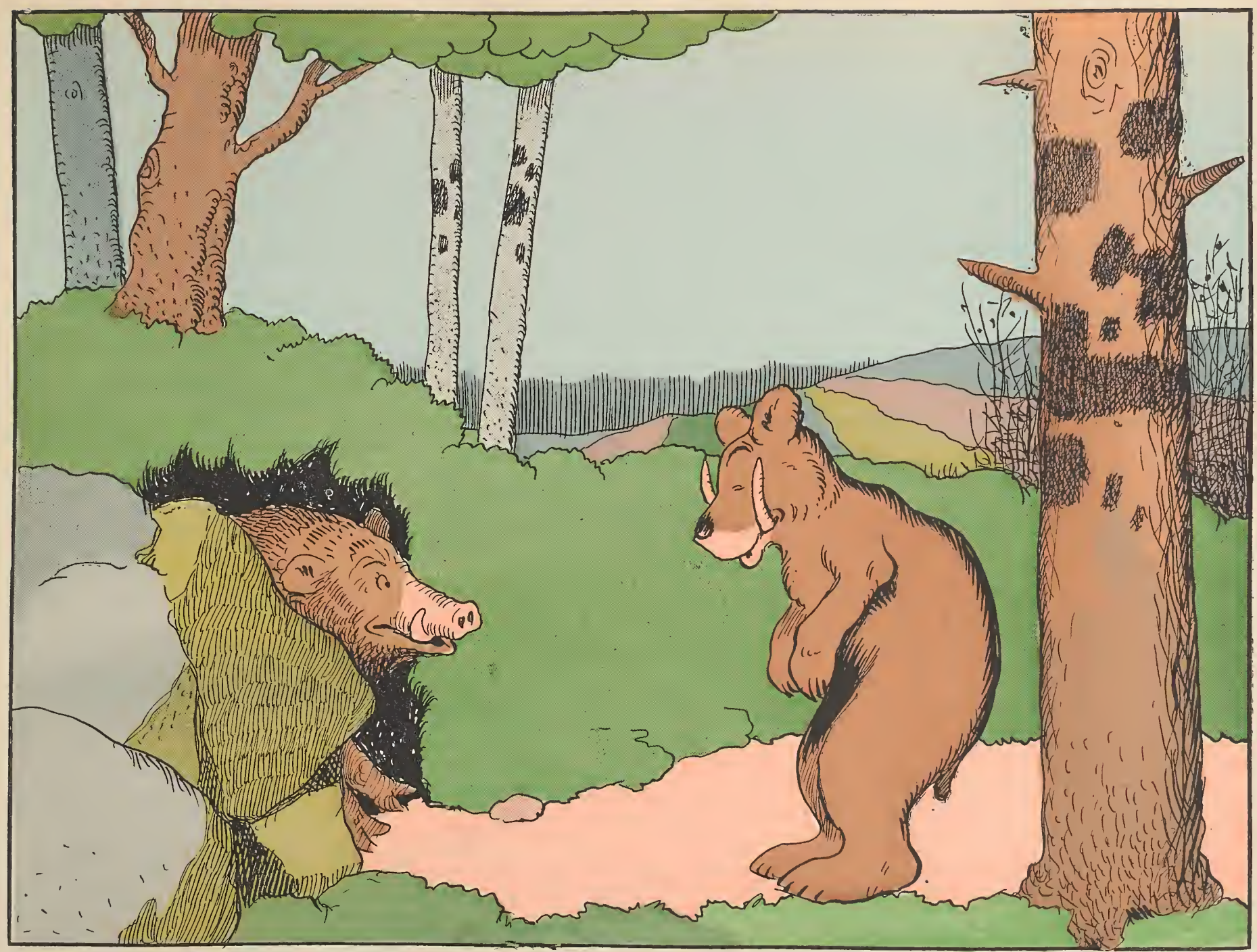

LEE SANGIIER. - Sapristi, quels boutoirs ! Vous faites concurrence aux sangliers? L'OURs. - Mais non : c'est une chèvre que je ne peux pas arriver à digérer. 


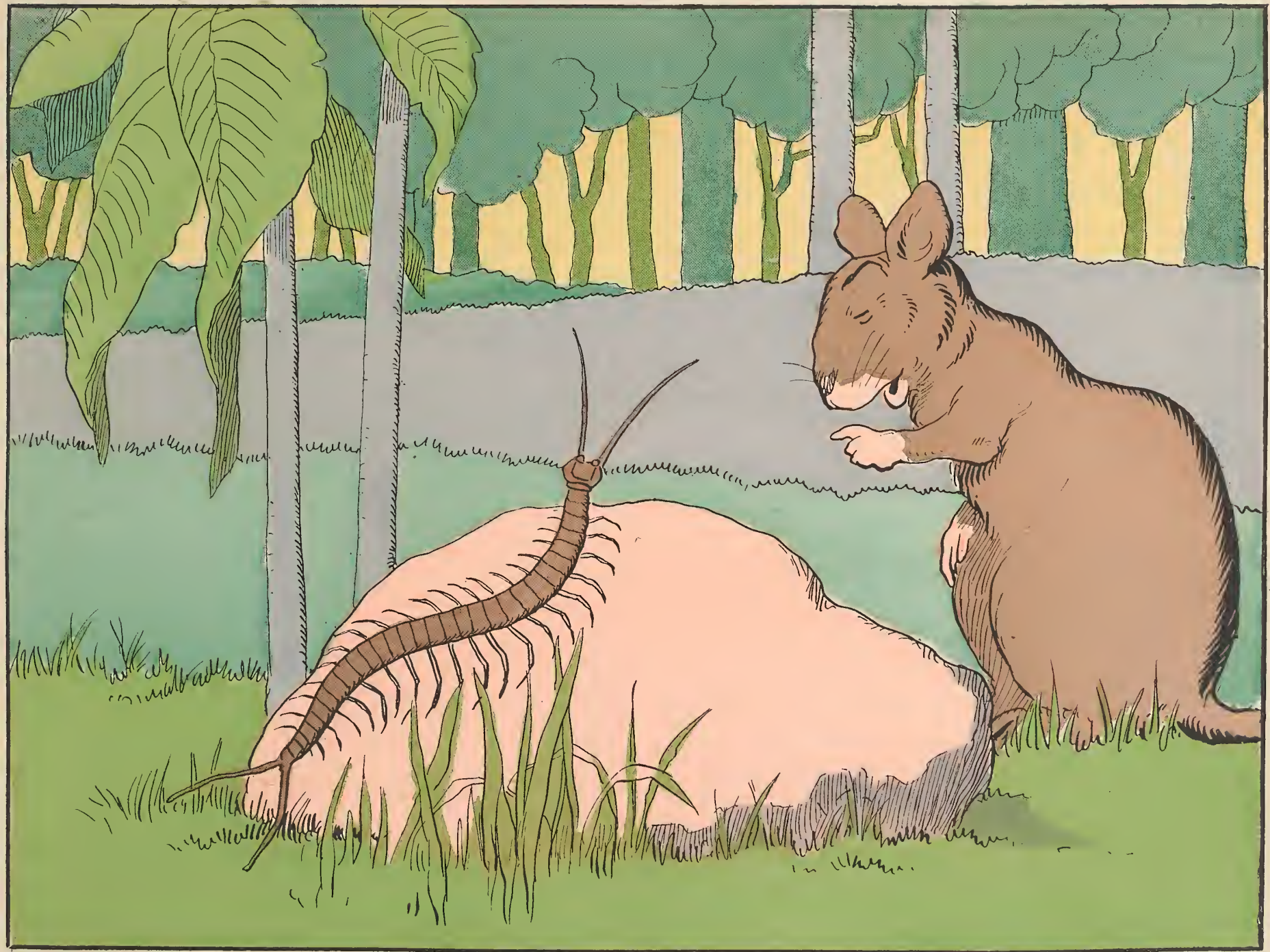

- Comme tu as grandi, mon vieux mille-pieds?

- Oui, je ne suis plus un bébé... il y a longtemps que je ne marche plus à quatre pattes ! 


\section{.}




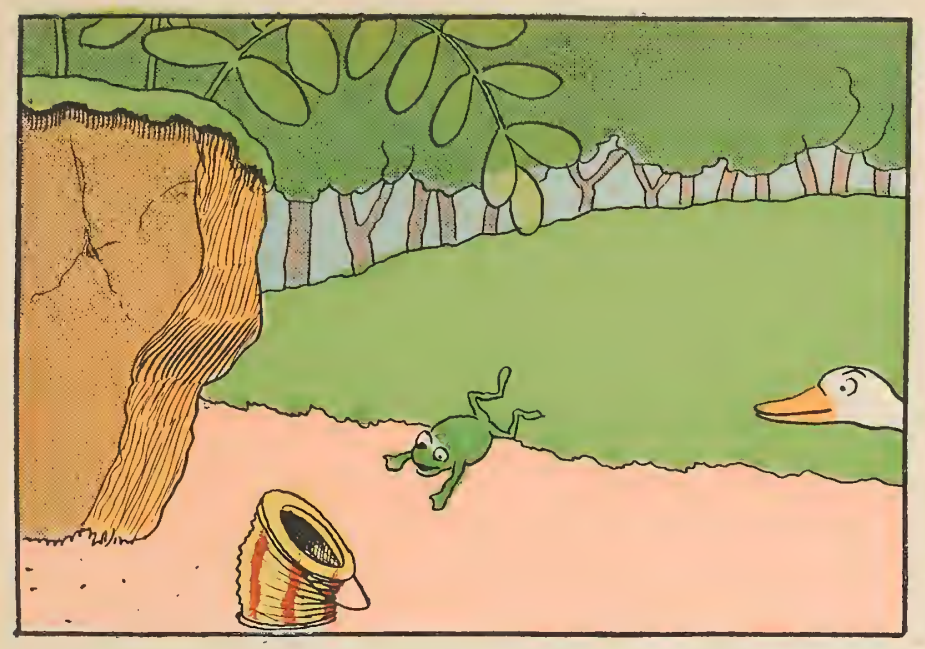

LA GRENOUILIE. — Un trou, je suis sauvée!

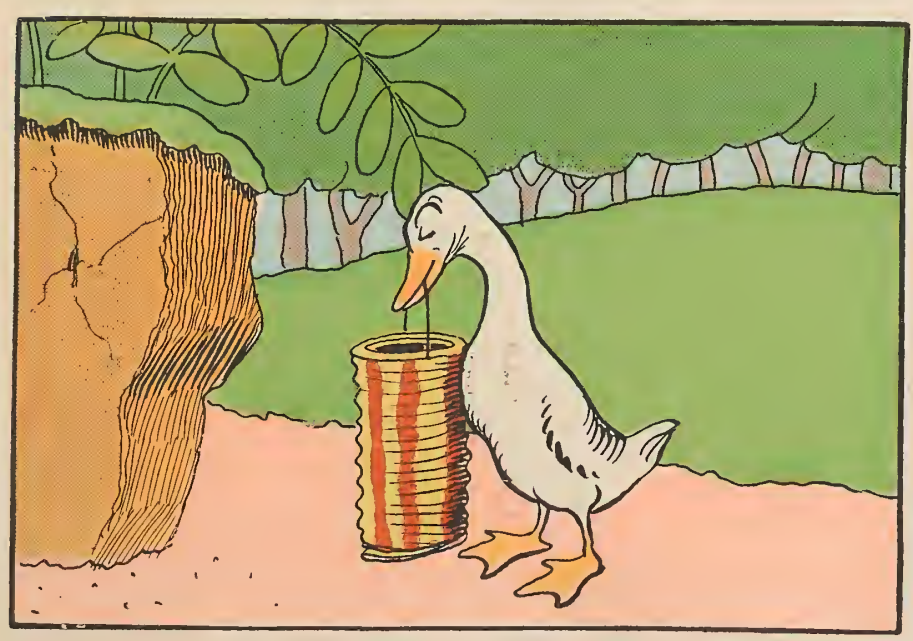

LE CANARD. - Je l'aperçois !...

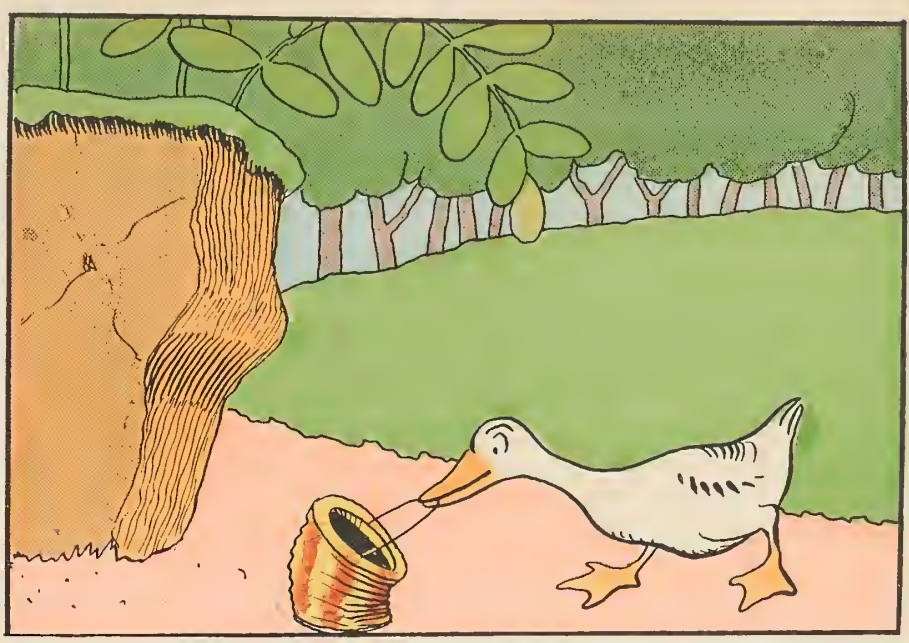

LE CANARD. - Je la tiens...

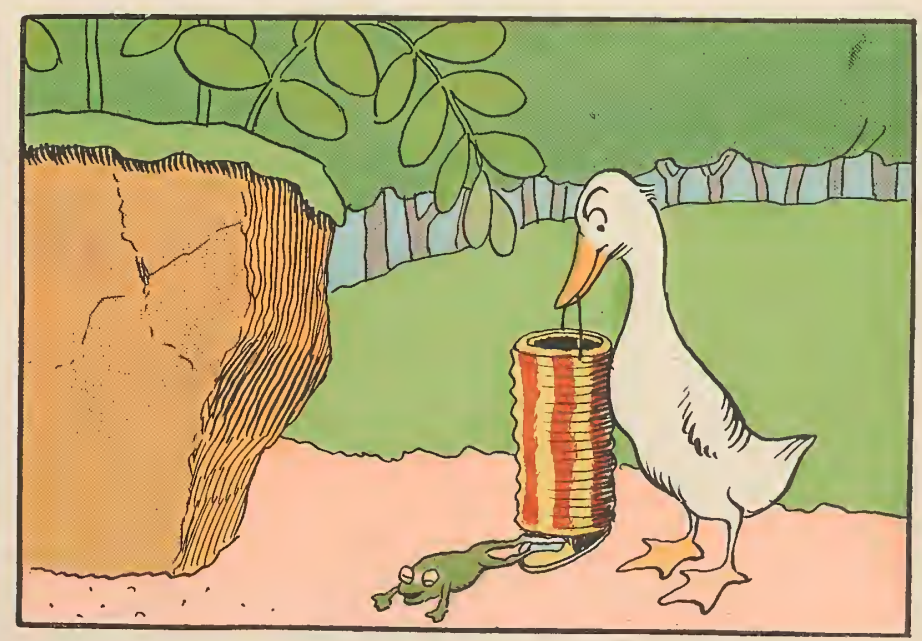

LE CANARD. - Je ne la vois plus I 


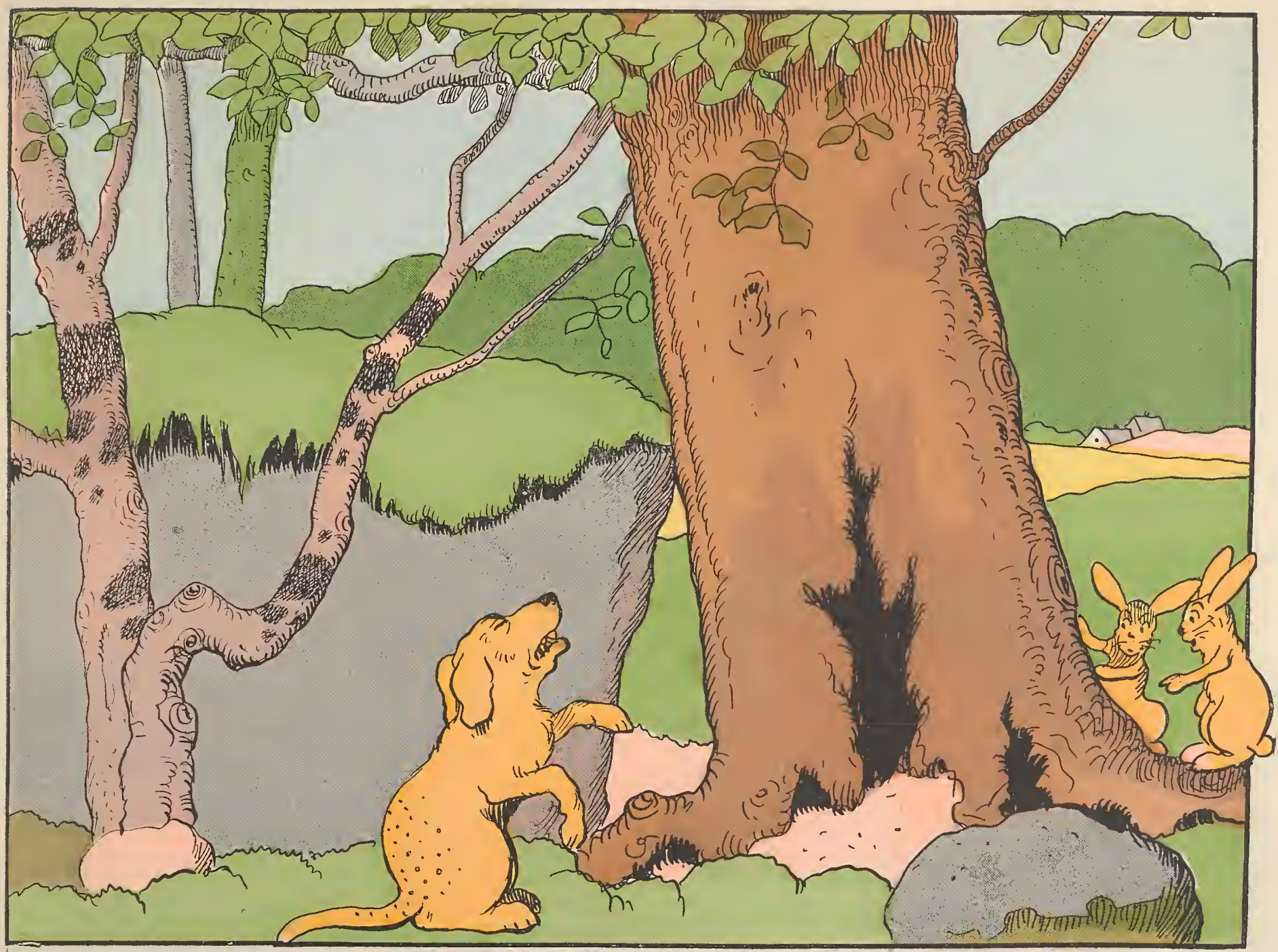

LE LAPIN. - Ça, c'est un bon chien : quand il a vu que son maitre me visait, il s'est placé entre le fusil et moi et c'est lui qui a reçu les petits plombs! 


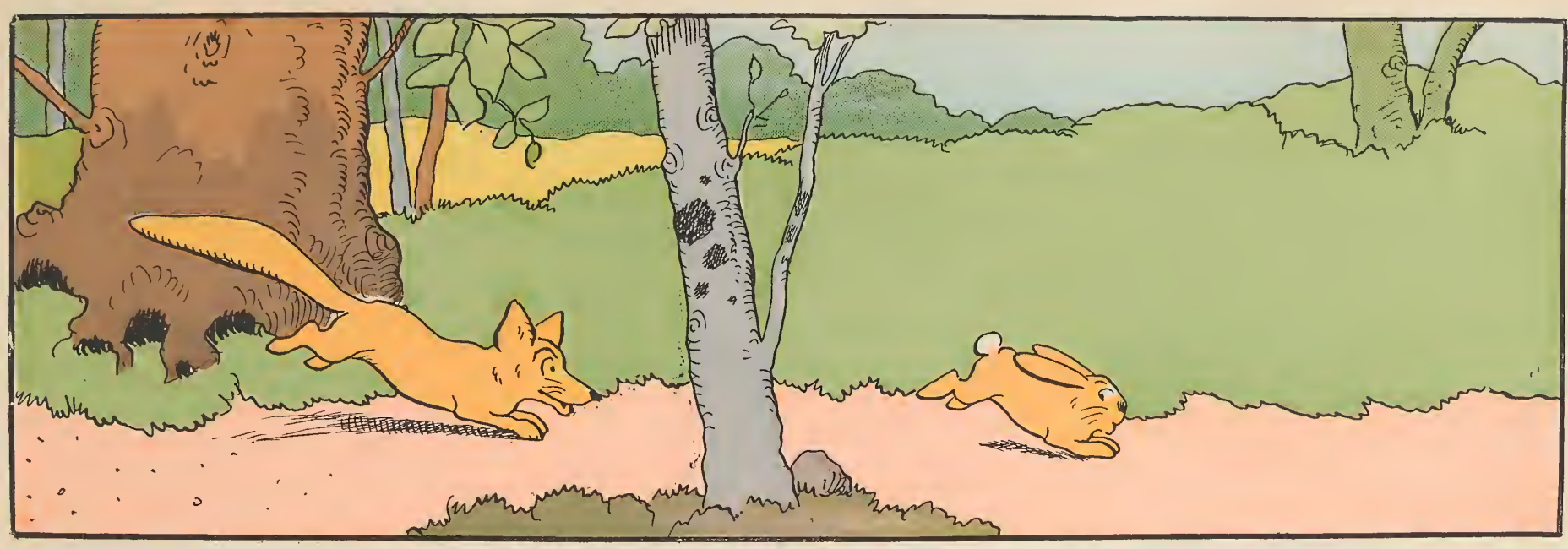

LE LAPIN. - Tu peux te fouiller pour m'avoir, je suis fin comme un renard!

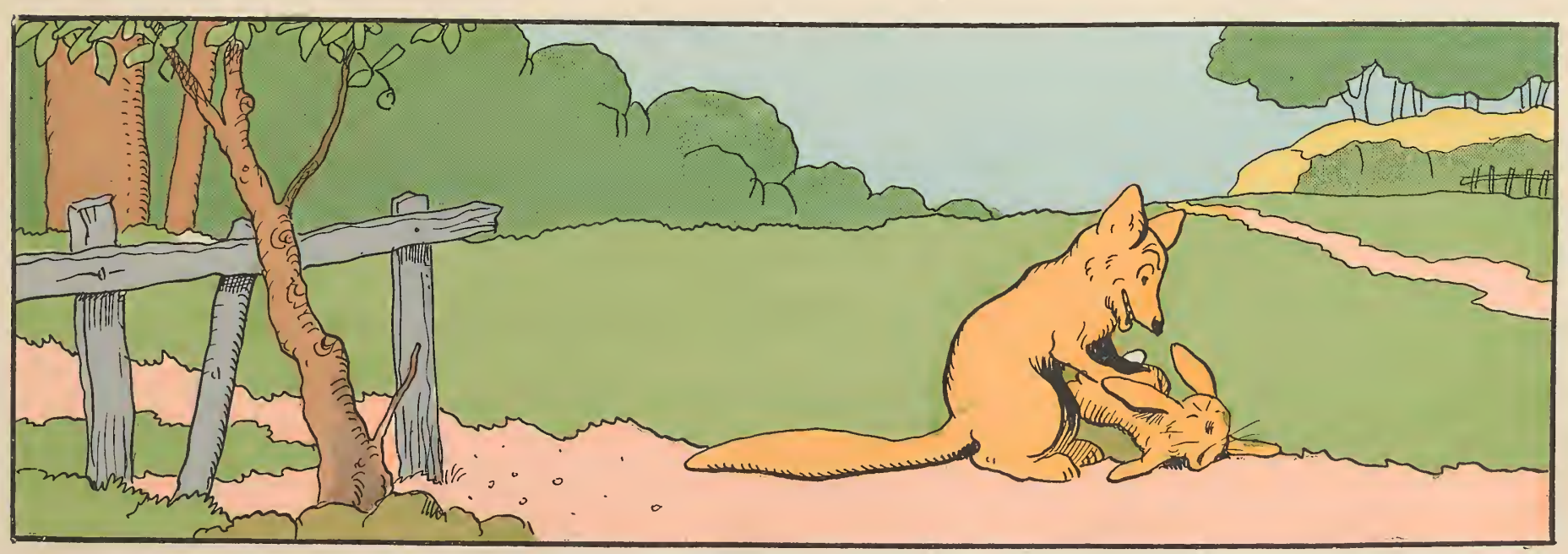

LE RENARD. - Mais moi, je suis un rude lapin ! 


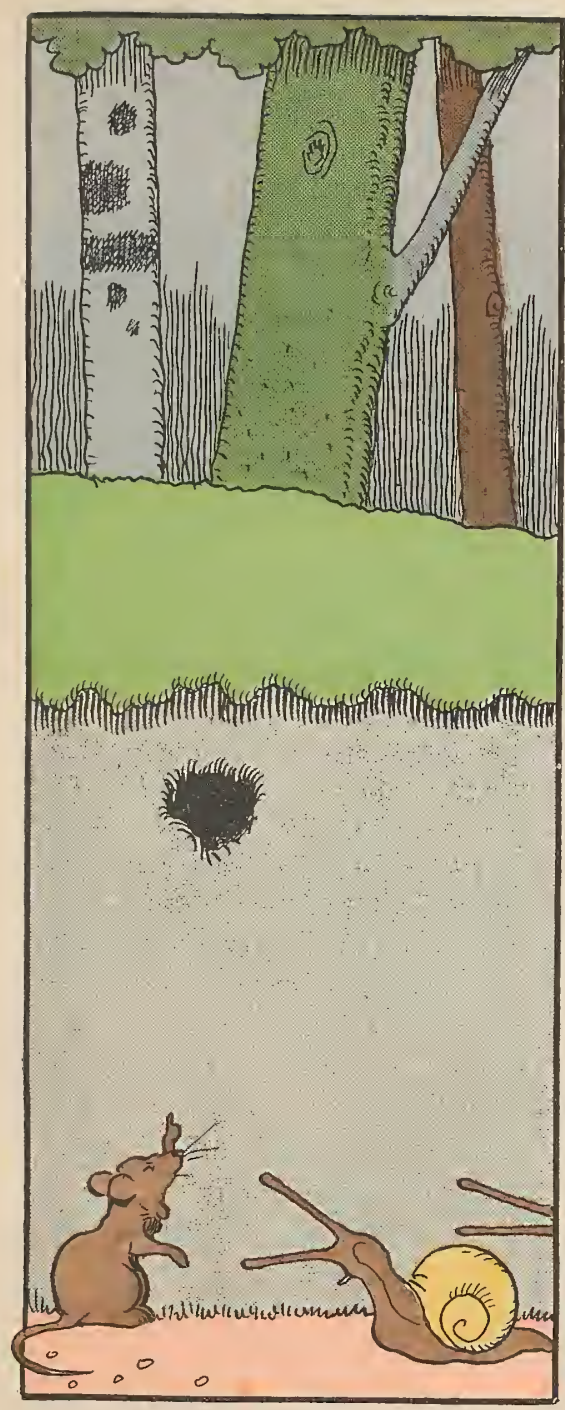

Le pauvre petit mulot se lamente parce qu'il est tombé de son trou.

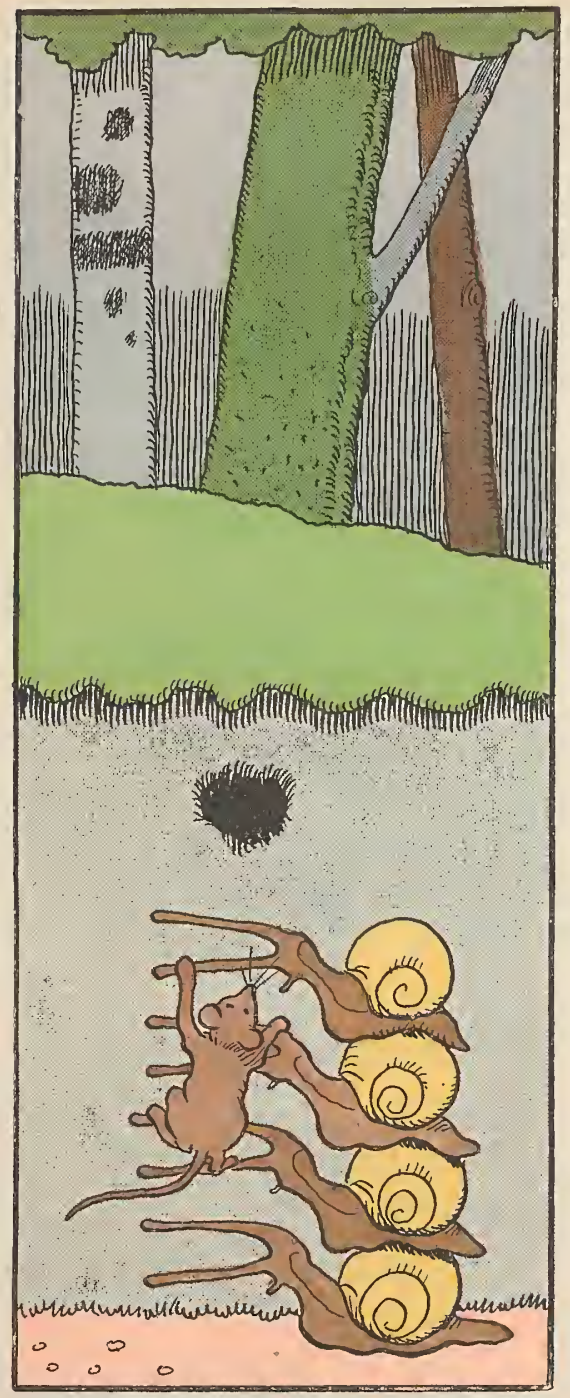

Quatre braves escargots de Bourgogne improvisenț une échelle..

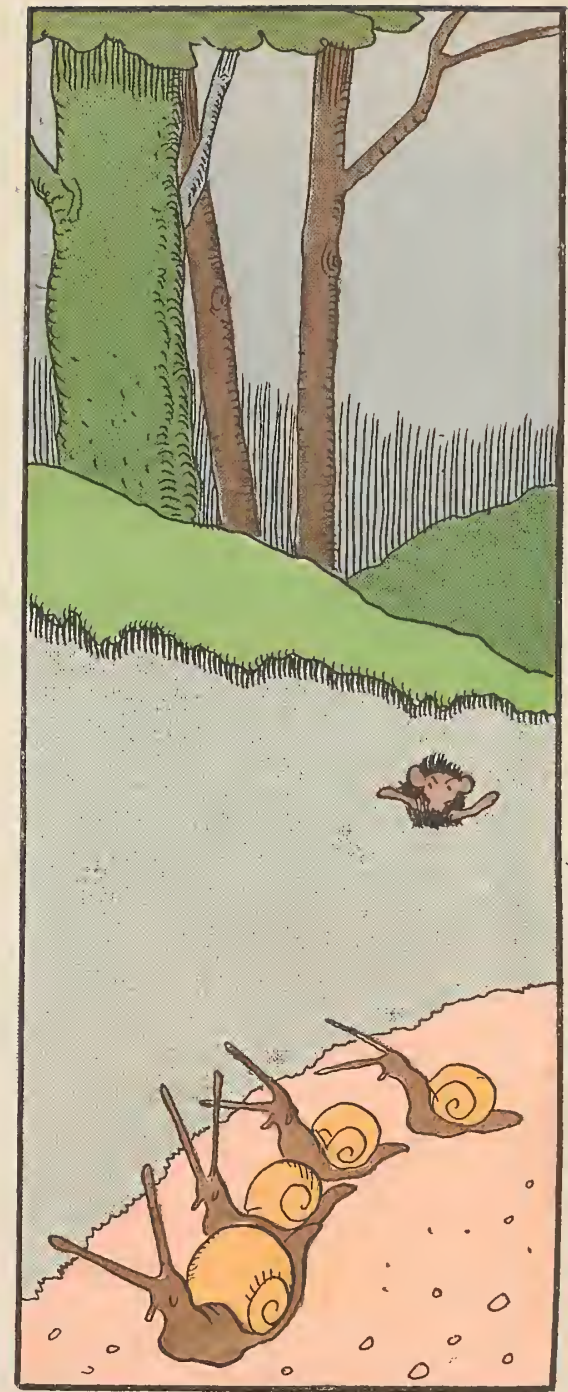

.. qui permet à l'imprudent mulot de regagner le logis paternel. 


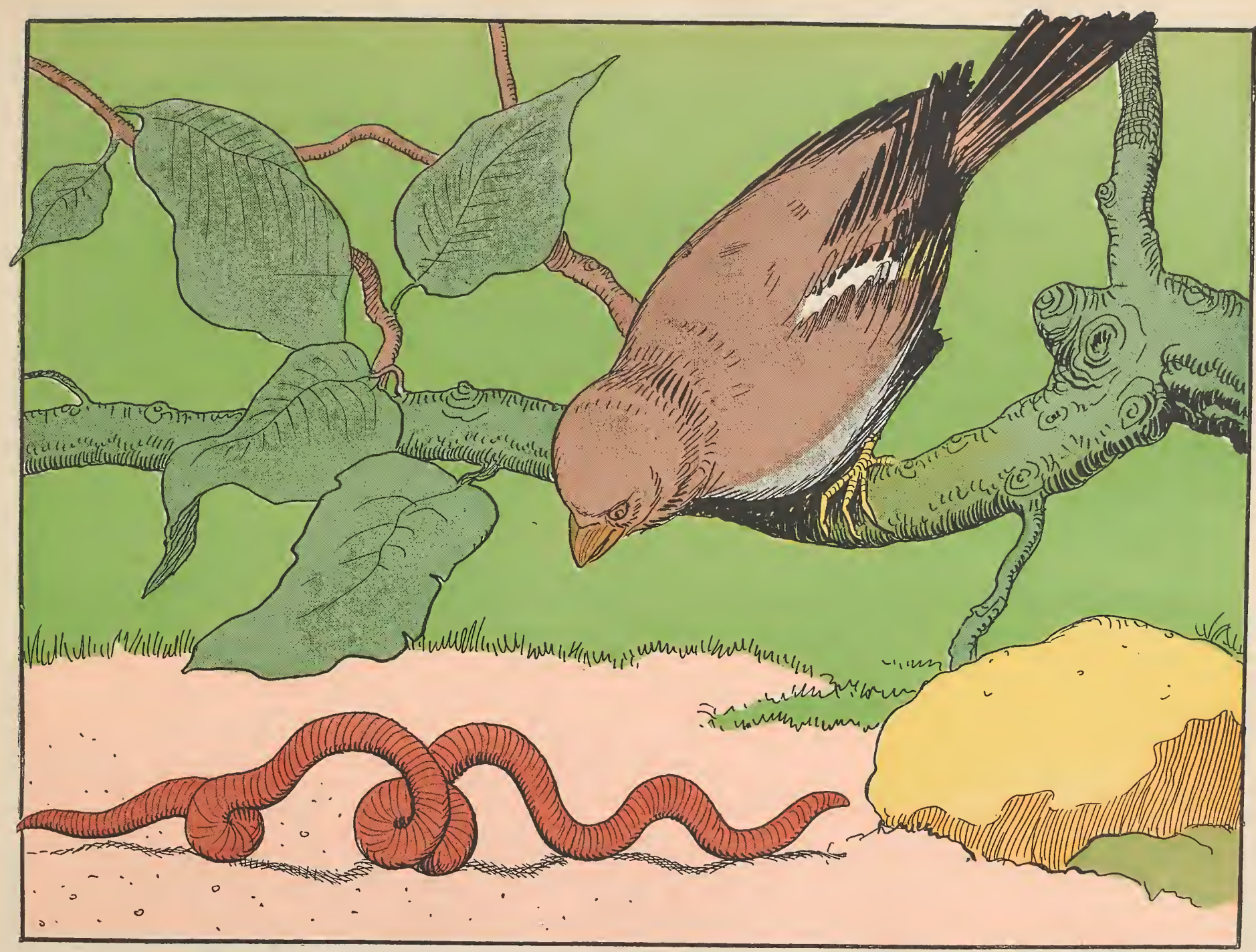

- Ça va ce matin, le ver?

— Très bien... j'ai toujours bon pied, bon œil ! 


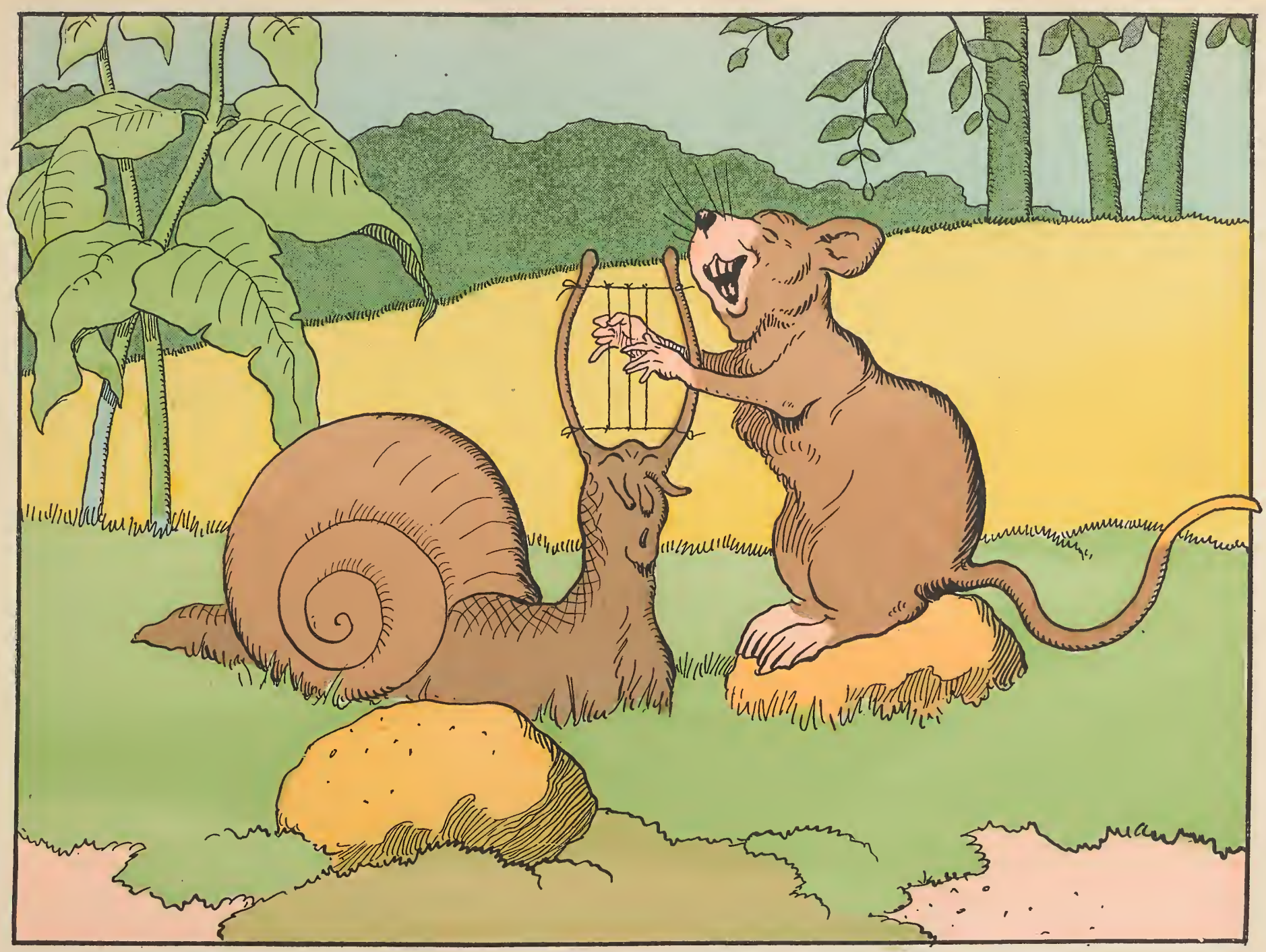


LE PASSAGE DU GuE A PIED SEC

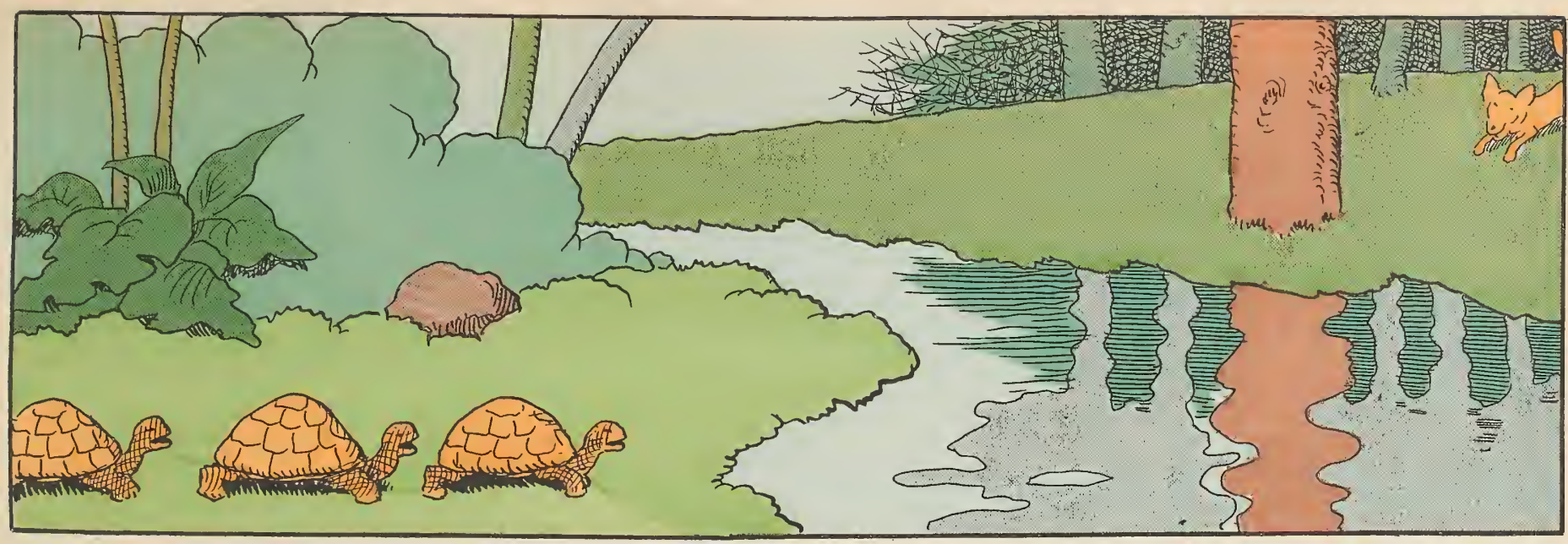

- Tiens... le courant a emporté les pierres du gué,

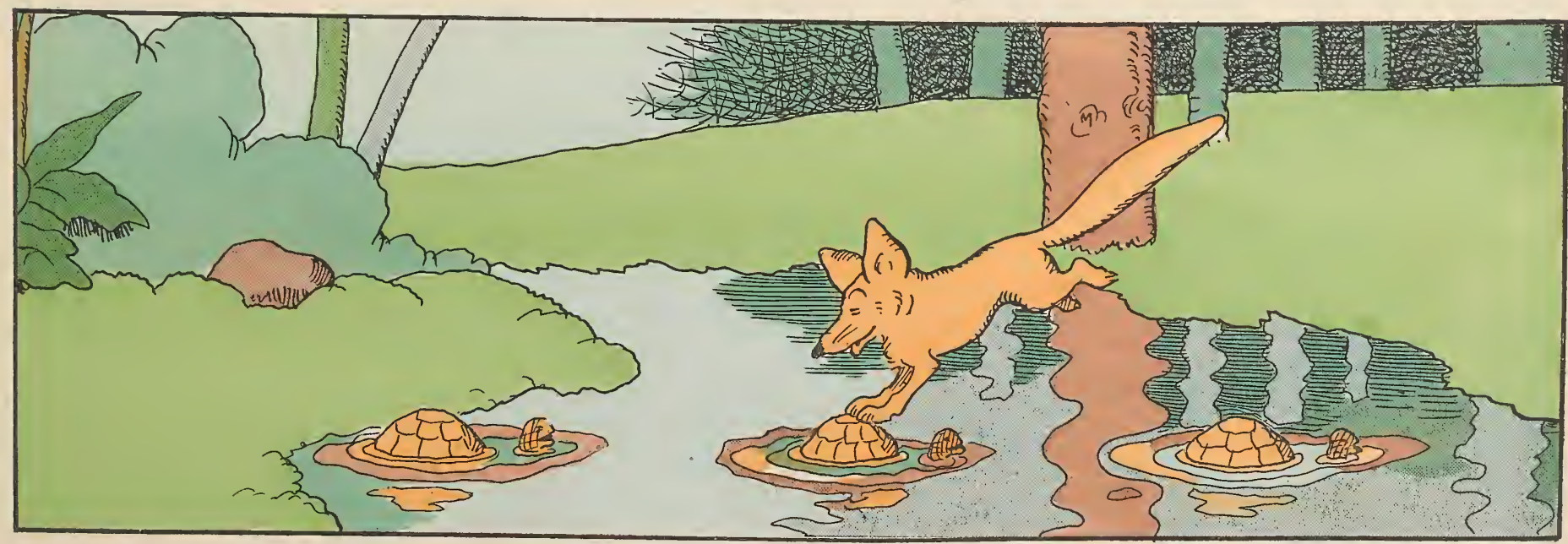

- Remplaçons-les pour permettre à maître Renard de passer. 


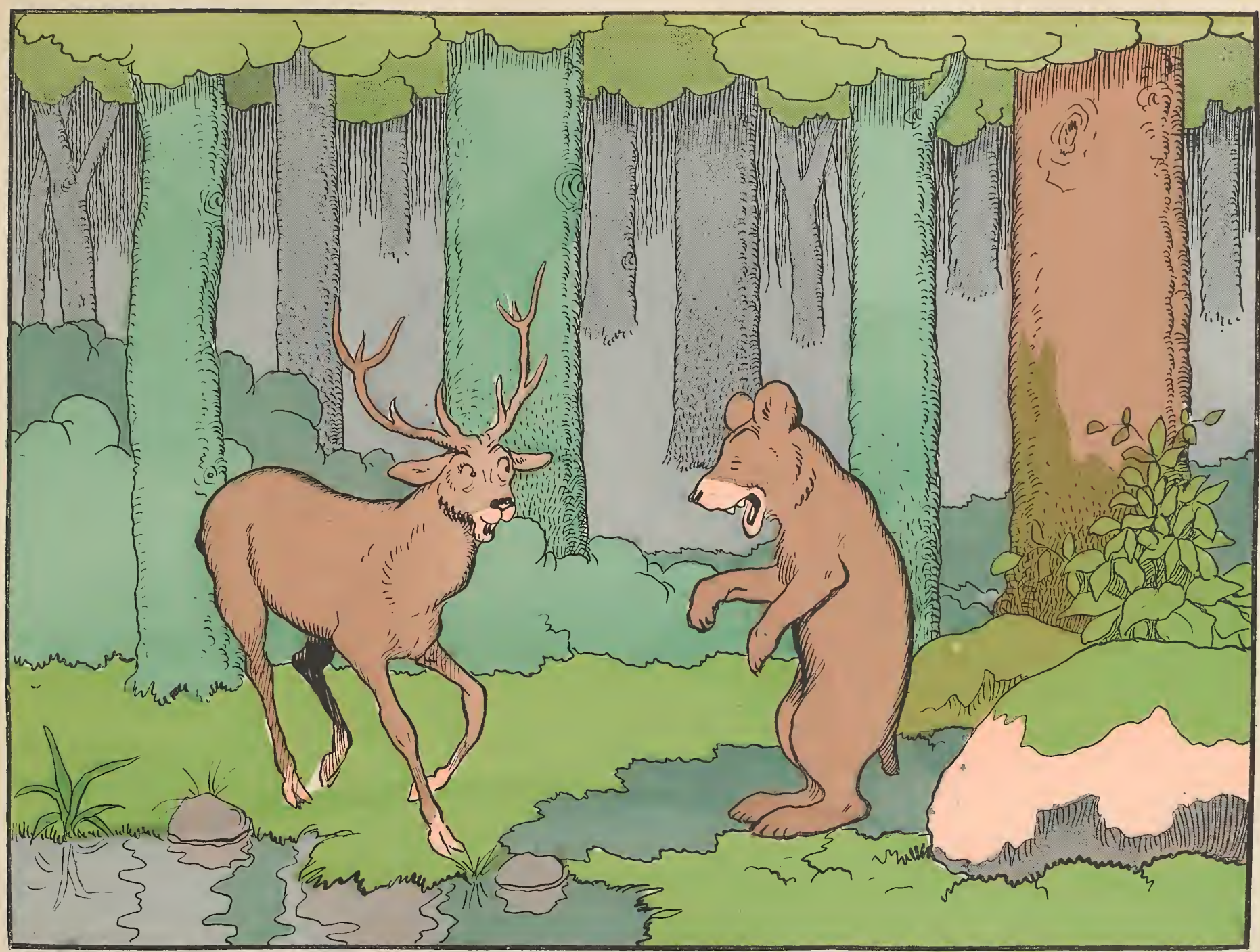

LE CERF. - Je ne cache pas mon âge... c'est sur ma tête que je porte mes cors... L'Ours. - Moi je suis plus discret : mes cors, je les porte aux pieds ! 


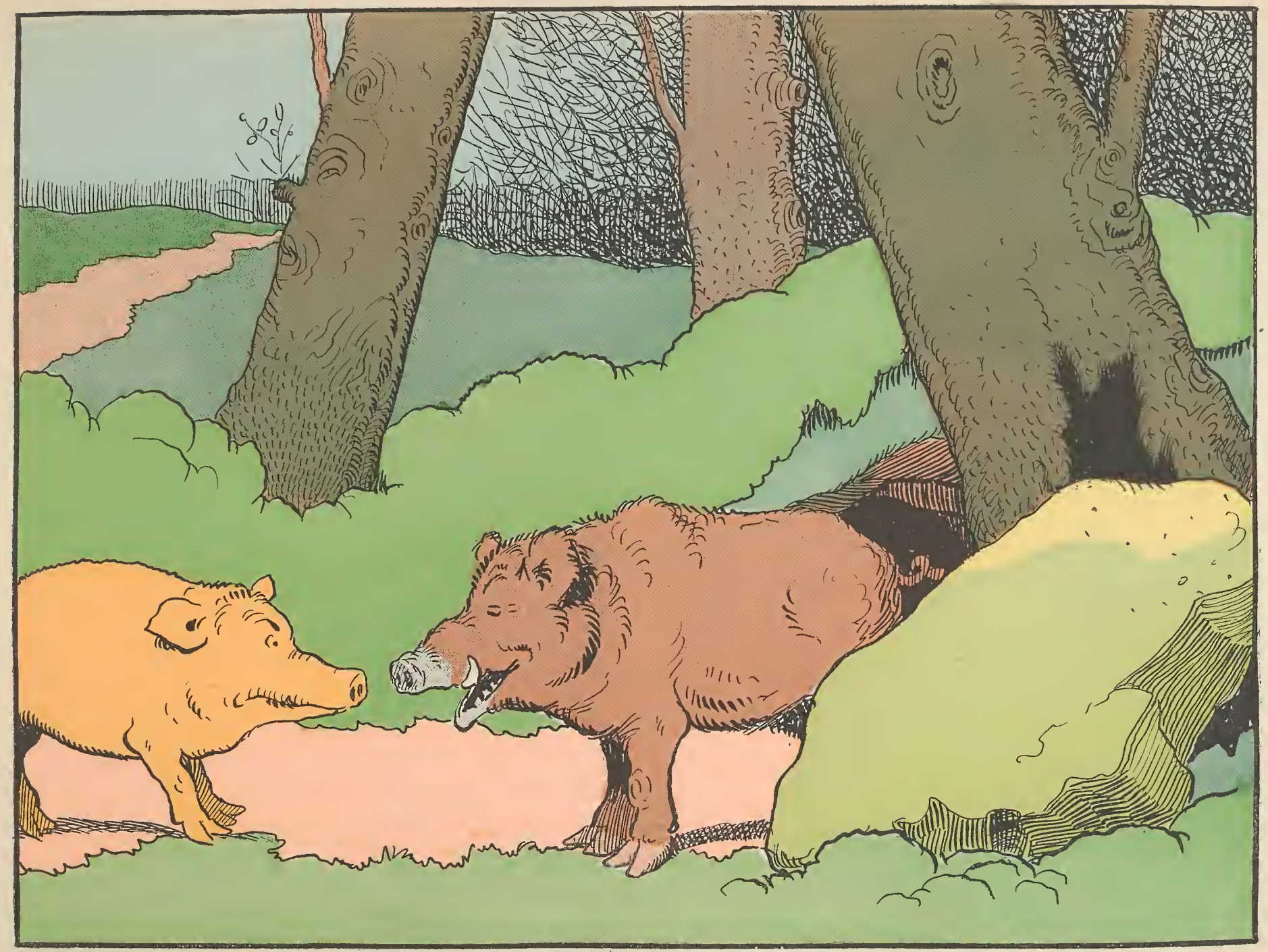

LE SANGLIER. - Salut, mon frère au visage pâle !... 


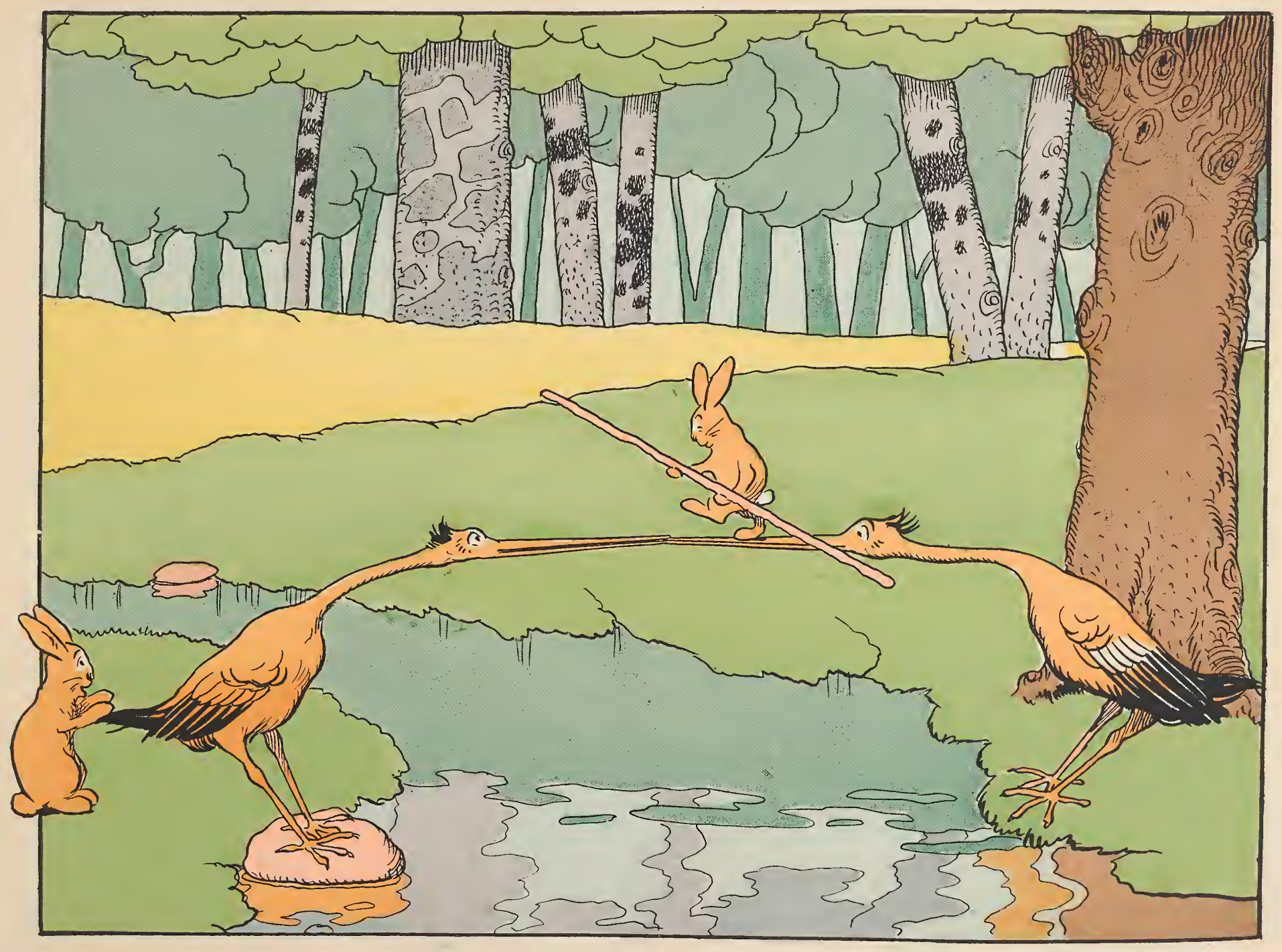

Le passage de la rivière à pied sec. 



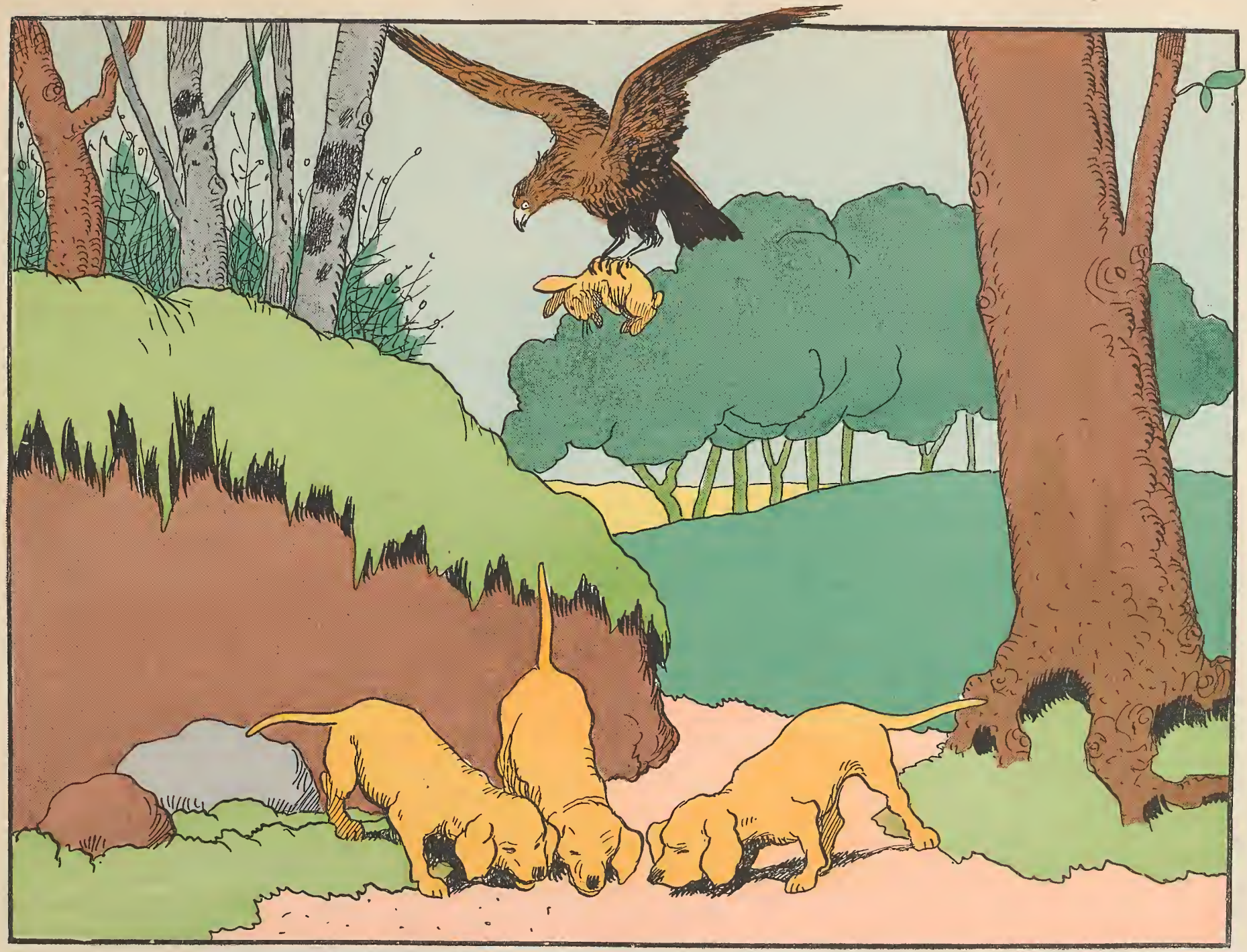

La piste perdue... 


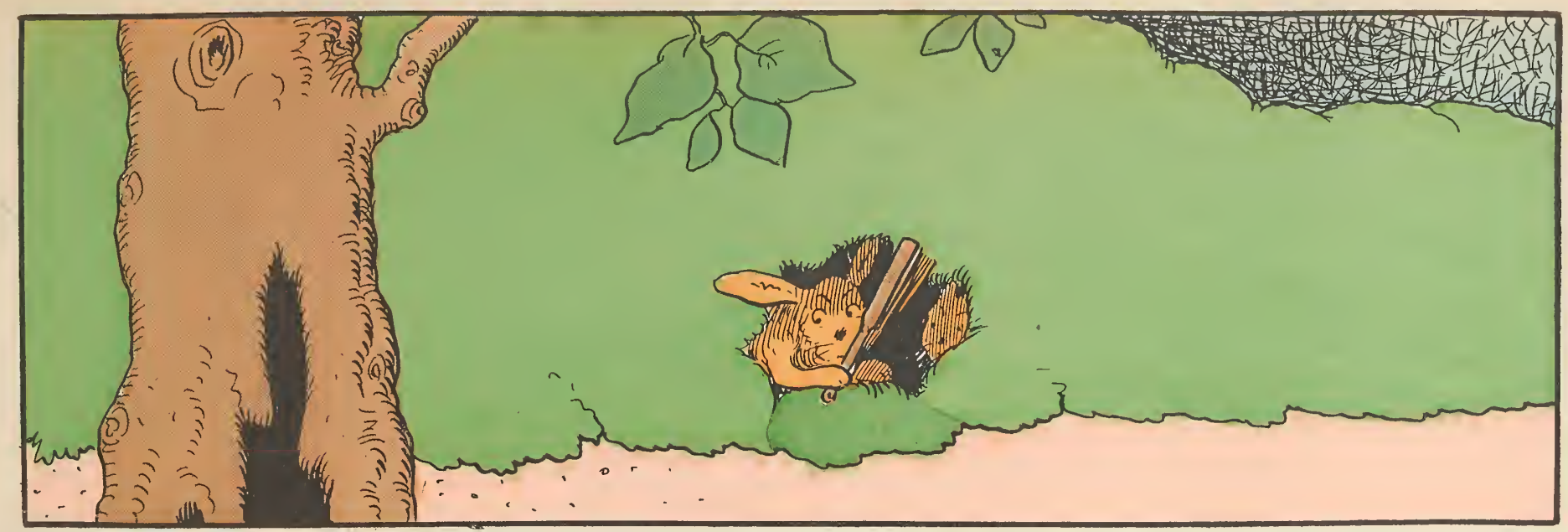

- Voilà le furet... ouvre l'éventail où nous sommes perdus !

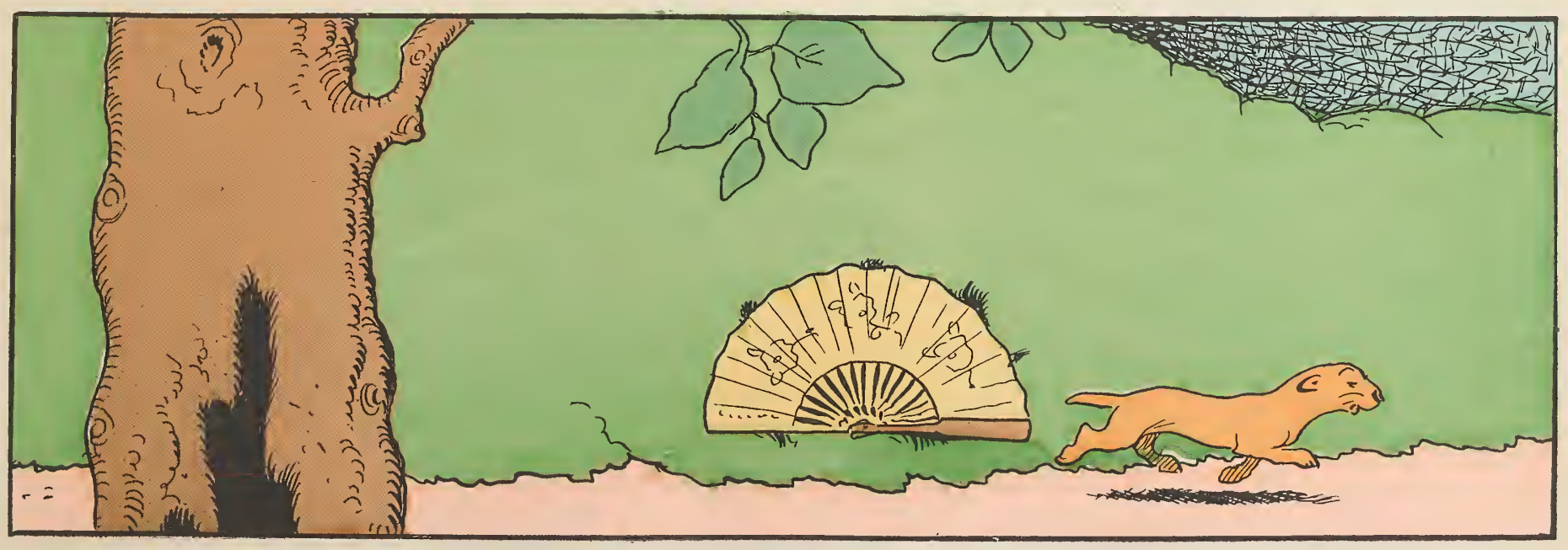



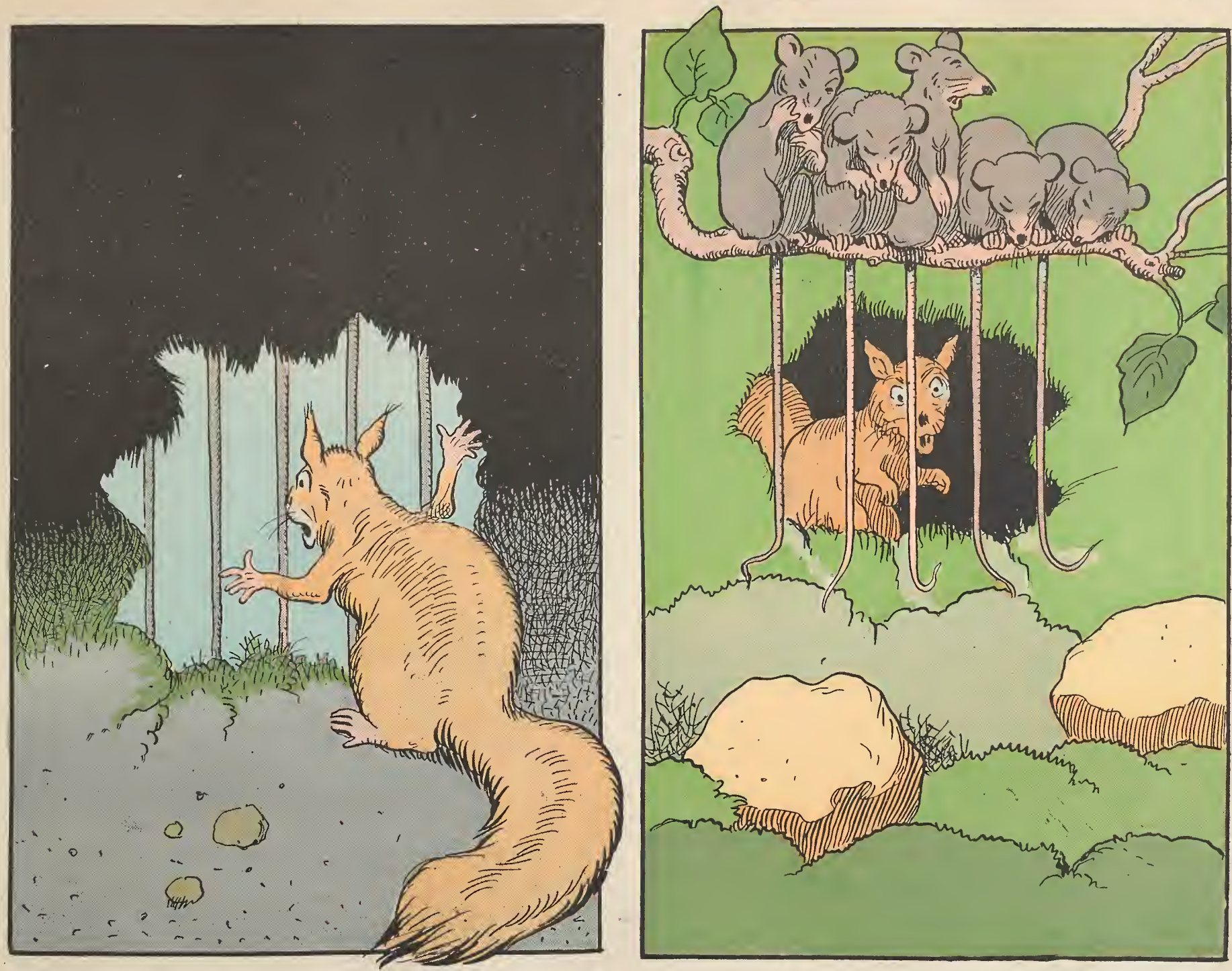

L'ÉCUREUIL. - On a mis une grille devant ma porte! Qu'est-ce qui m’a fait cette blague-là ? ! 


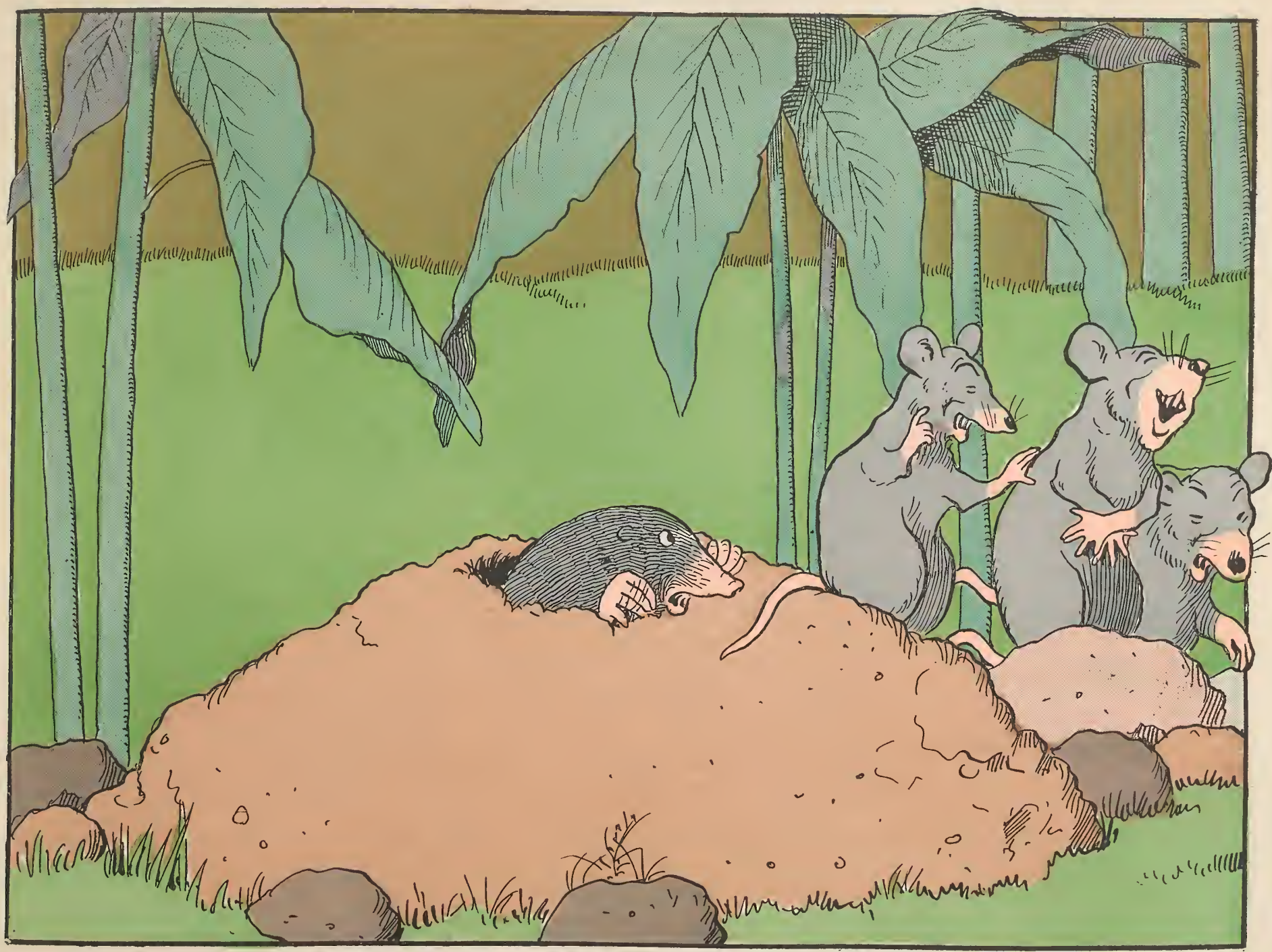

IA TAUPE. - Un peu de silence... il y a un malade au-dessous ! 
ÉGALITÉ DEVANT LE TREPAS

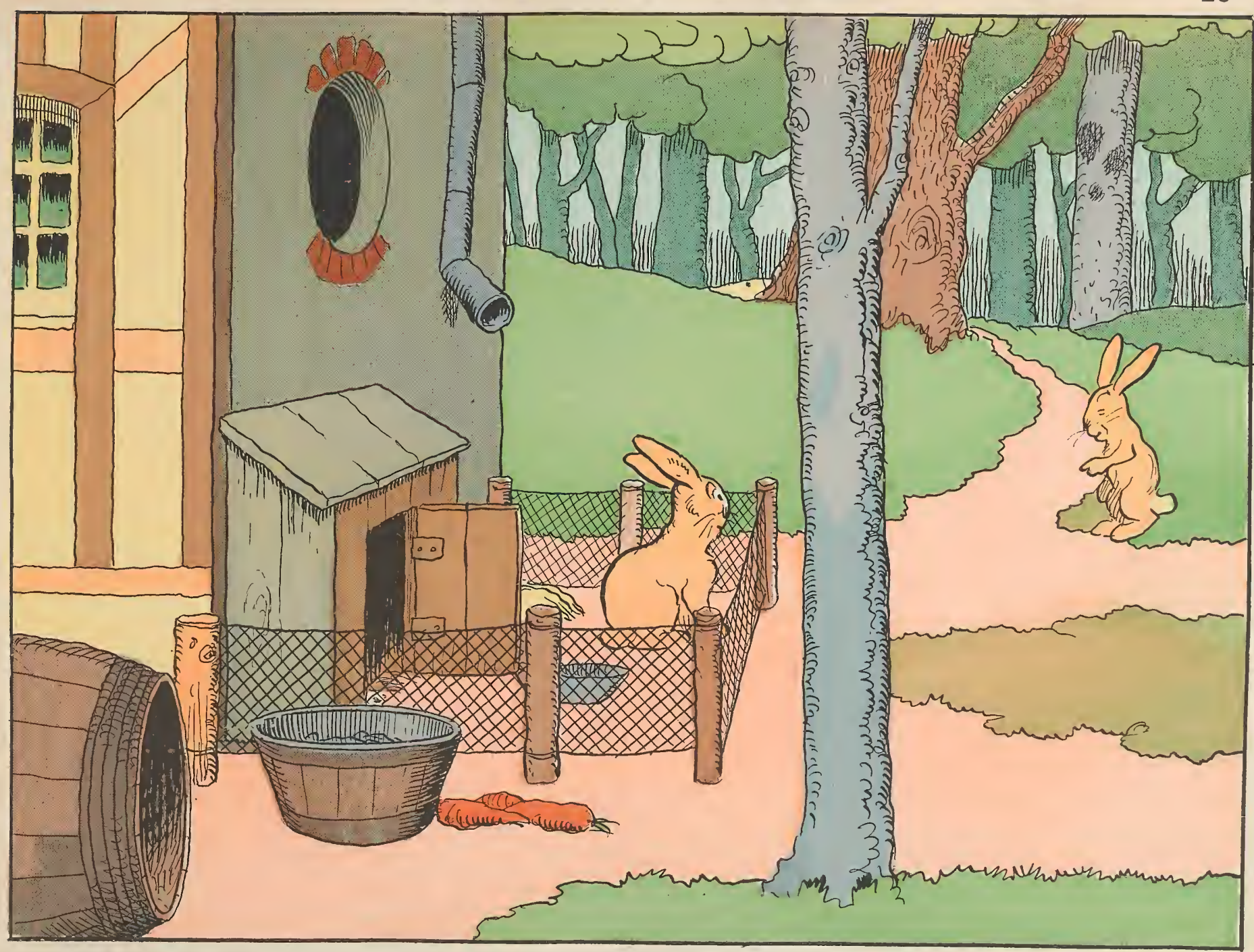

LE LAPIN DOMESTIQUE. - Tu es plus à plaindre que moi, mon pauvre lapin de garenne: 1'homme te fait la chasse sans merci; moi, il me nourrit abondamment.

LE LAPIN DE GARENNE. - En attendant que nous nous retrouvions dans un civet. 
th 


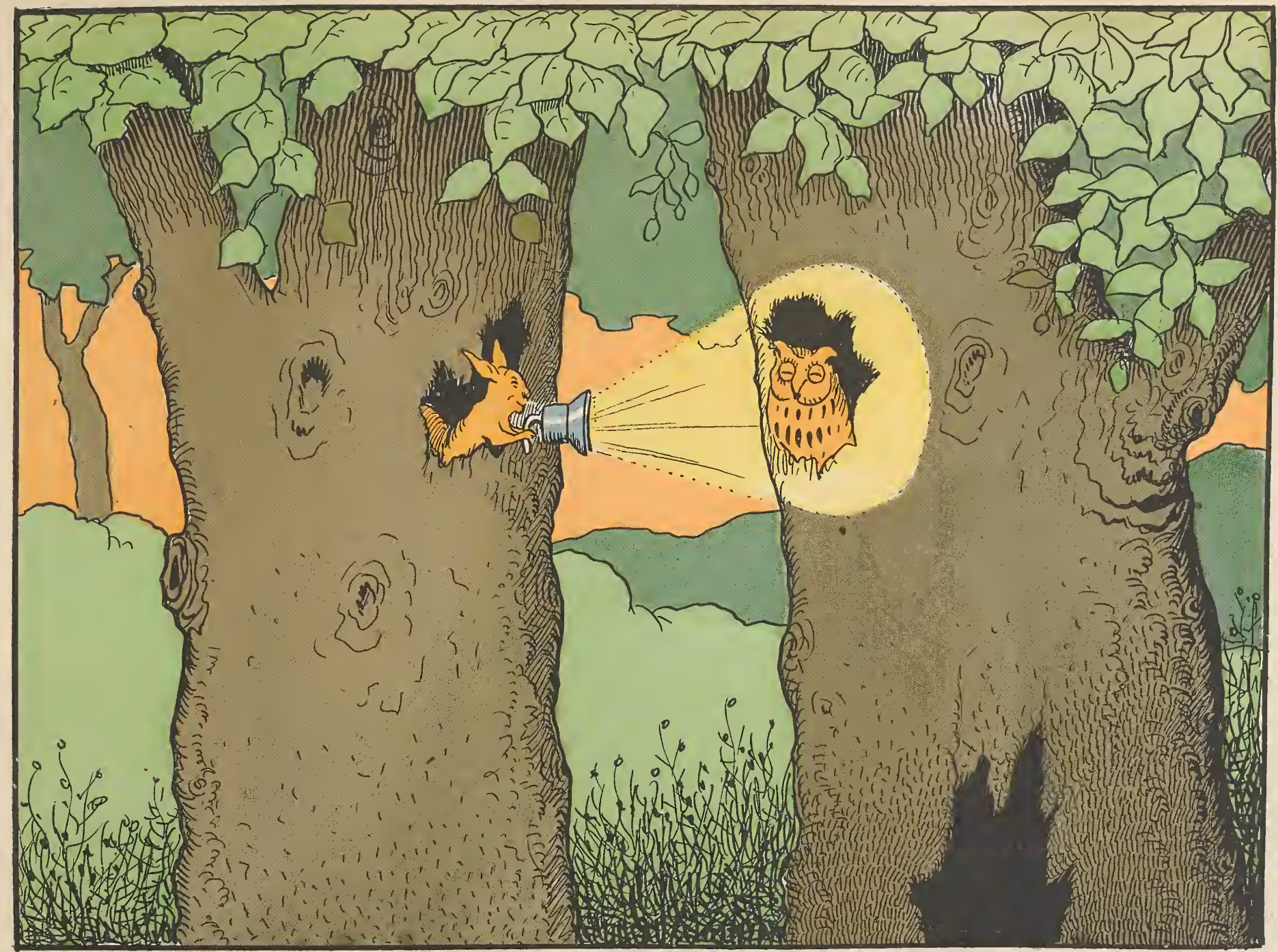

LE HrBov. - Je ne suis pas content de vous, 1 'écuretuil... Vous faites un peu trop la fête, mon ami.

L'ÉCUREUIL. - Aussi j'ai ramassé une lanterne de bicyclette dans la forêt, dans l'intention de vous obliger à fermer les yeux sur mes écarts de conduite ! 


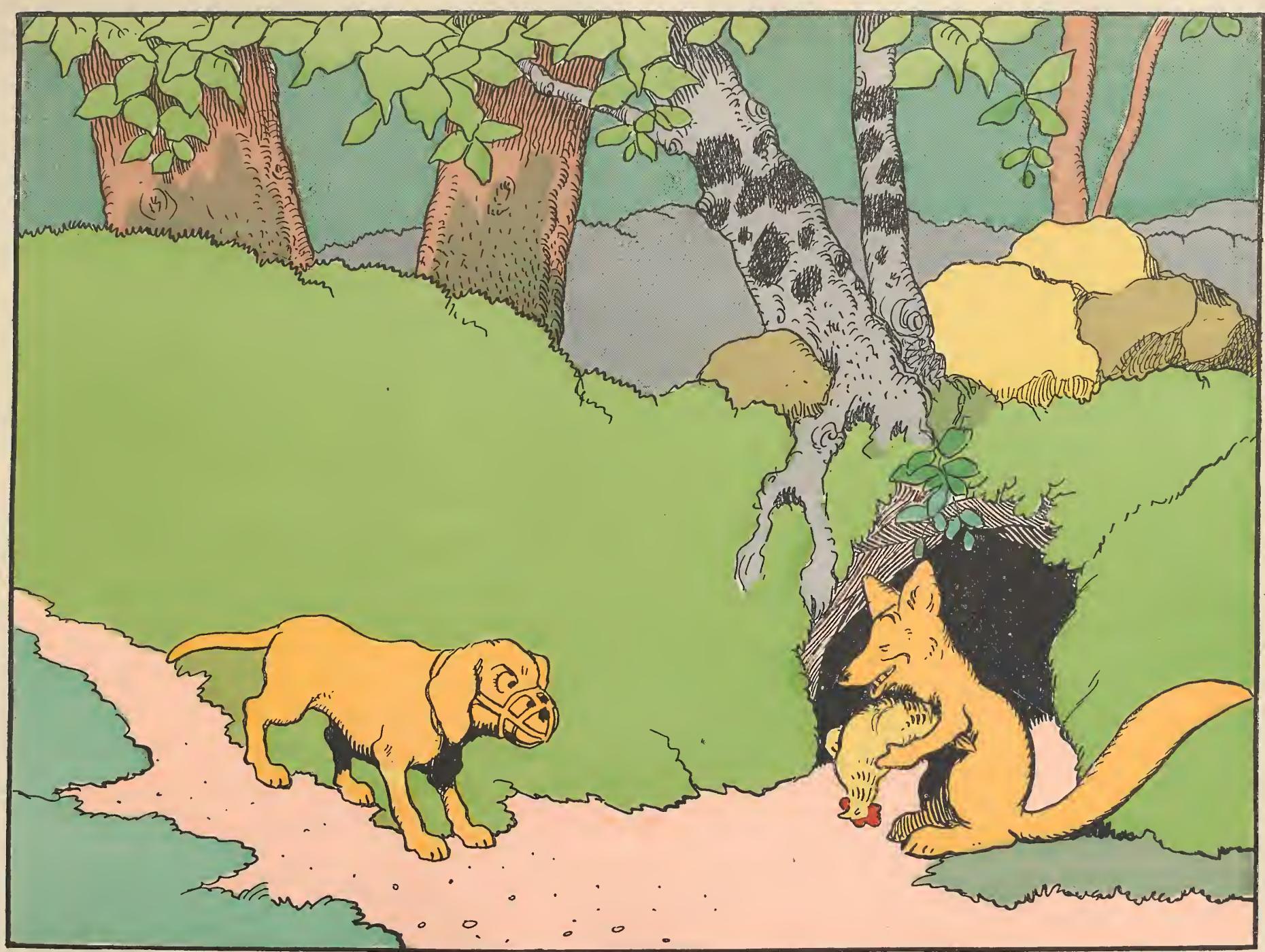

IEE RENARD. - Après toi, la muselière !... 


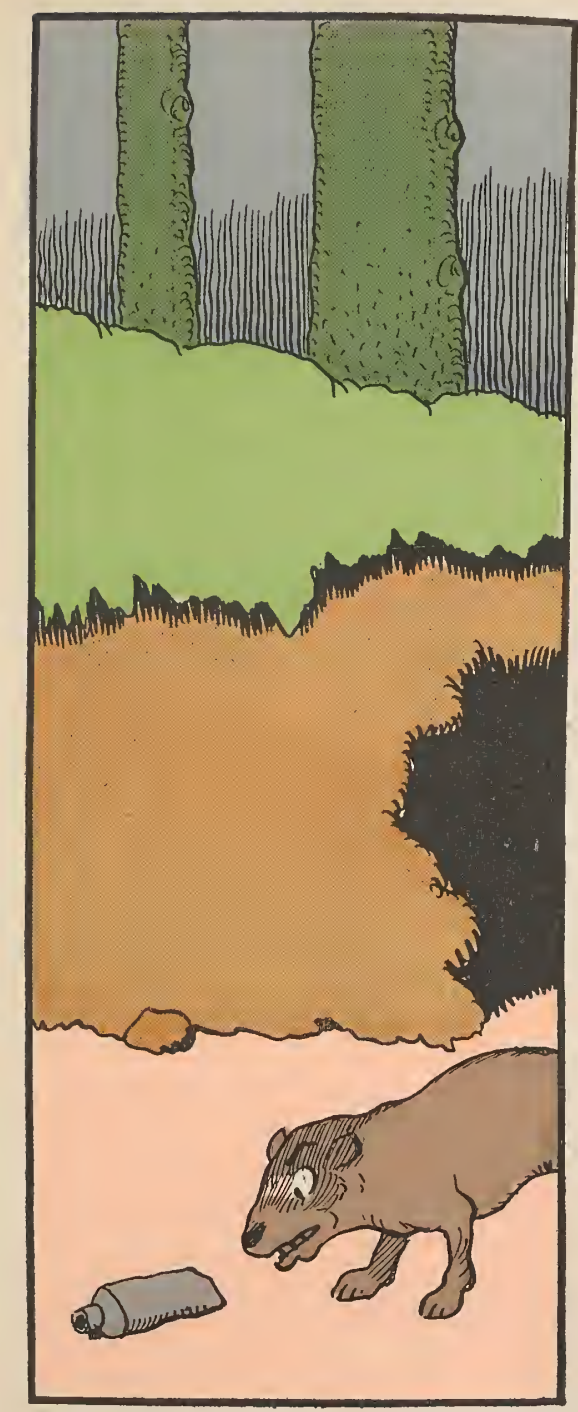

—Qu'est-ce que c'est que cet ustensile?...

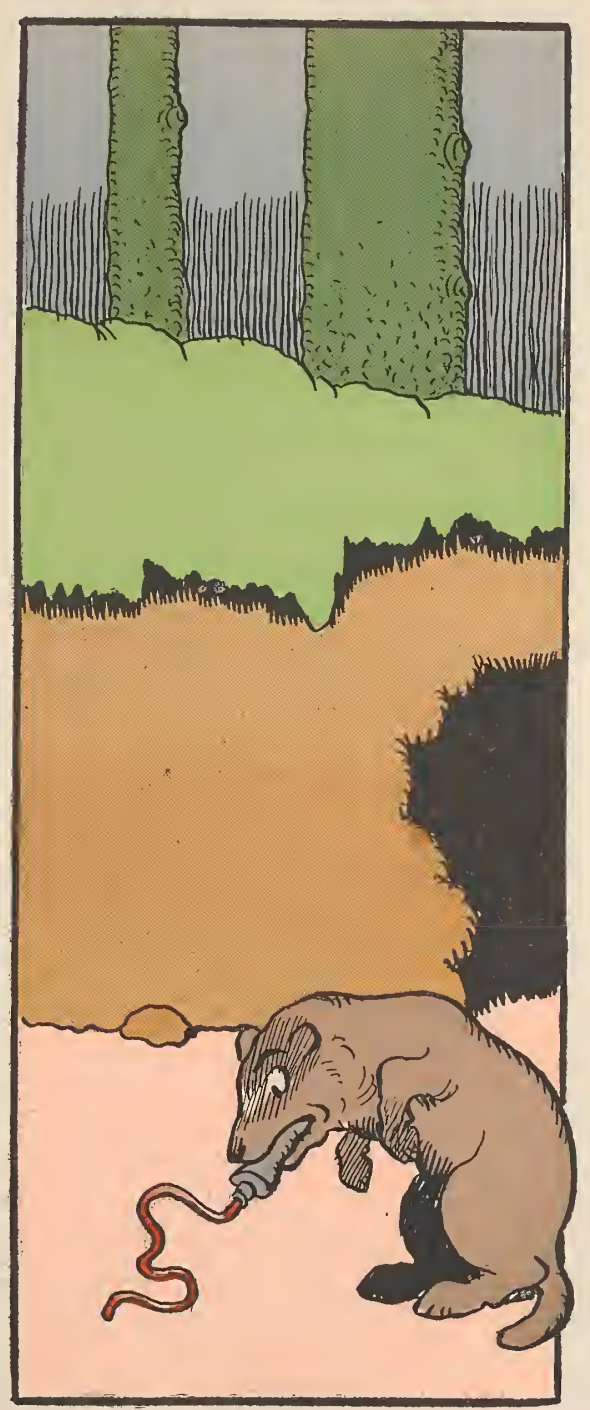

- Une vipère $! . .$.

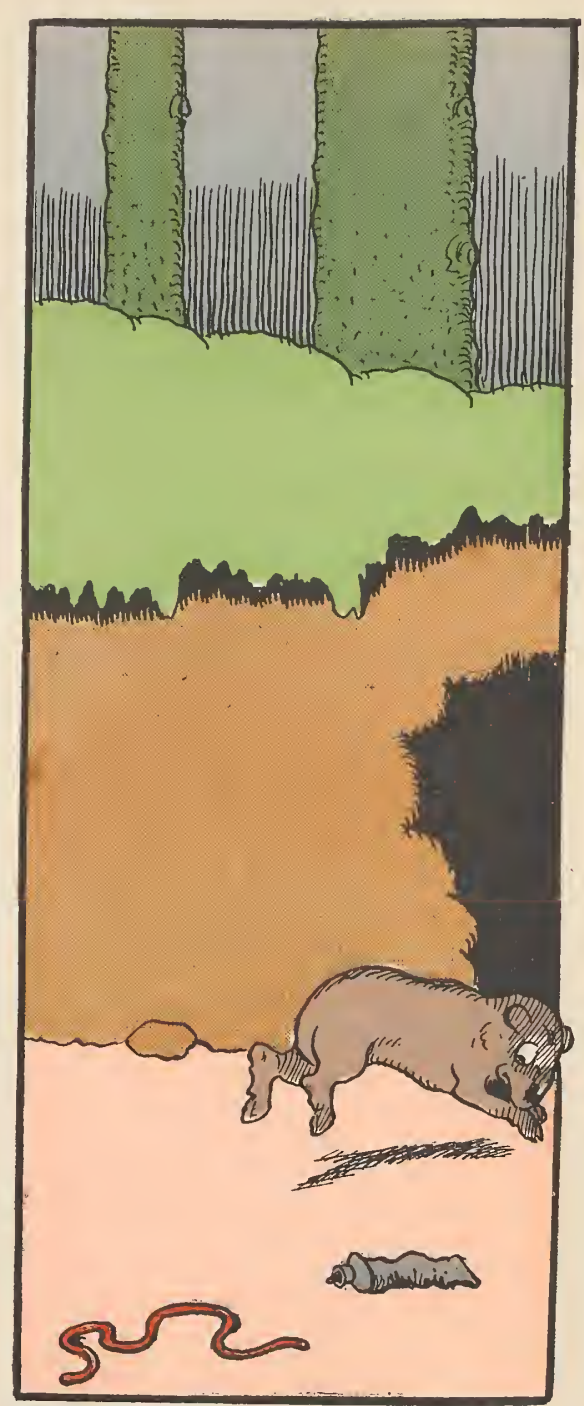

— Sauve qui peut. 


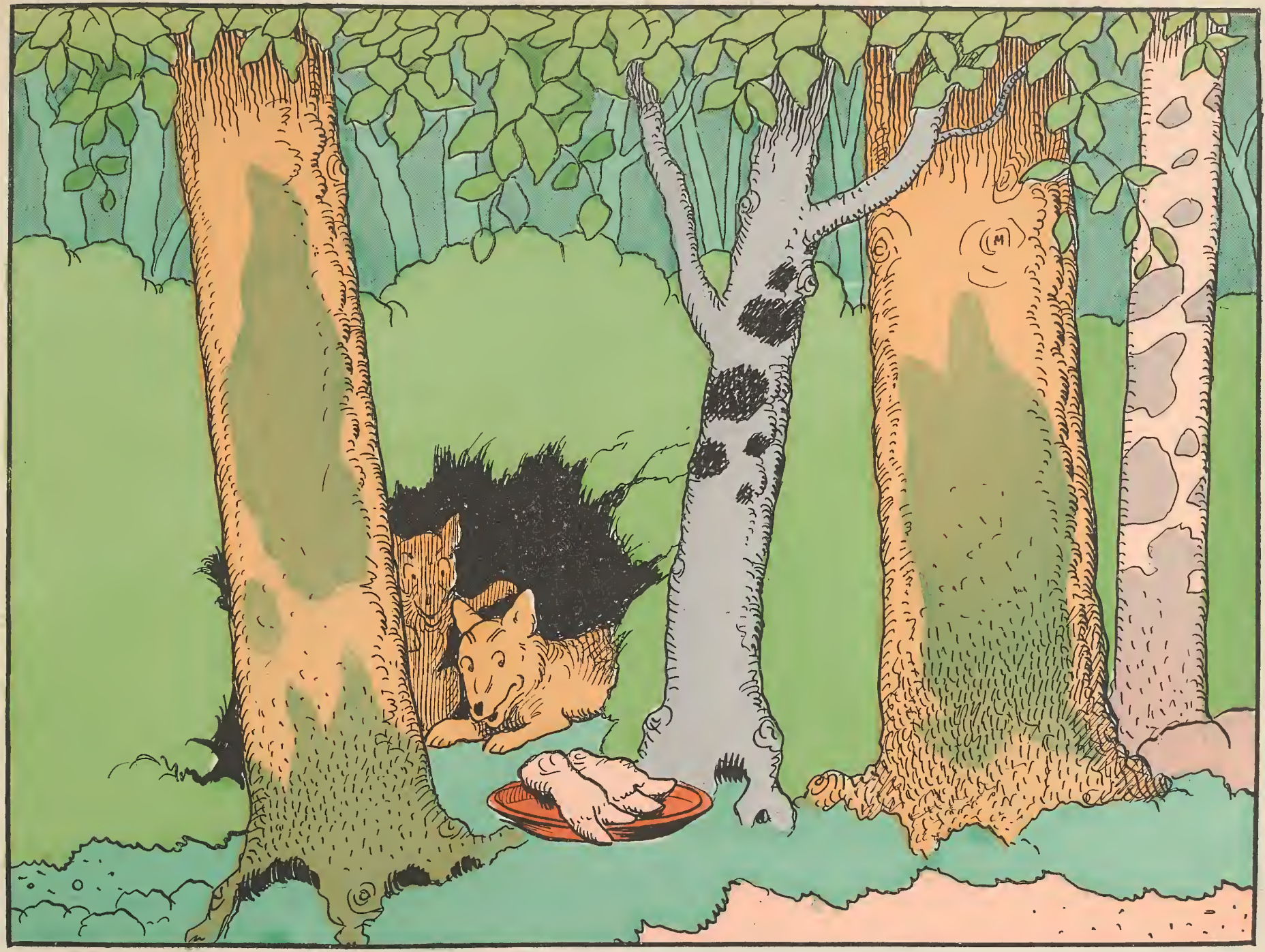

- Pourquoi ne rentres-tu pas les pieds du veau que nous avons mangé hier?...

- Je ne le connaissais pas assez pour lui permettre de mettre les pieds chez moi 


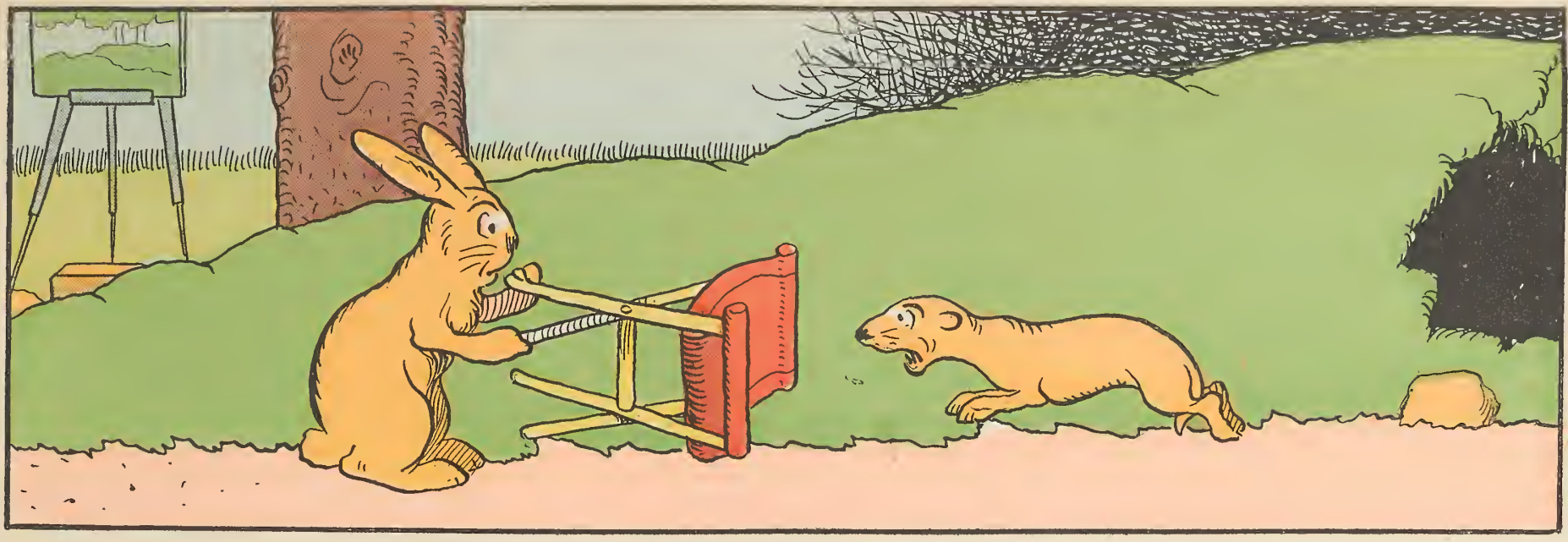

?...

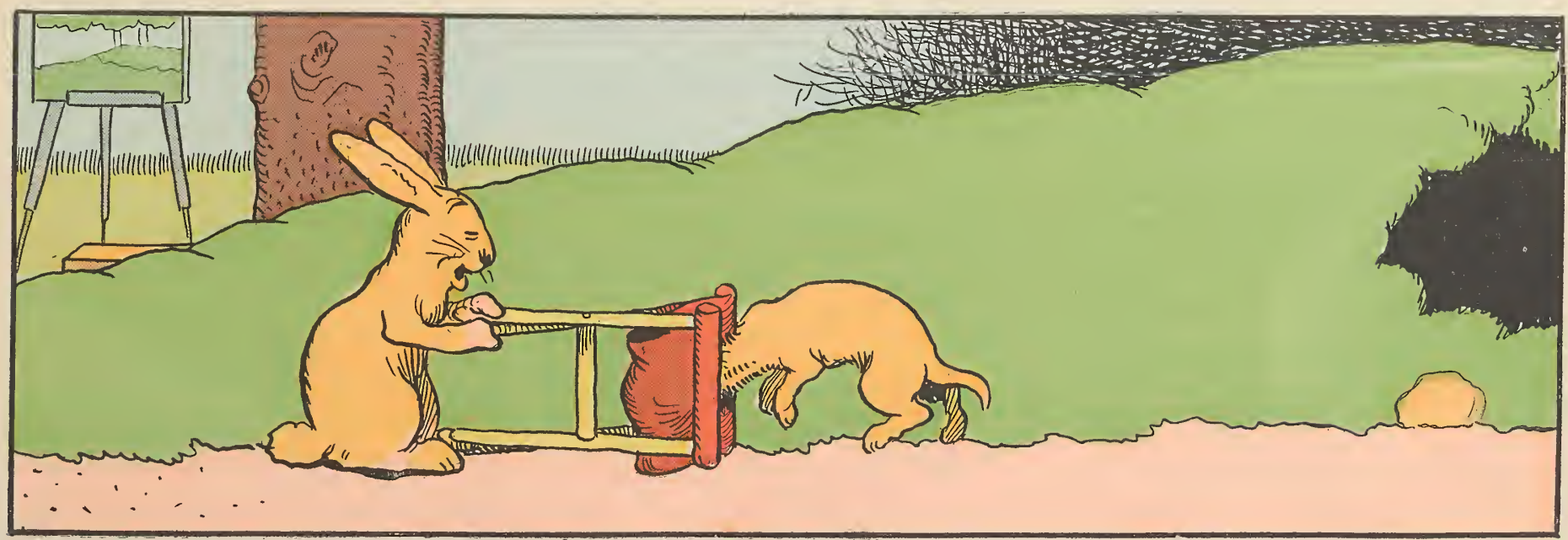




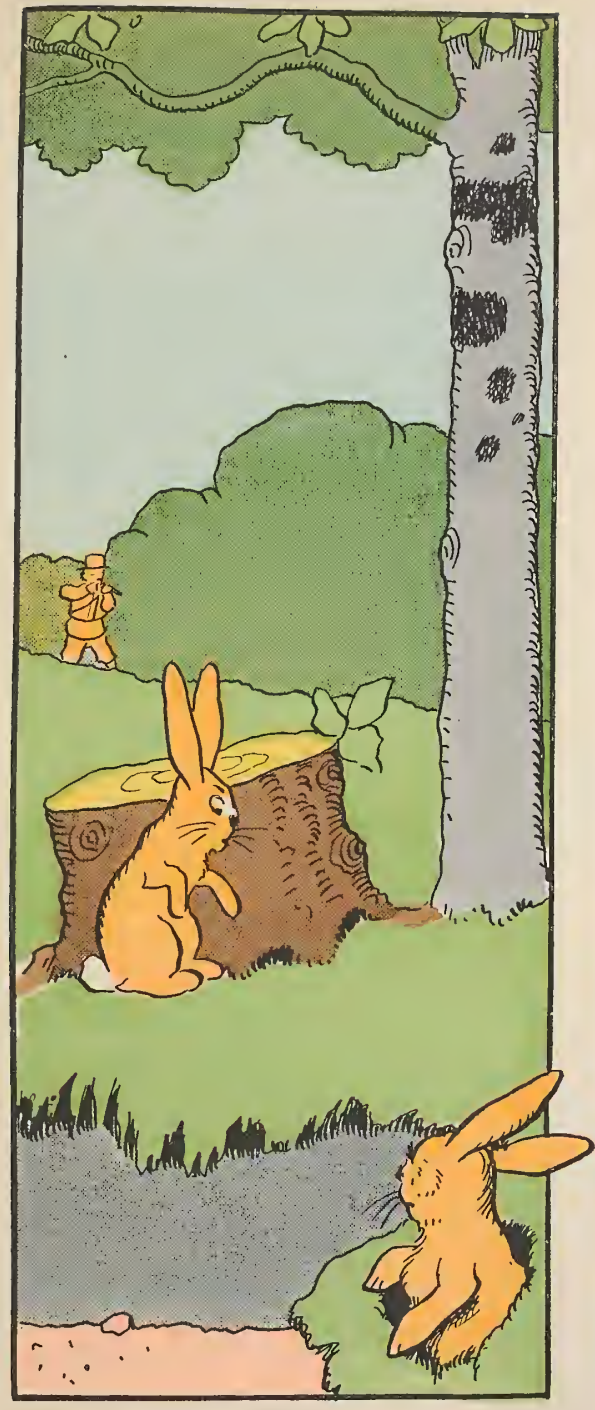

-Dresse les oreilles, petit, et avertis-moi dès que des bruits de chasse frapperont tes oreilles...

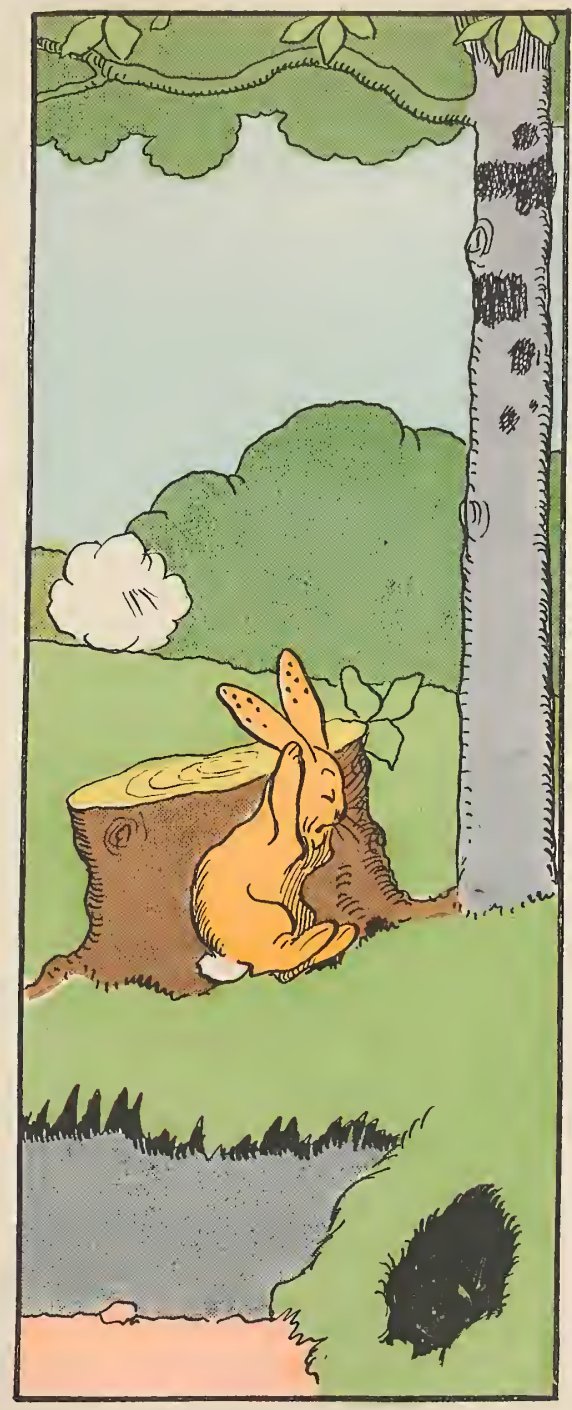

- Ça y est...

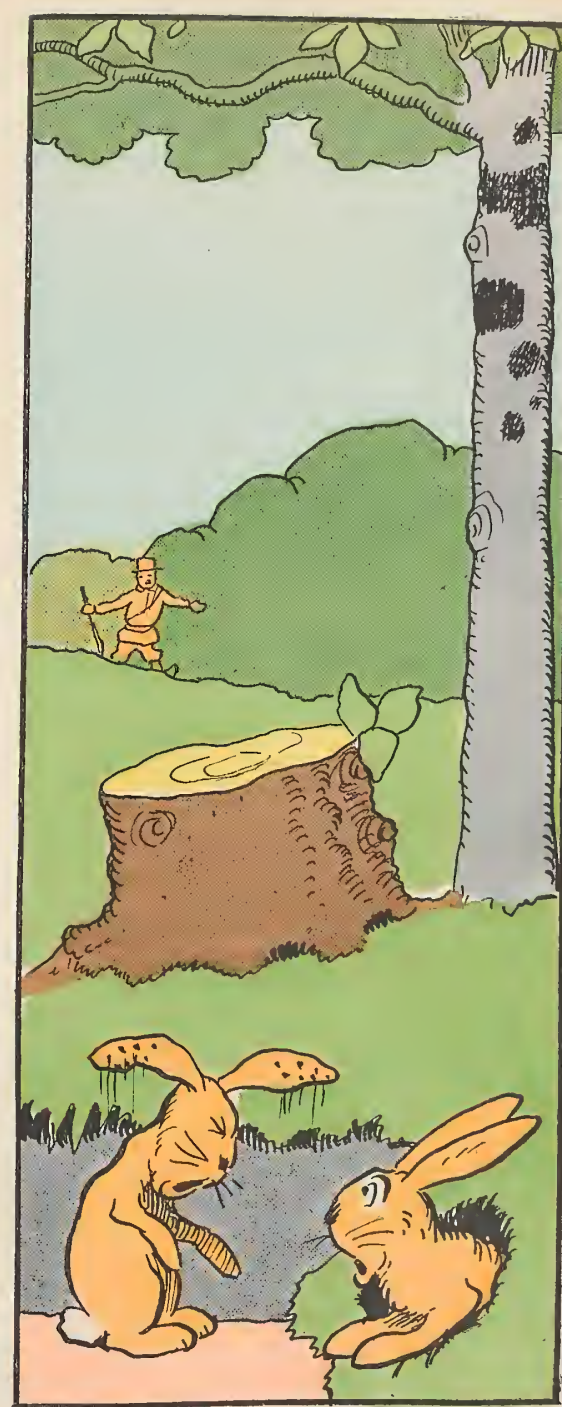

- ... Mes oreilles sont frappées $! . .$. 


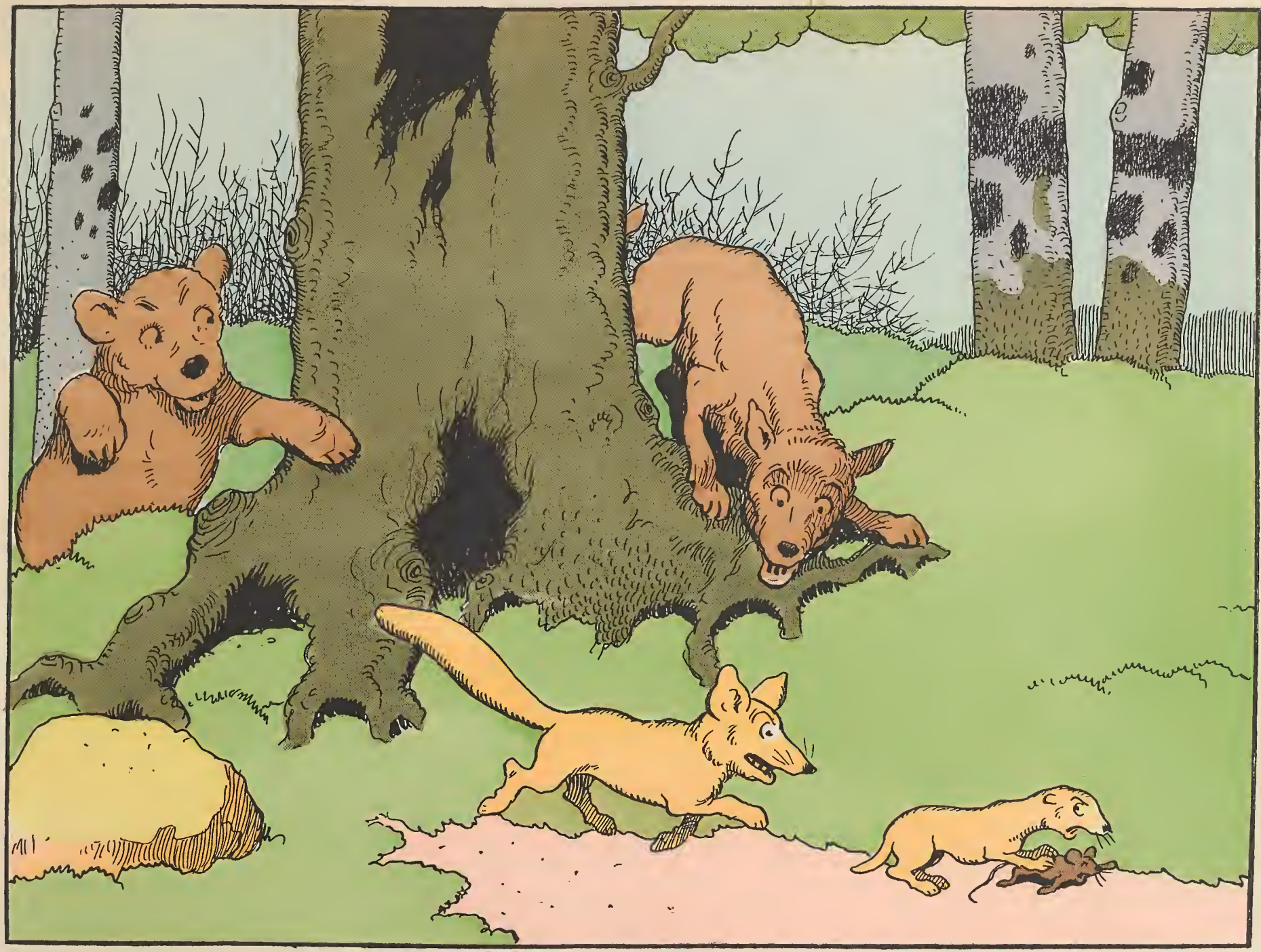

IE RENARD. - Part à deux, le rat, mon vieux furet! LE LOUP. - Dis donc, renard, part à deux, le furet! 

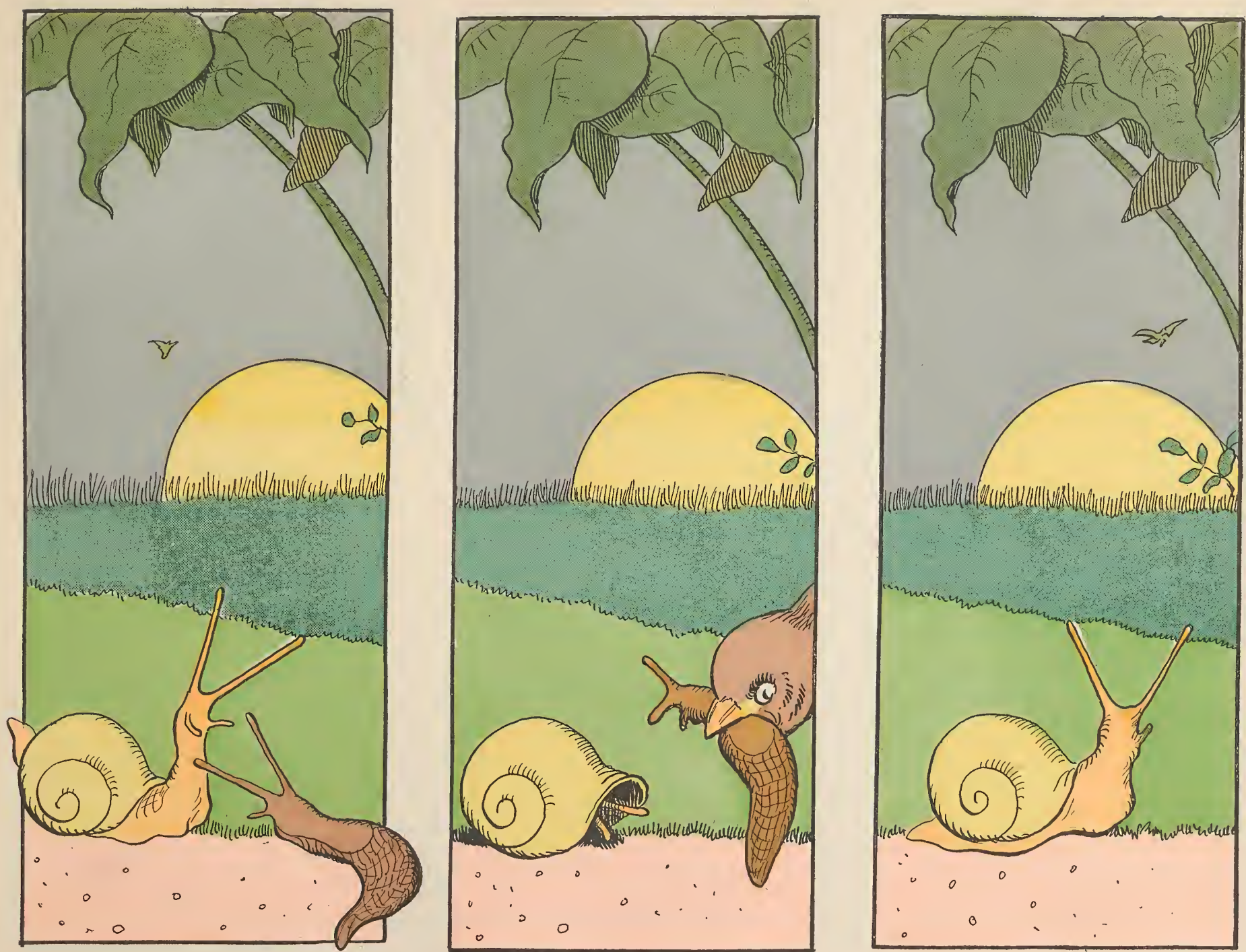

LA LIMACE. - Ça ne vous gêne pas de promener sur l'échine cette disgracieuse coquille?

L'E'SCARGO'T. - C'est, au contraire, un doux fardeau quand on songe aux services qu'elle peut nous rendre. 


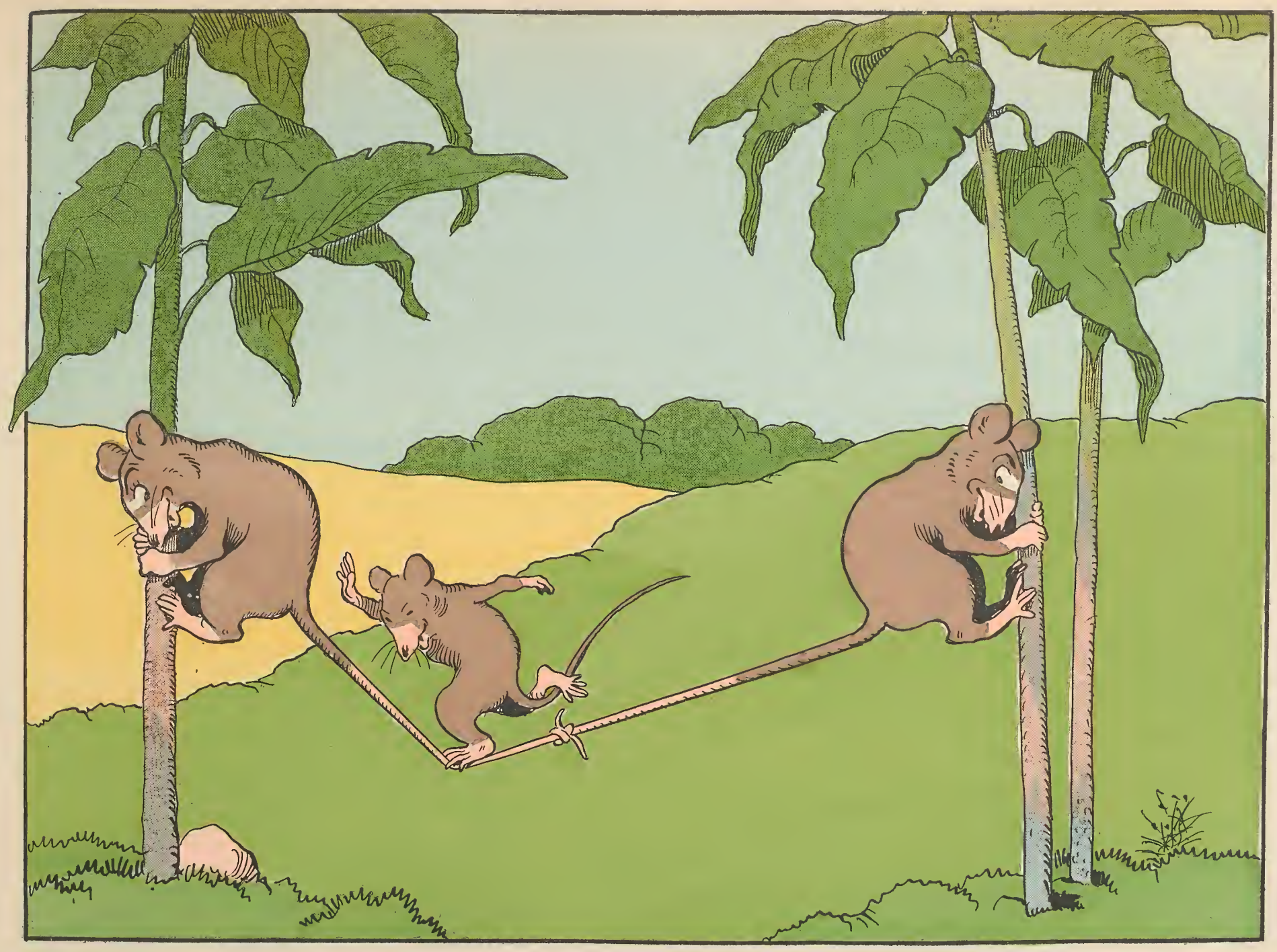

Travail sur le fil de fer ou idylle acrobatique. 


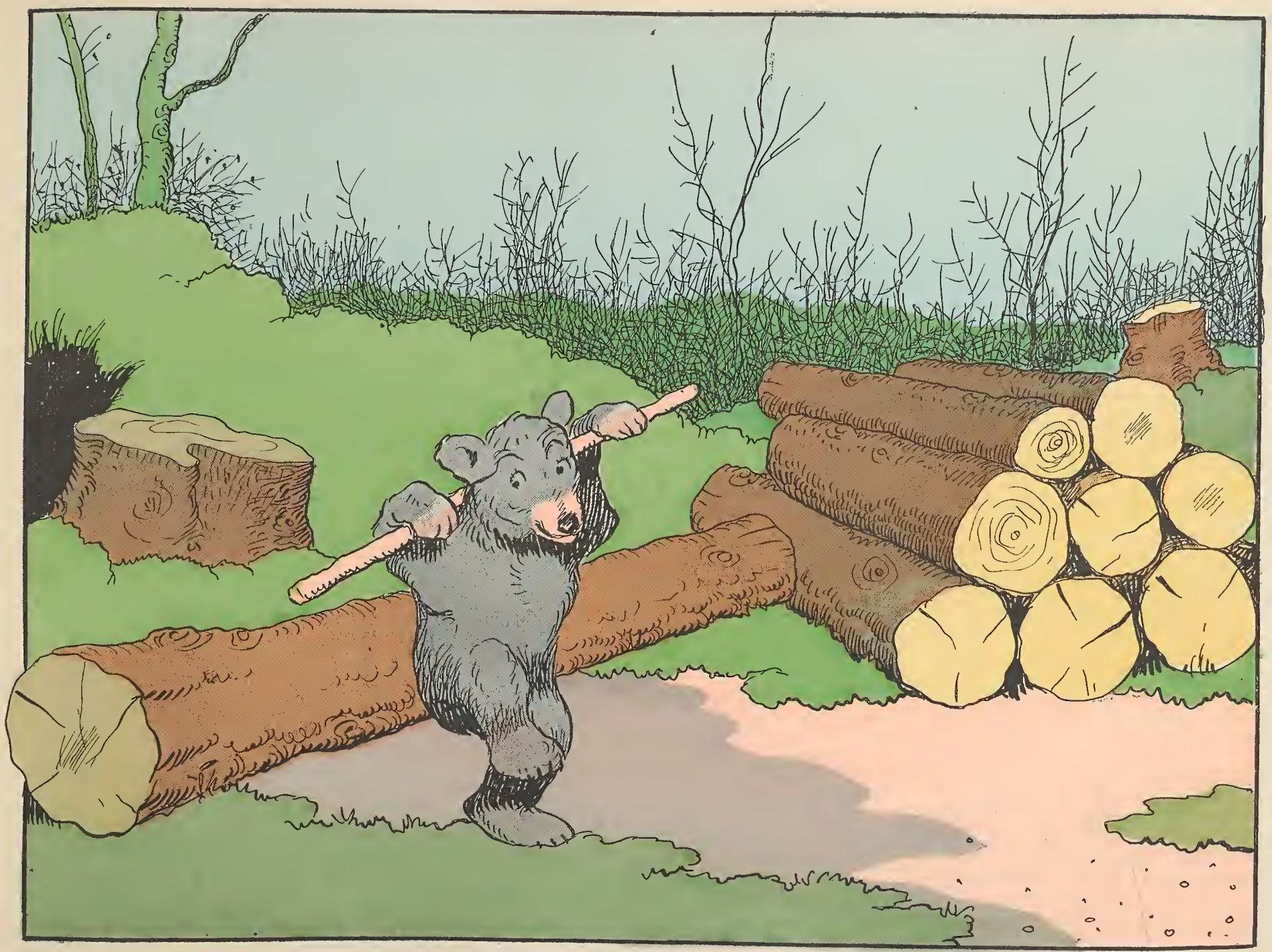

L'OuRs. - Maintenant qu'on coupe forêts et bois... il devient presque indispensable que j'apprenne un métier. 


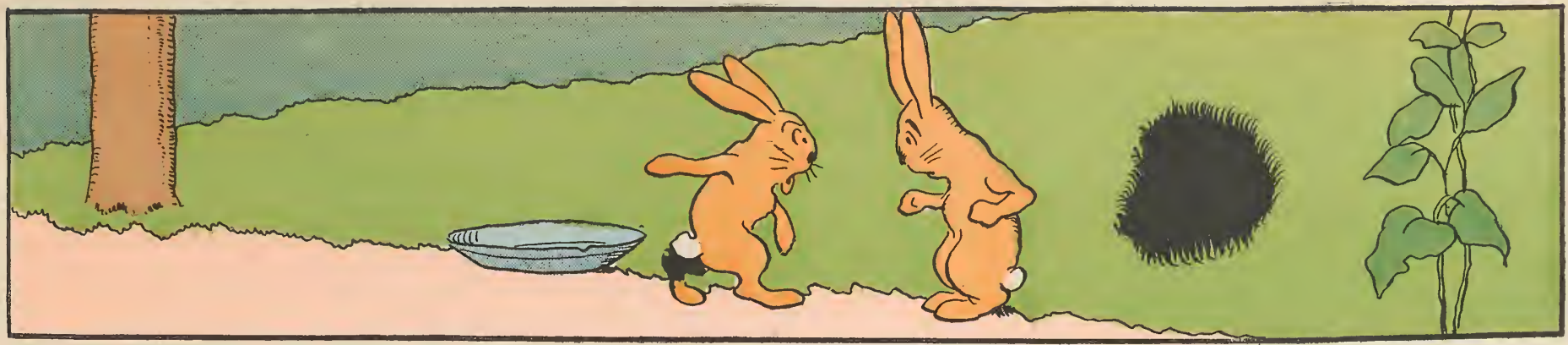

- Oui, j'en ai assez... je viens mettre les pieds dans le plat!

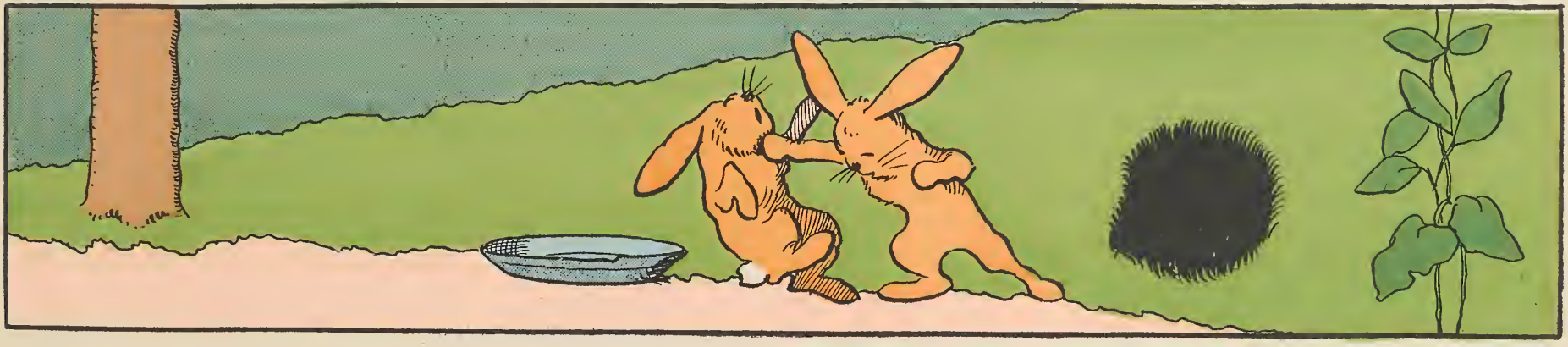

$-111$

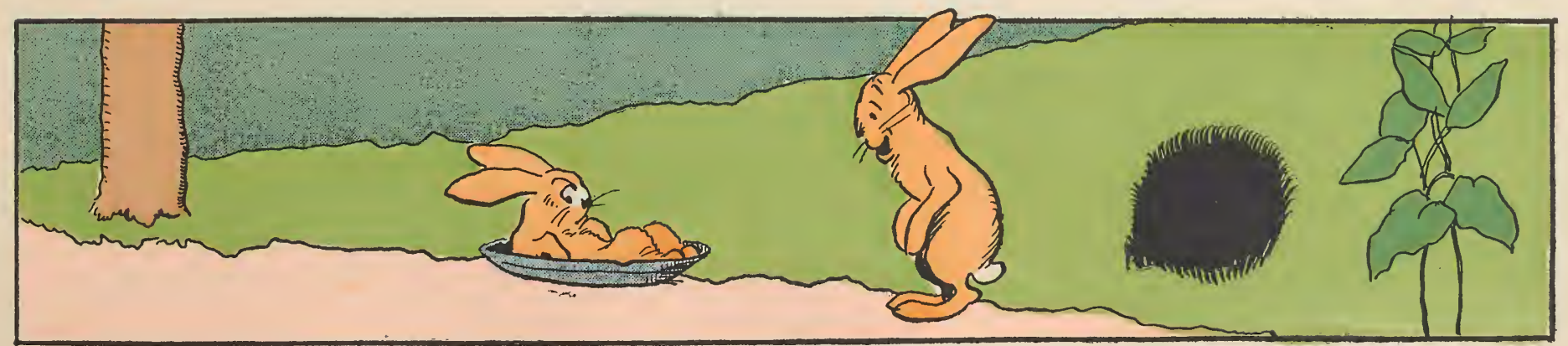

— Eh bien !... Tu es satisfait ! 
L'HALTĖRE

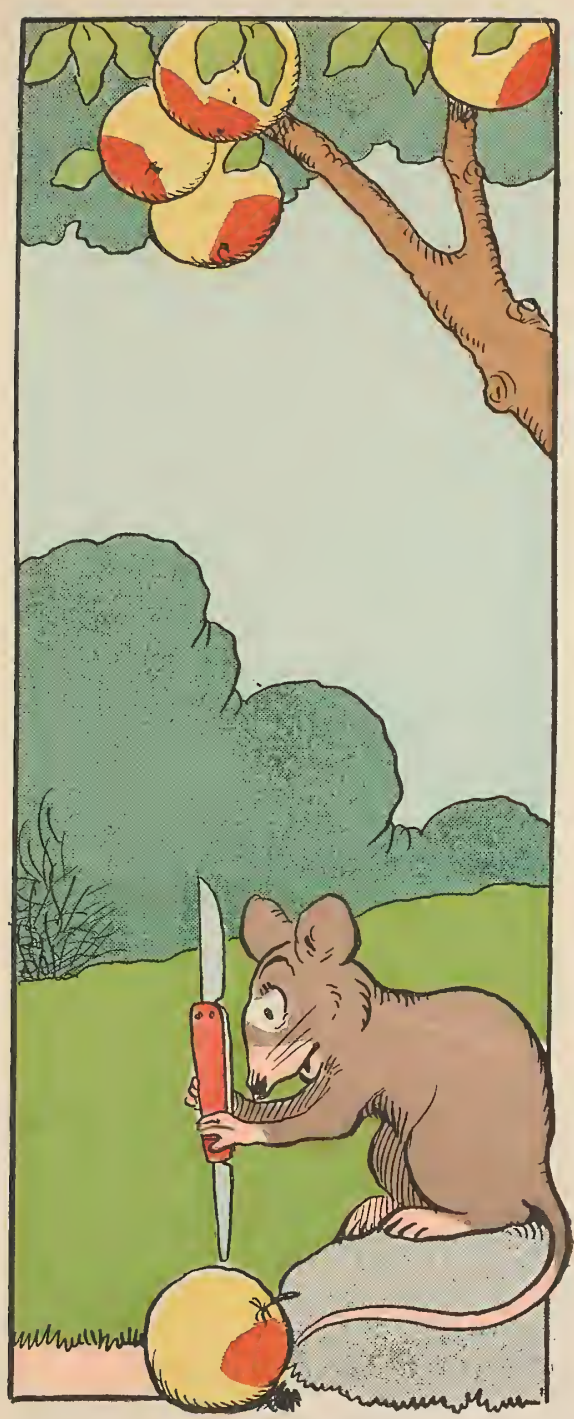

- Tiens... un canif !..

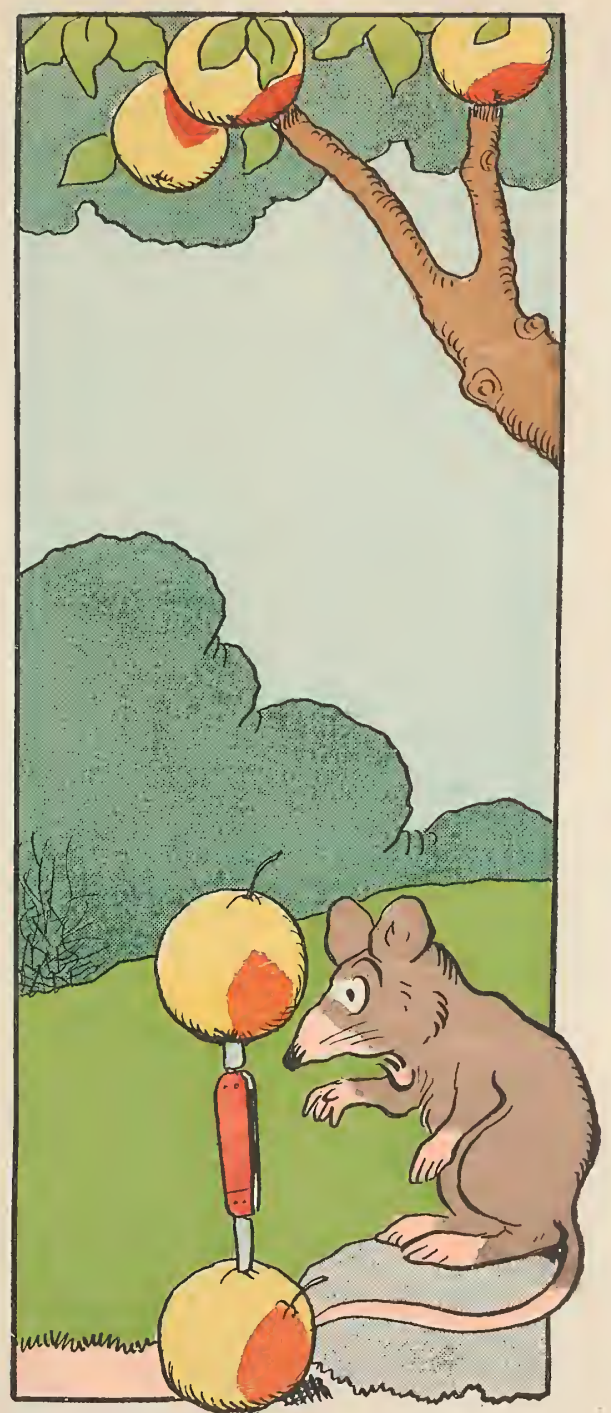

- Allons bon ! voilà les pommes qui

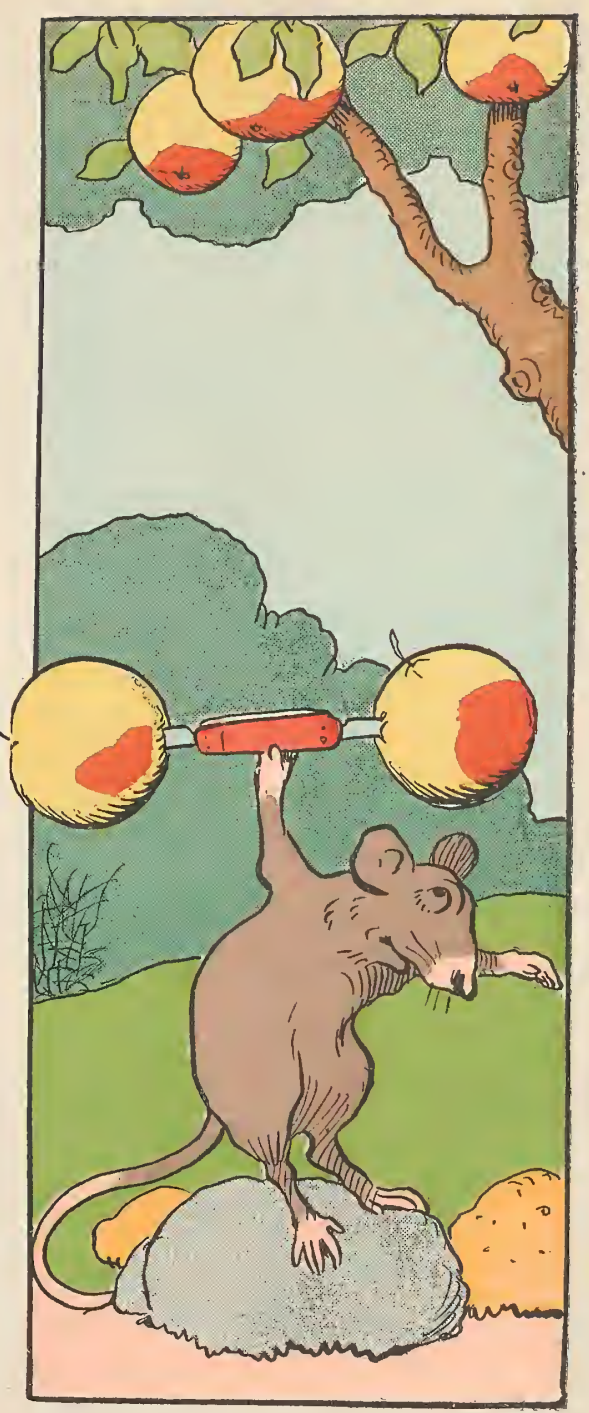

- Cela va me faire une excellente et économique haltère !... 


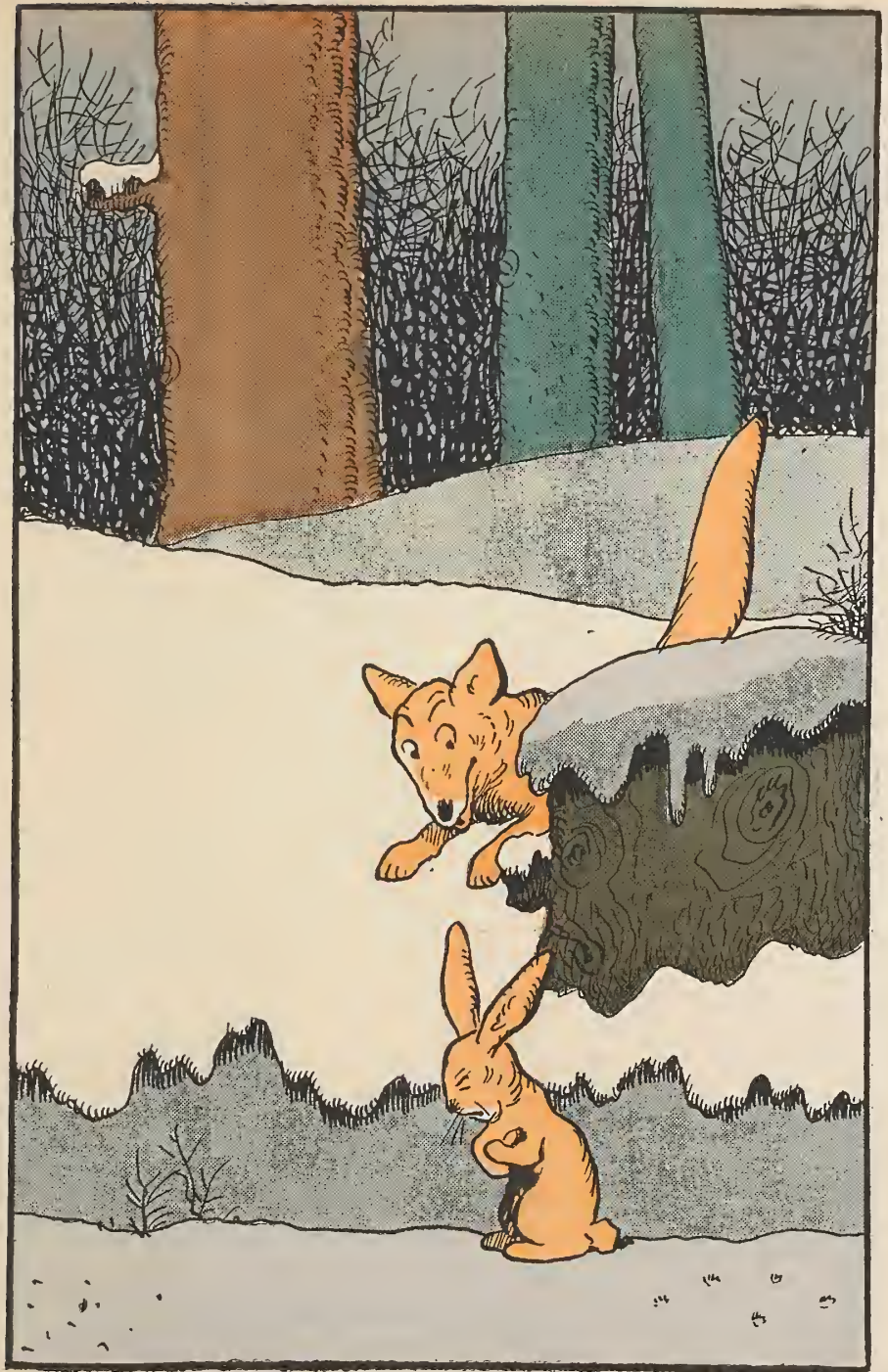

LE LAPIN. - Sapristi, qu'il fait froid. J'envie les élégantes qui s'enveloppent dans la fourrure d’un renard !

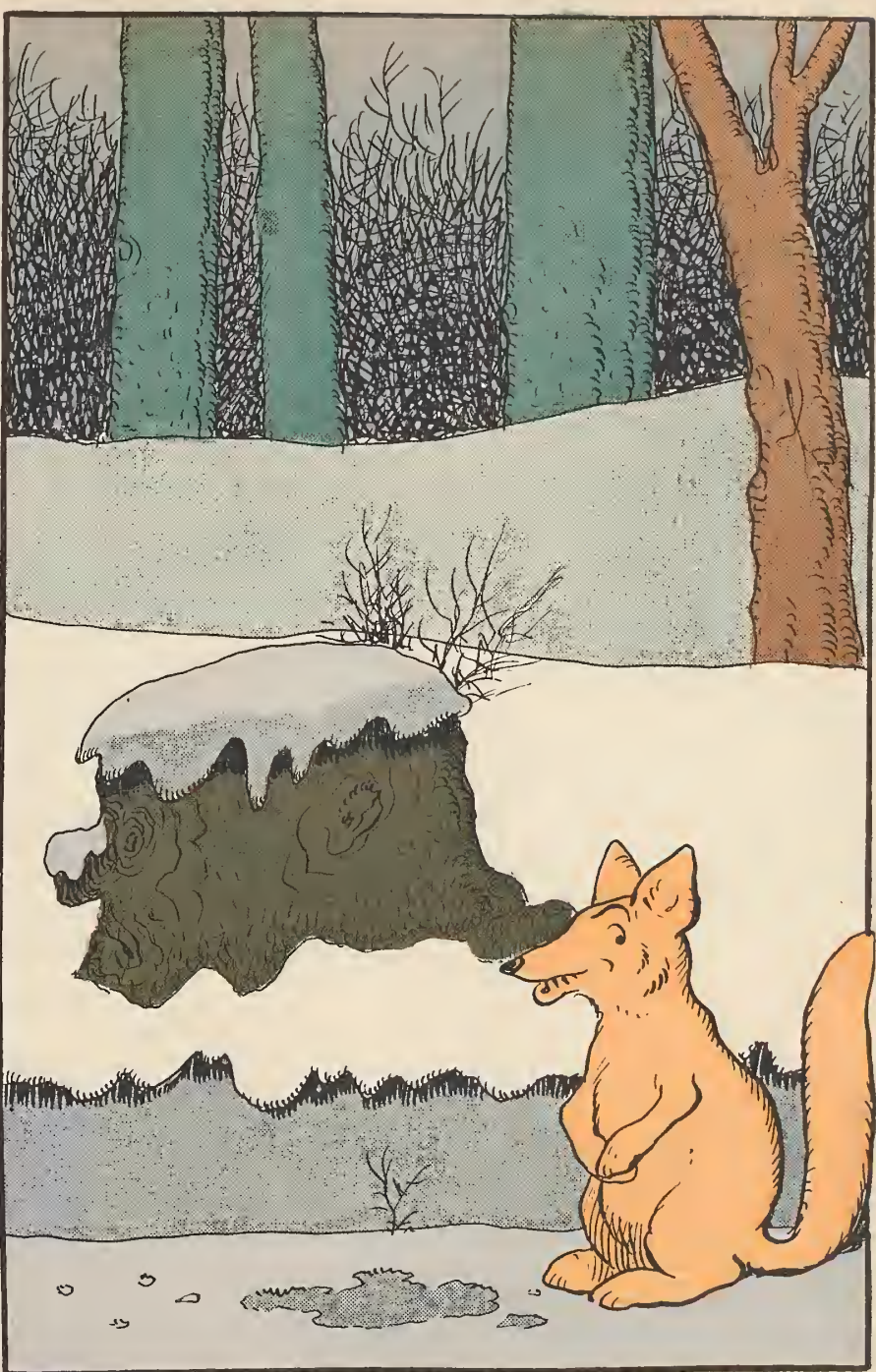

LE RENARD. - Pauvre petit lapin transi de froid; j'ai exaucé son vœu I 


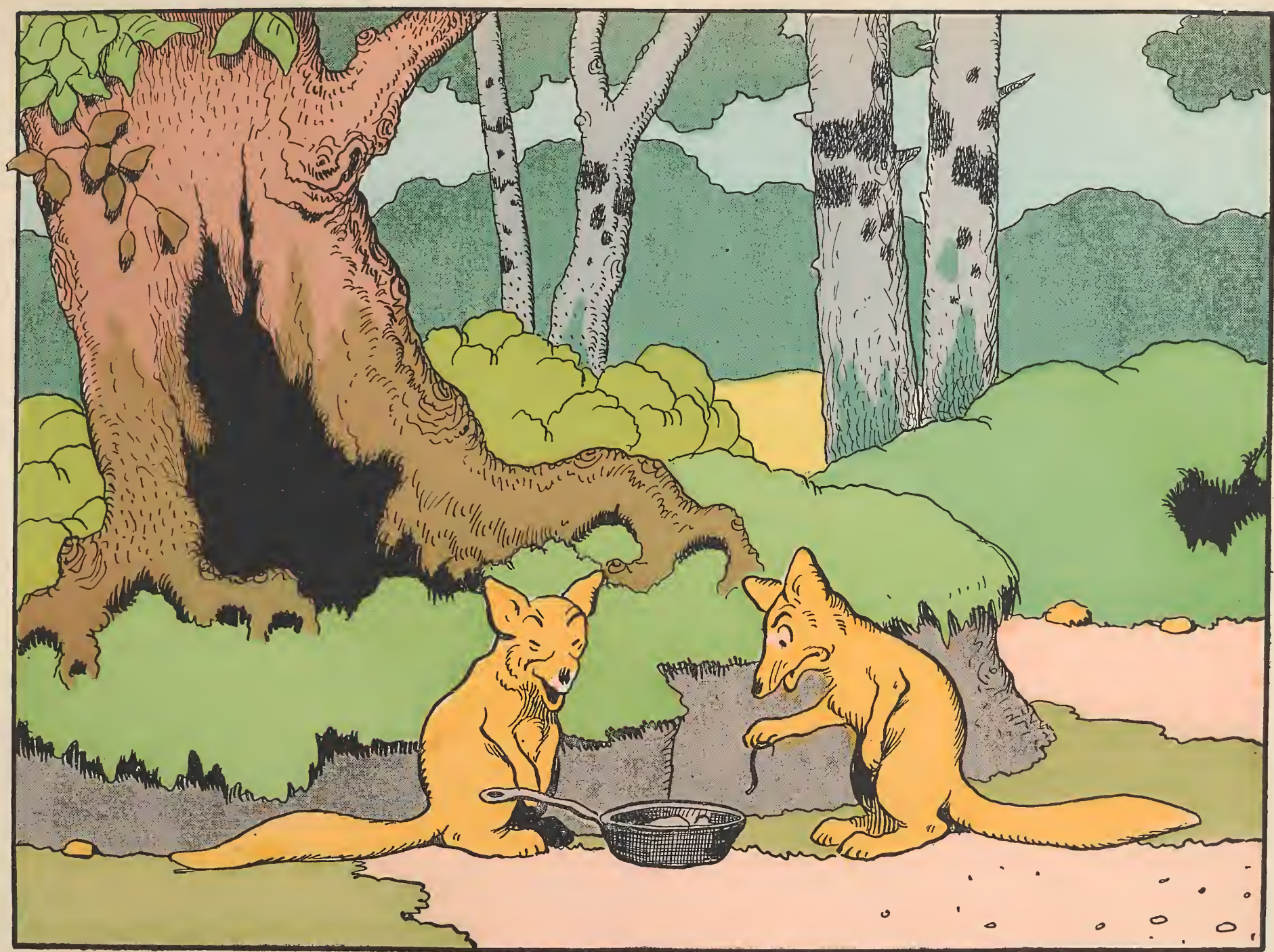

- Une queue de souris dans la gibelotte que j'ai chipée au "Cheval Blanc »! Qu'est-ce que cela veut dire ?...

- Cela veut dire que ce lapin digérait bien mal l... 


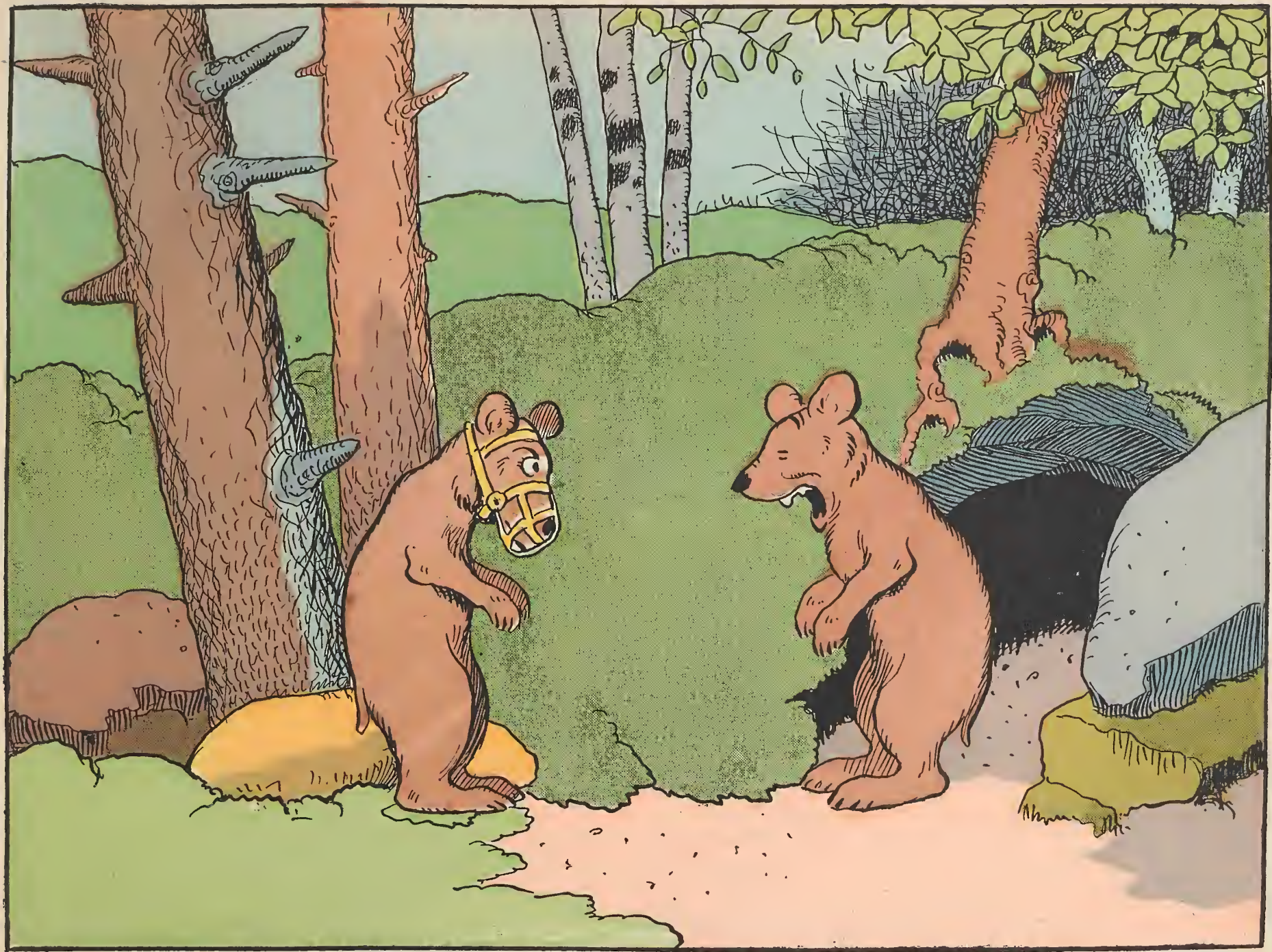

L'OURS. - Enfin, te voilà revenue, ma pauvre femme, je te croyais perdue?... L'OURSE. - J'ai été enlevée par des bohémiens... Vois l'instrument qu'ils m’ont ajusté sur le museau : ça_me gêne pour manger.
L'OURS. - Heureusement que ça ne te gêne pas pour parler ! 


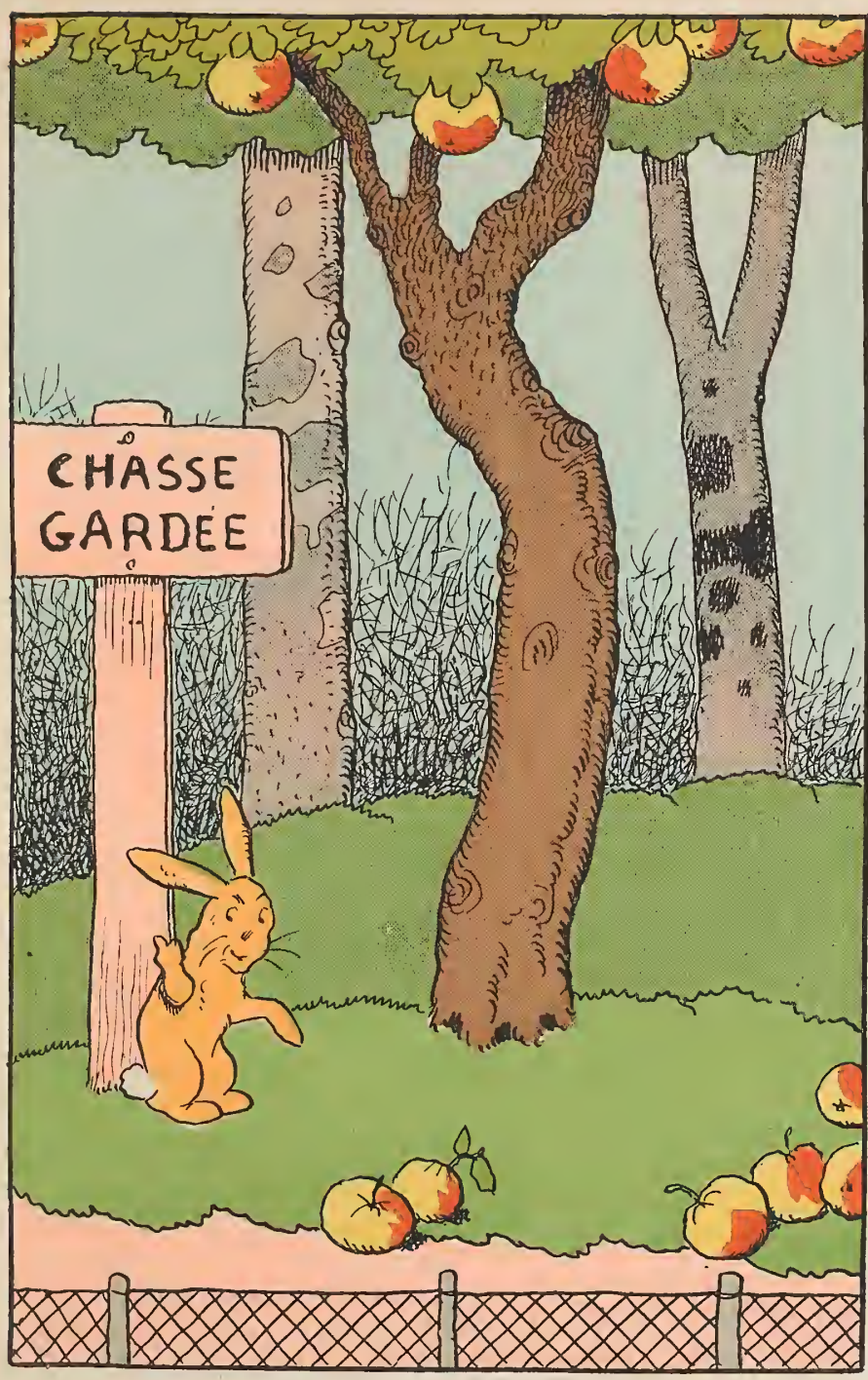

— Enfin, me voilà en sûreté et à l’abri...

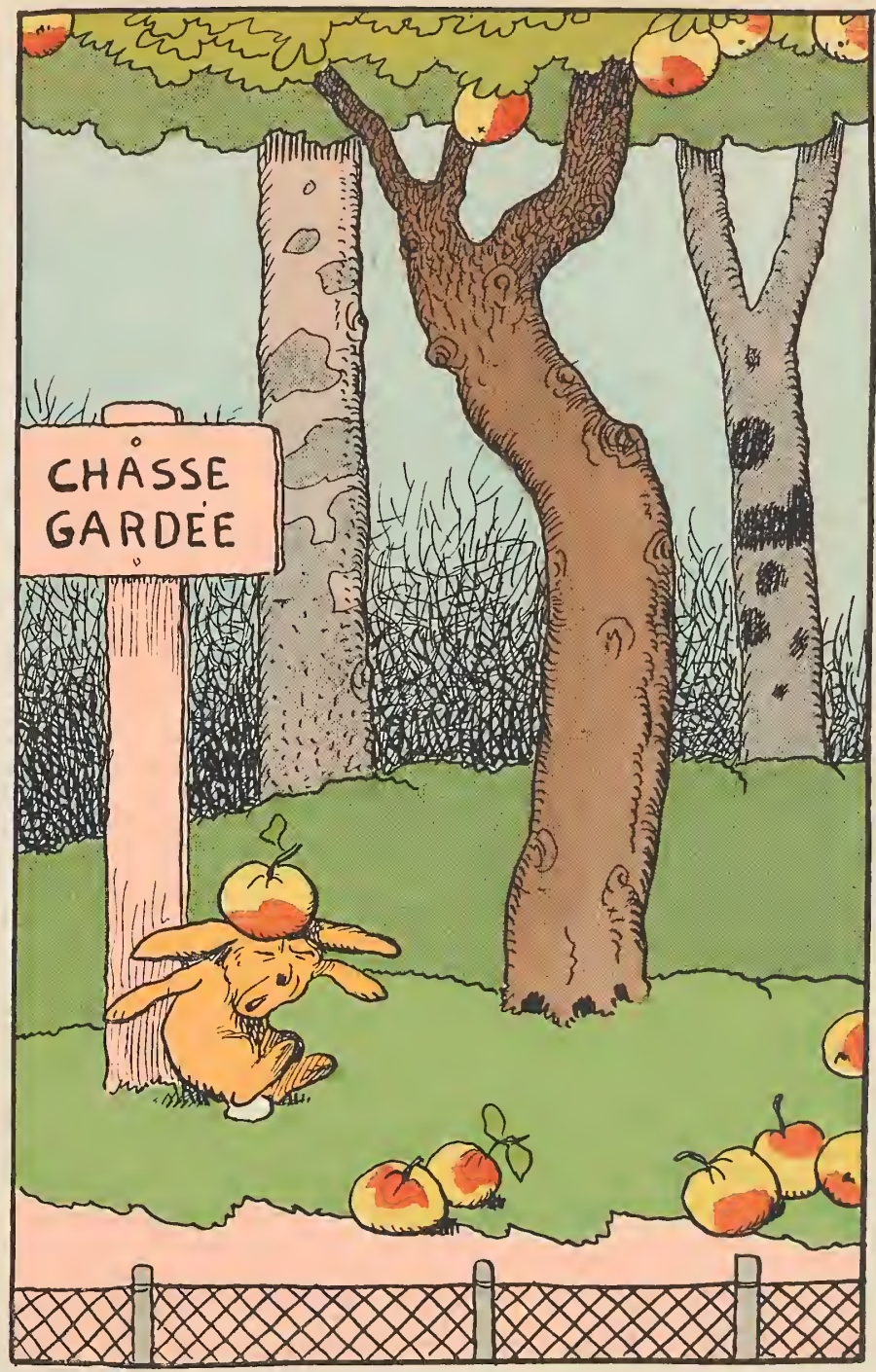

- ... des projectiles $! . .$. 


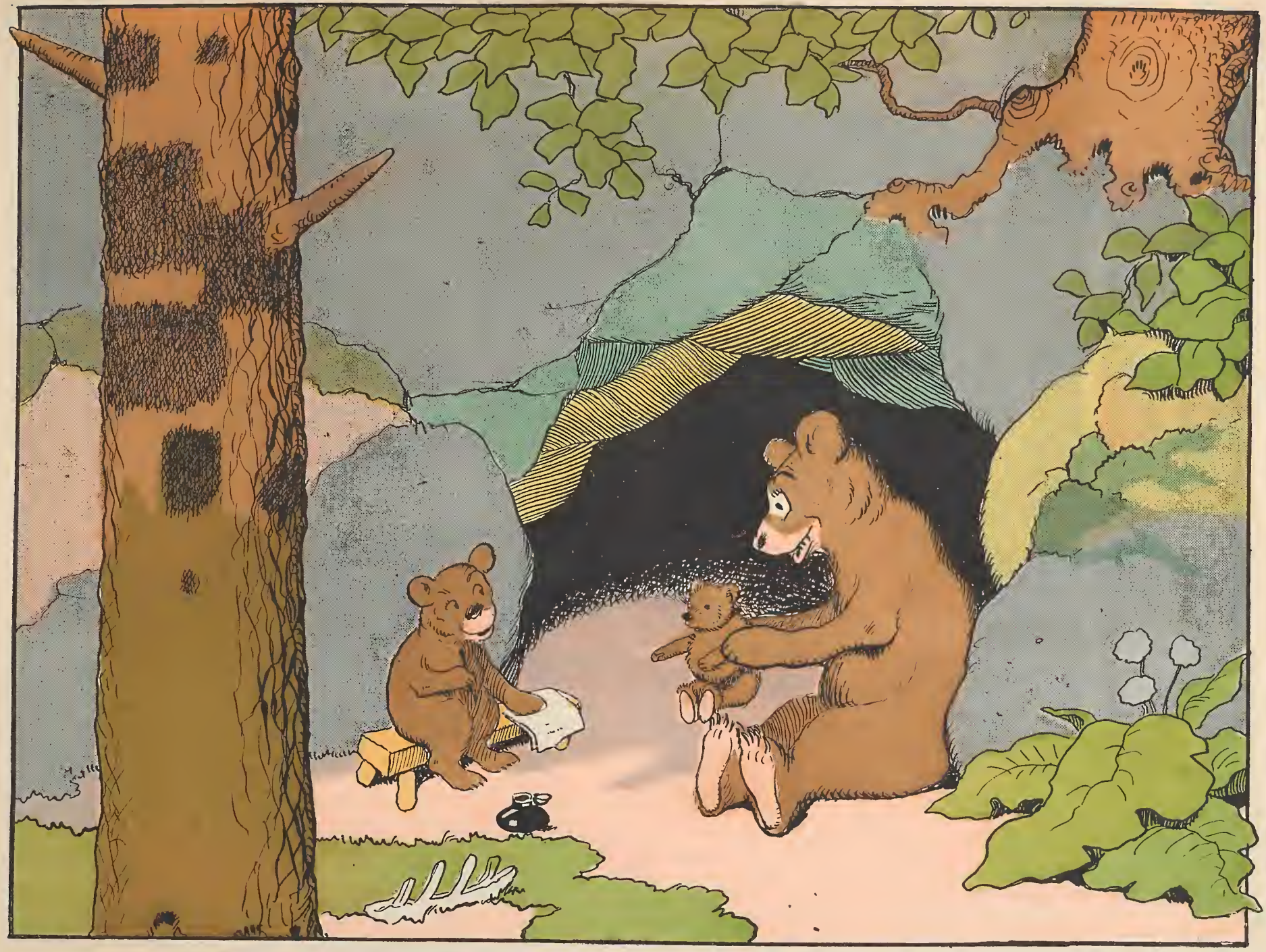

Étant donné que les hommes vendent 2 fr. 25 cet ours, qui pèse 500 grammes, quel serait le prix de ton père dont le poids est de quatre-vingt-dix kilos?... 


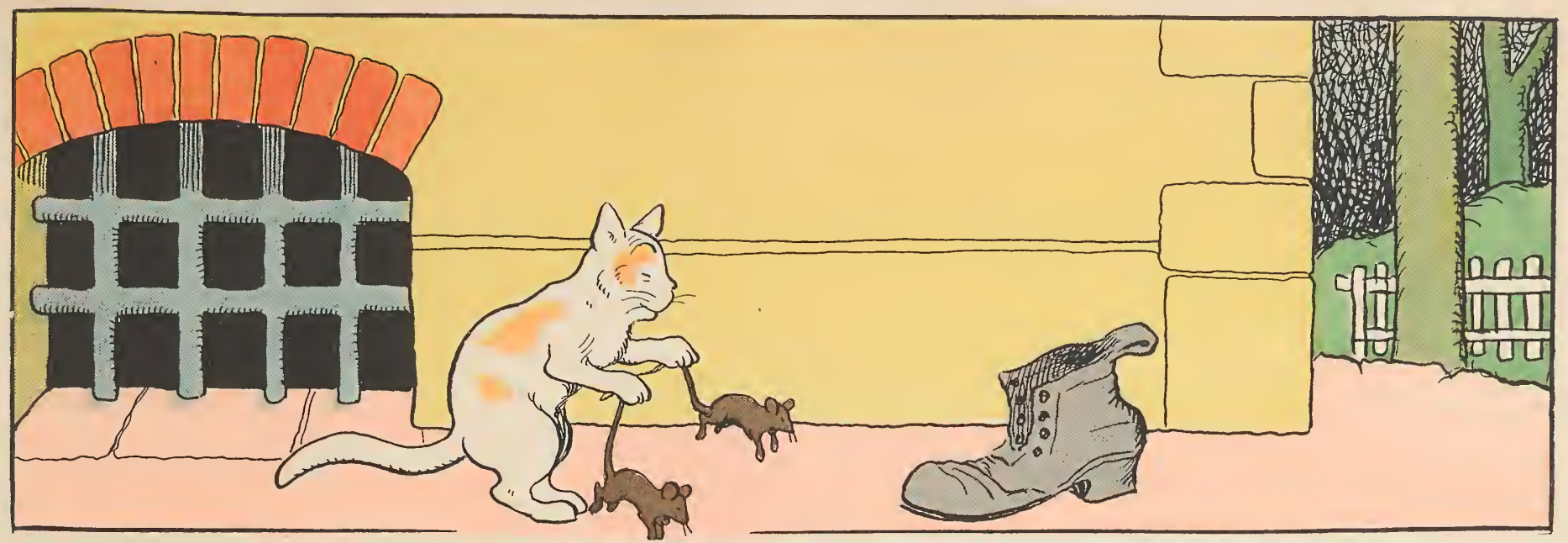

LE Chat. - C'est sans doute pour que je lui trouve un lacet que le garde-chasse a déposé cette bottine devant son pavillon.

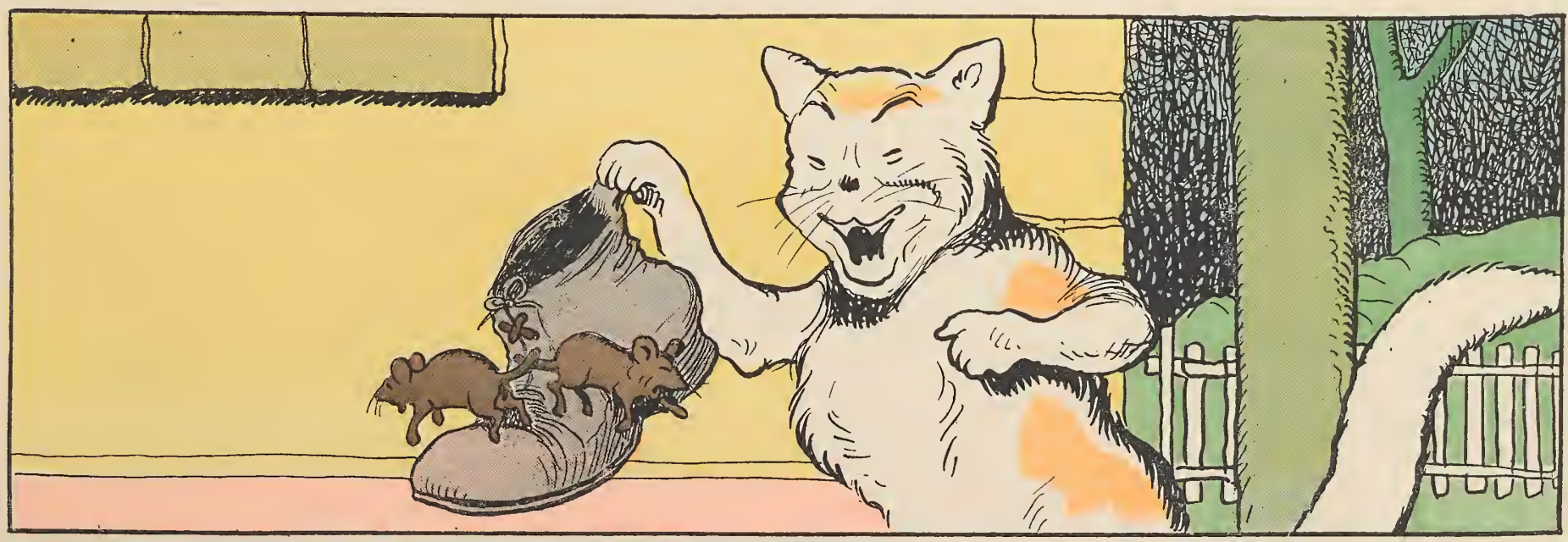

LE CHAT. - Le voilà satisfait ! 


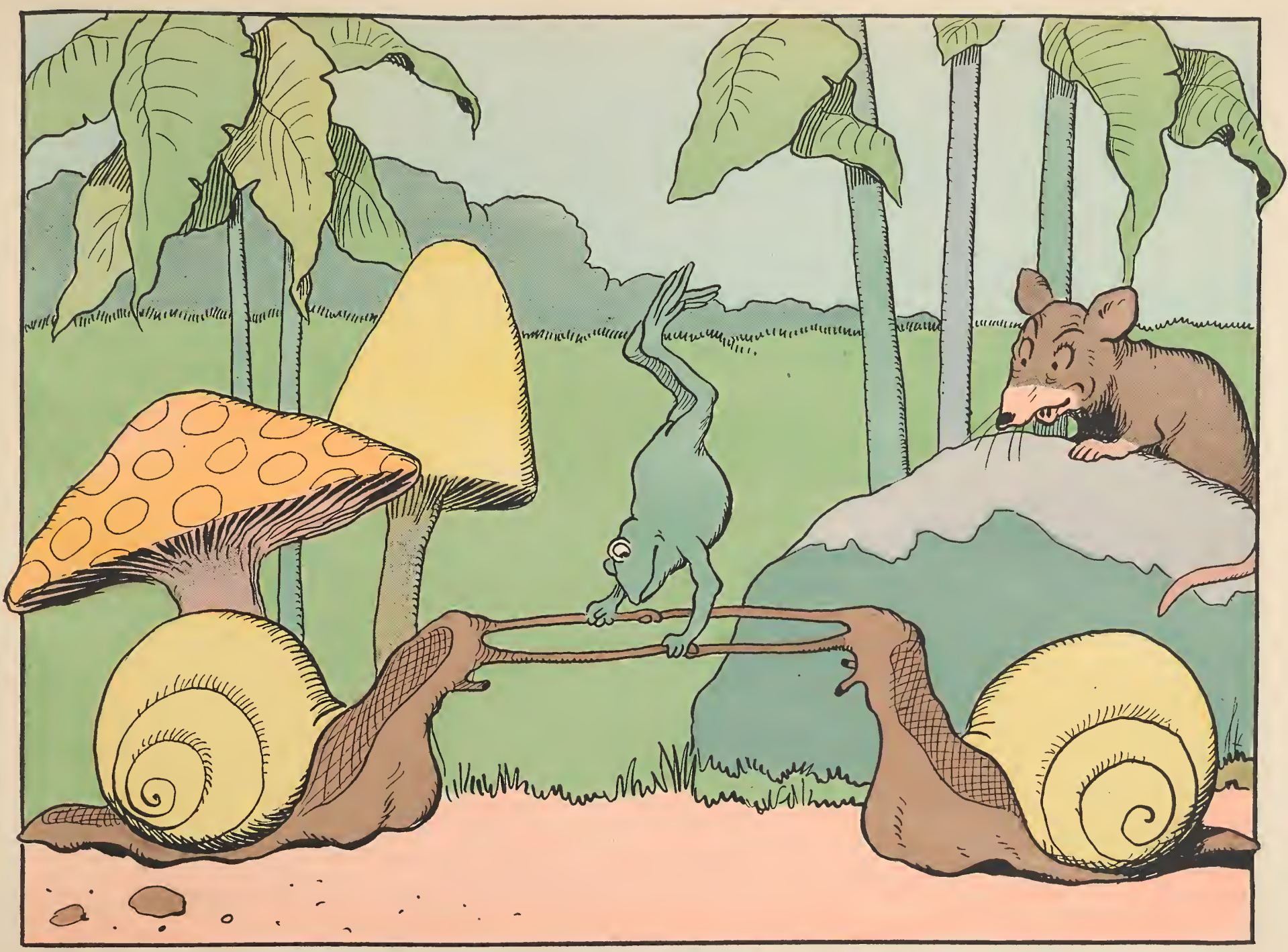

La gymnastique sur les barres parallèles. 


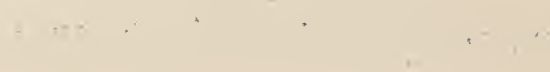


MAL CALCULÉ

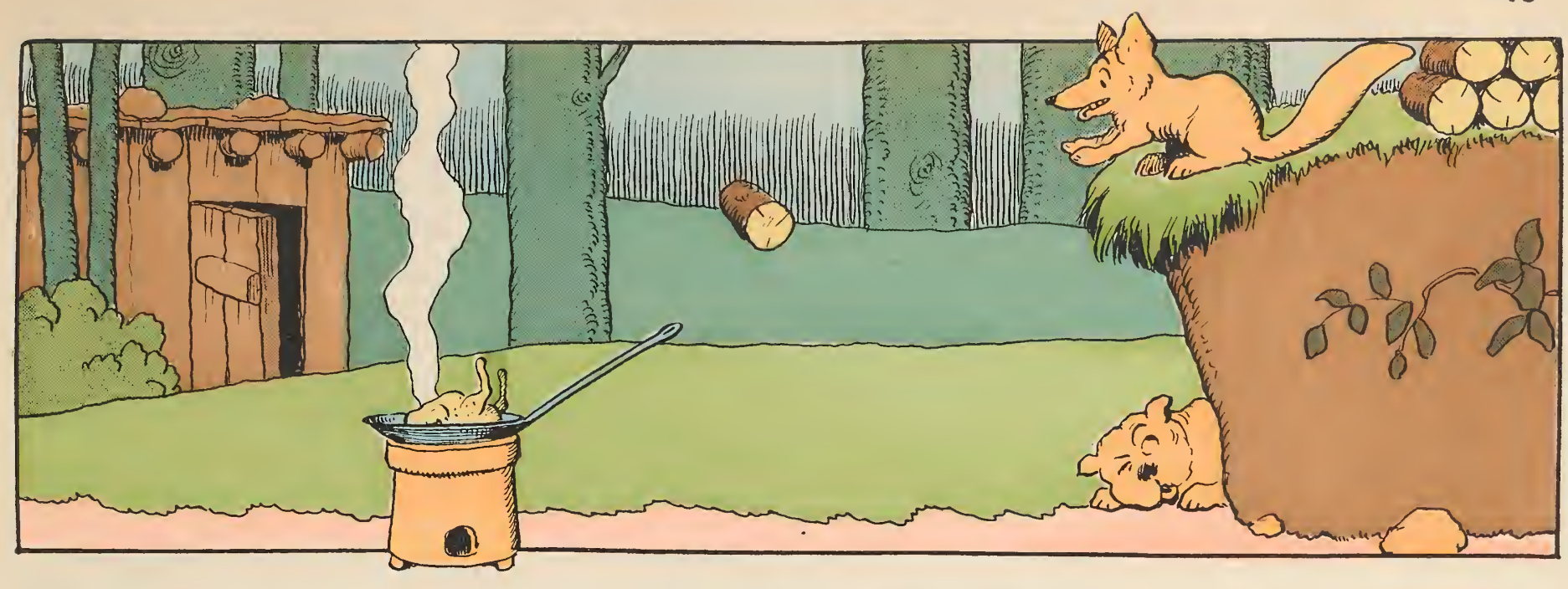

LE RENARD, - Visons bien, et le poulet rôti est à moi.

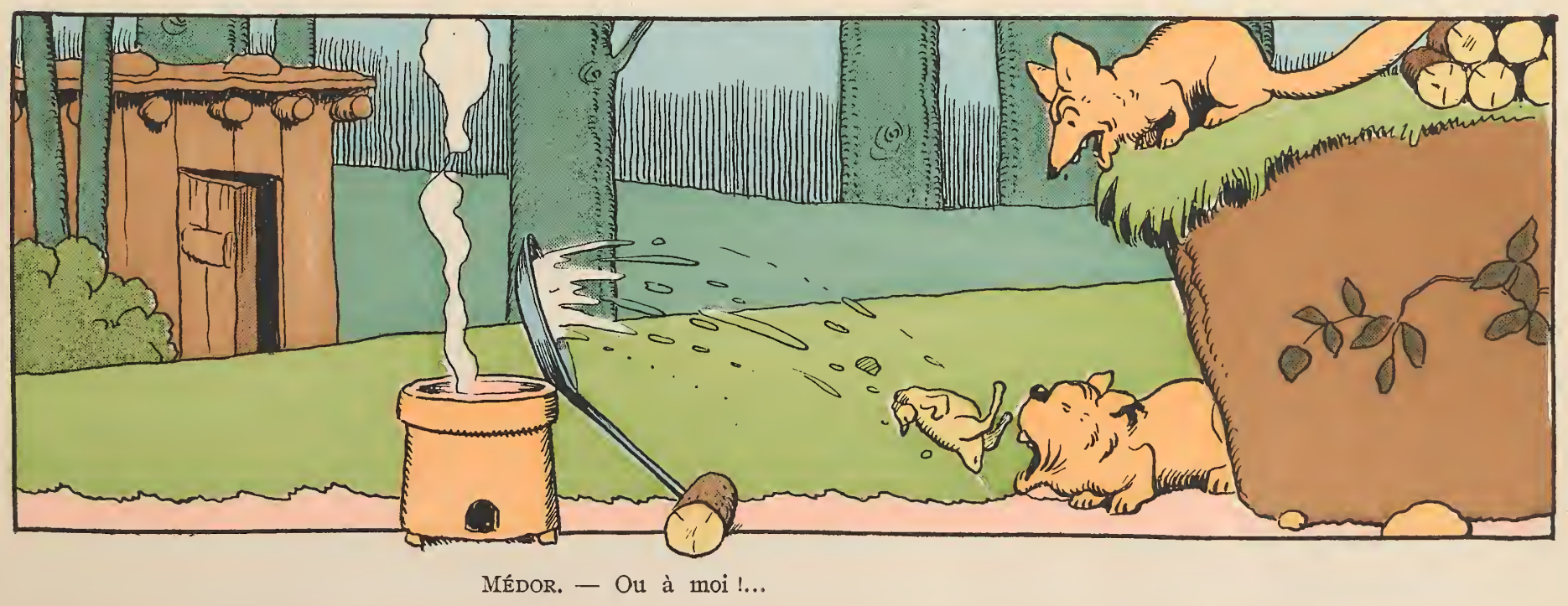




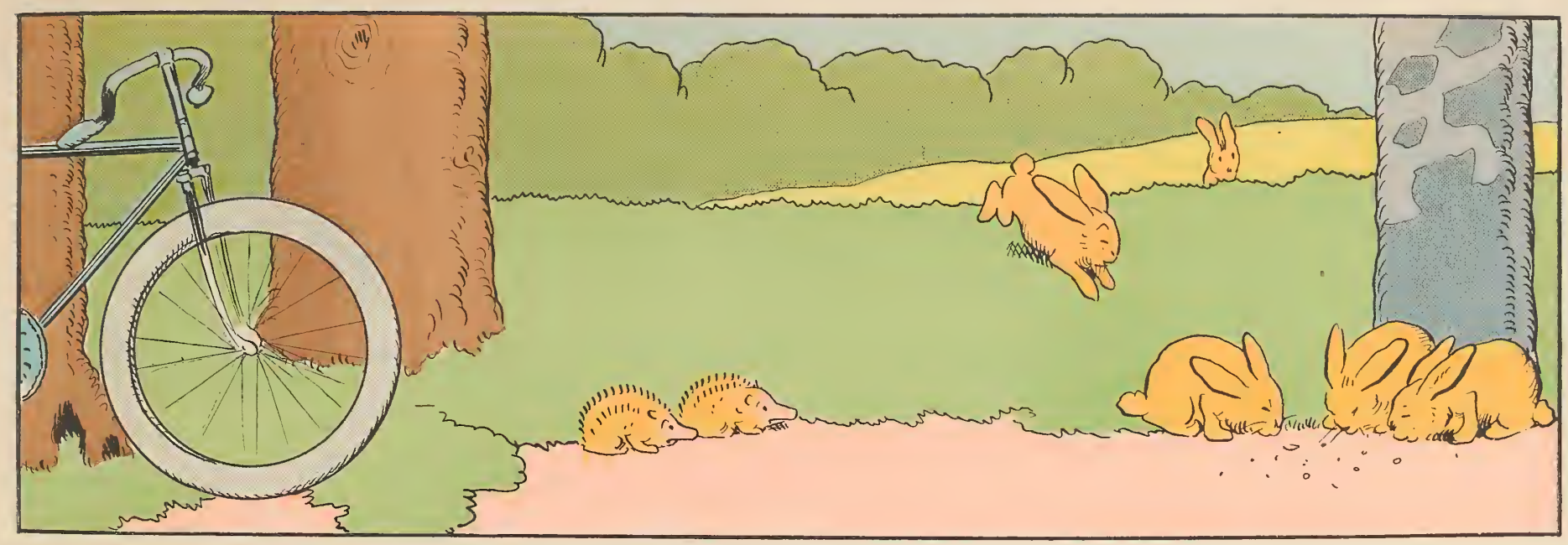

PREMIER HÉRISSON. - C'est embêtant, ces lapins vont manger tous ces bourgeons.

DEUTIÈme hérisson. - Comment faire pour les déloger?...

PREMIER hérisson. - J'ai une idée... je vais, avec mes pics, crever un pneu de la bicyclette du garde-forestier.

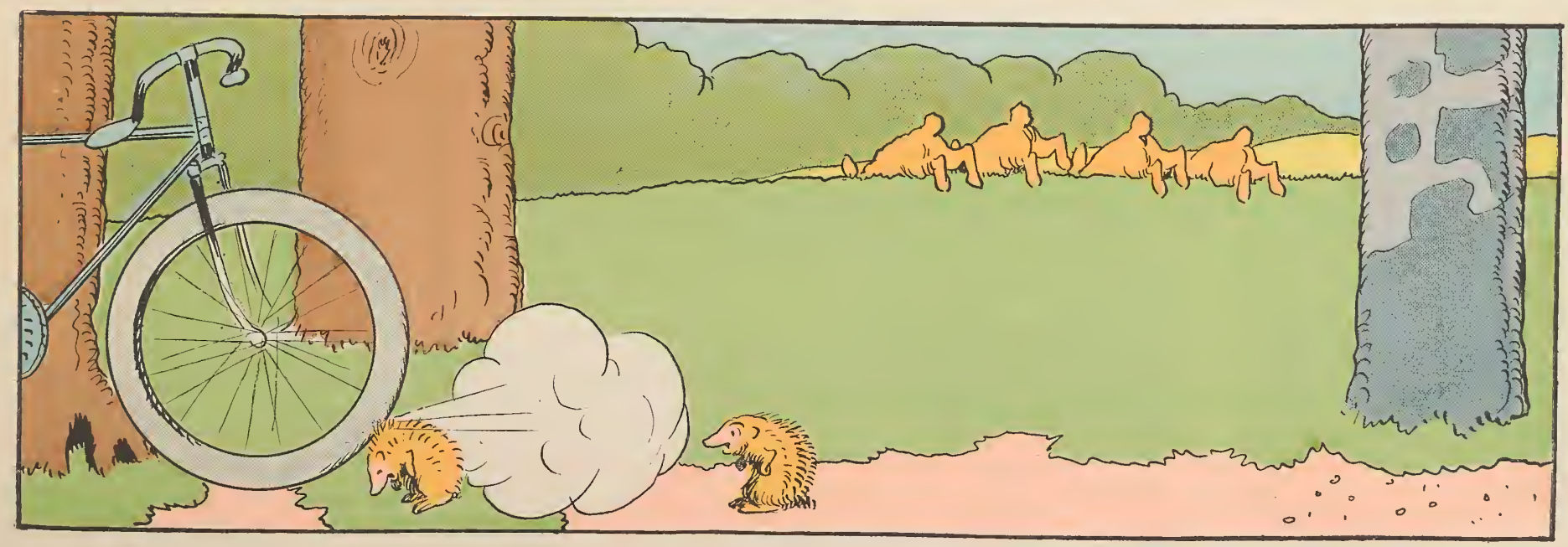

LE PNEU. - Pan ! ! !

LES LAPINS. - Sauve qui peut... la chasse est ouverte ! ! ! 


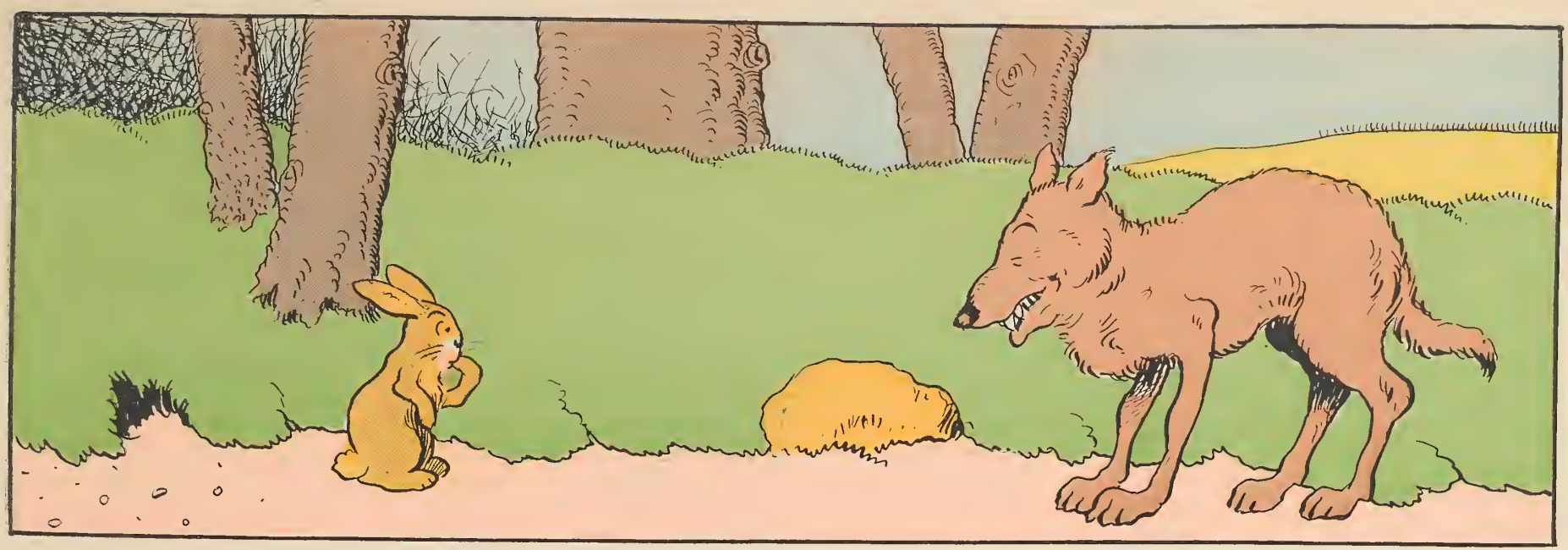

LE LARIN. - Voilà le loup... je vais avoir bien du mal à passer !...

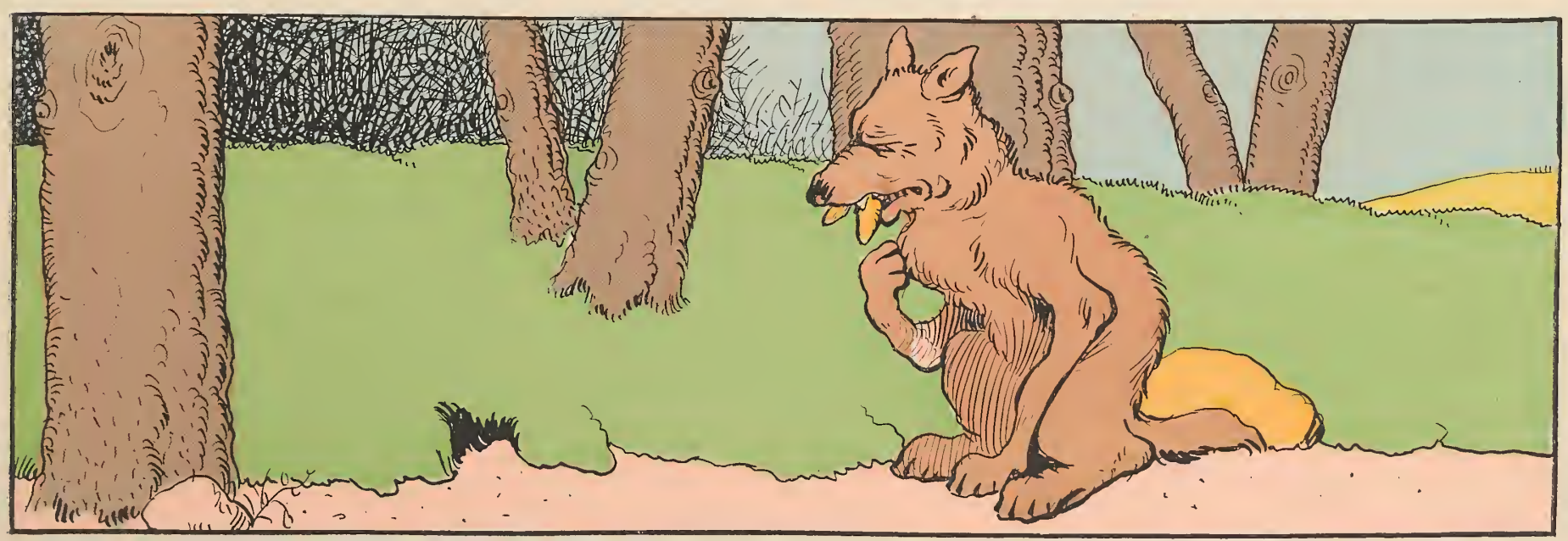

LE LOUP. - Il avait raison, le petit... Il a bien du mal à passer! 


\section{.}




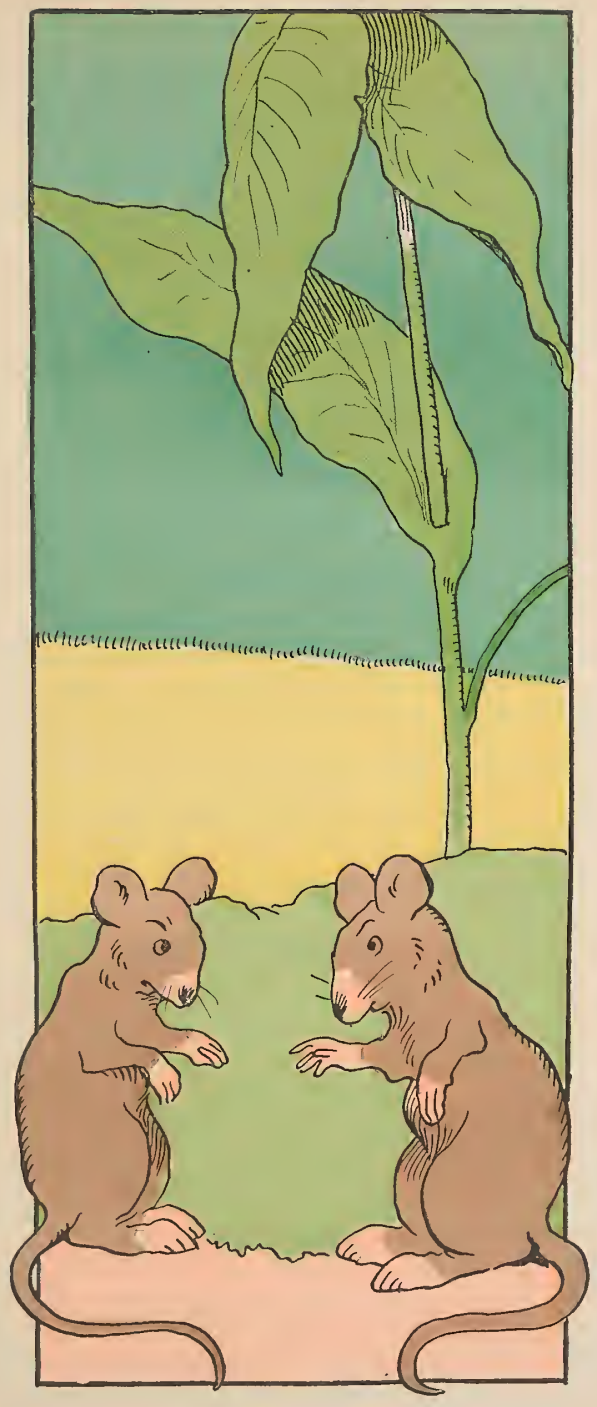

- Tu paies un ver, ce matin?

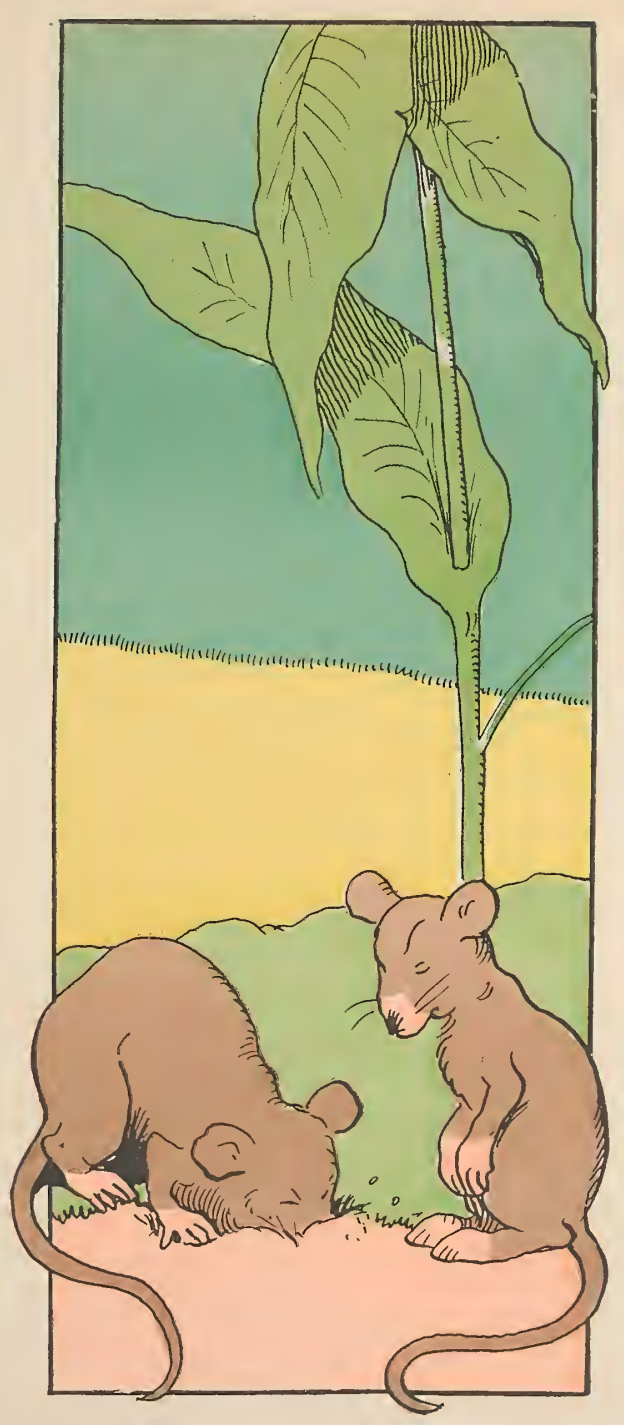

- Si tu veux...

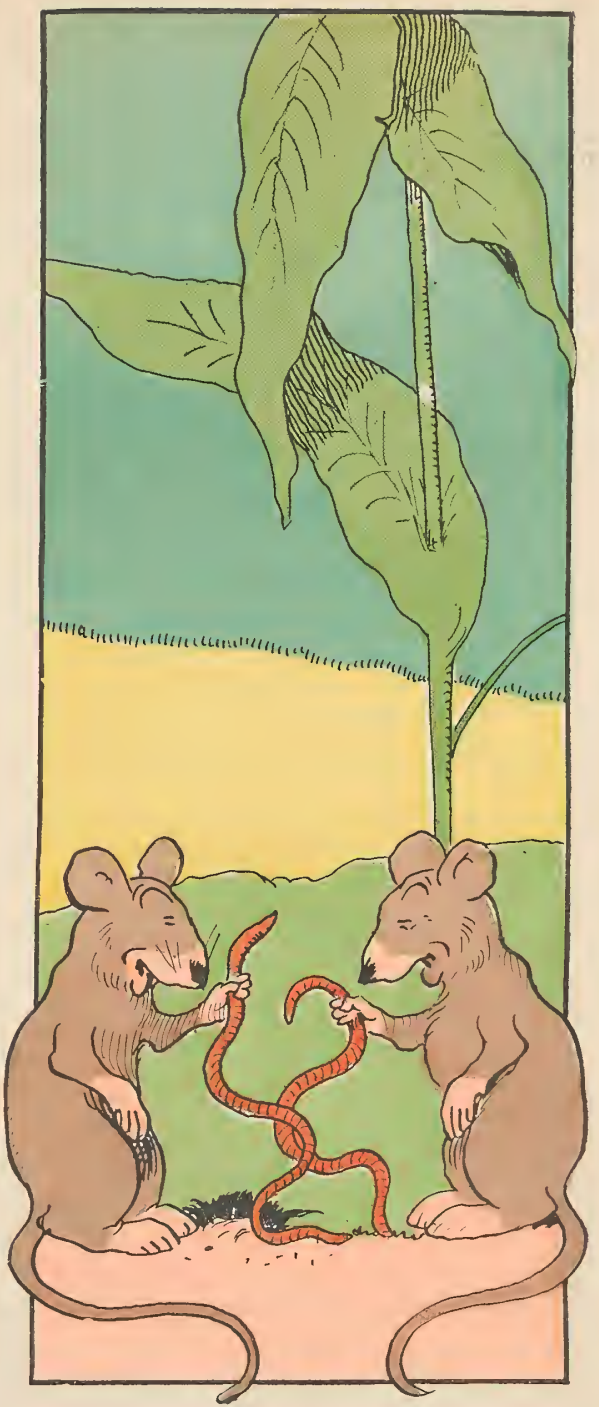

- A la tienne !... 


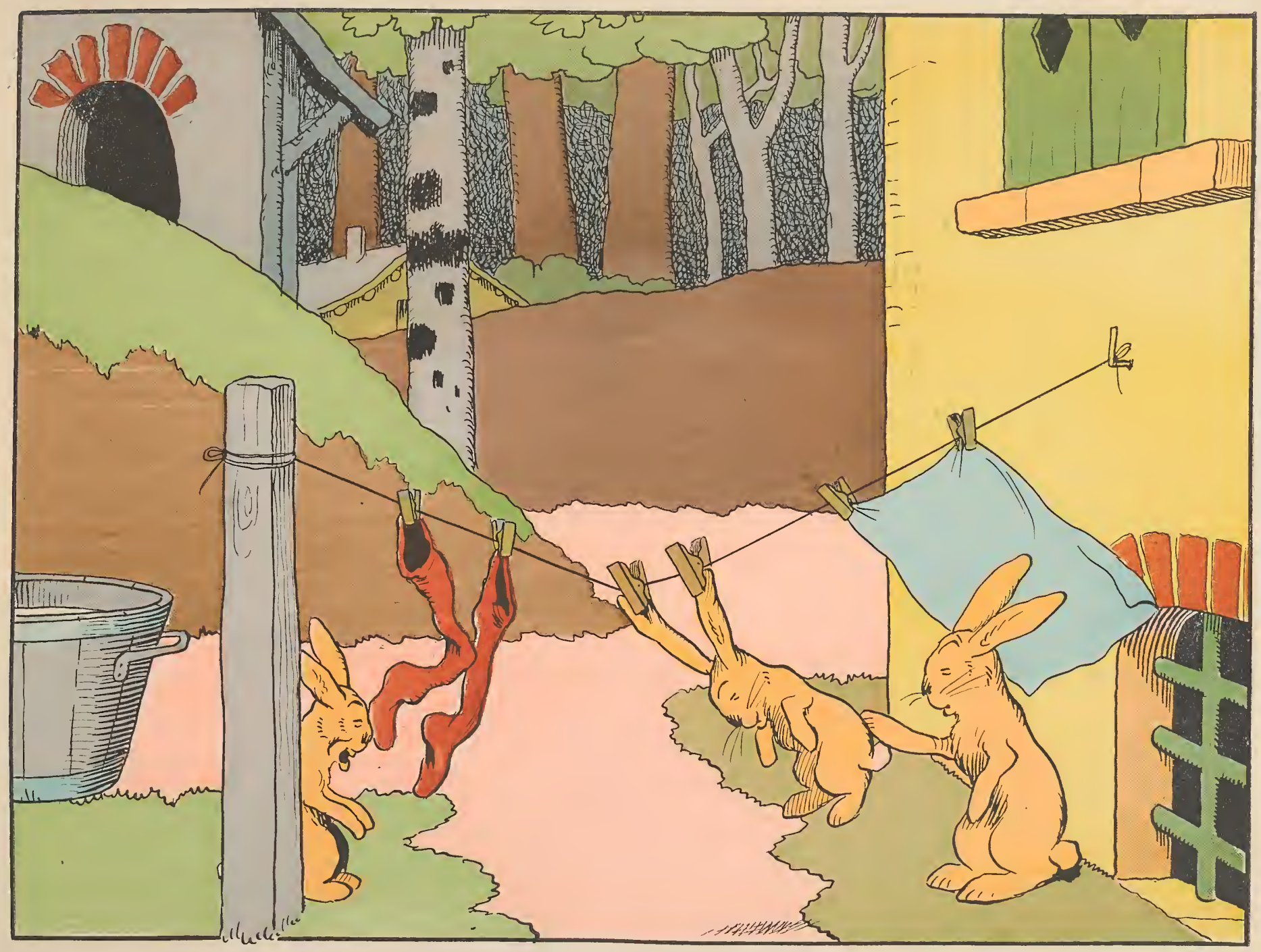

Une idylle familiale à la ferme du garde-chasse. 
Paris. - Imprimerie E. Desfossés, 13, quai Voltaire. - 52956.7-12

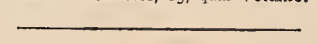






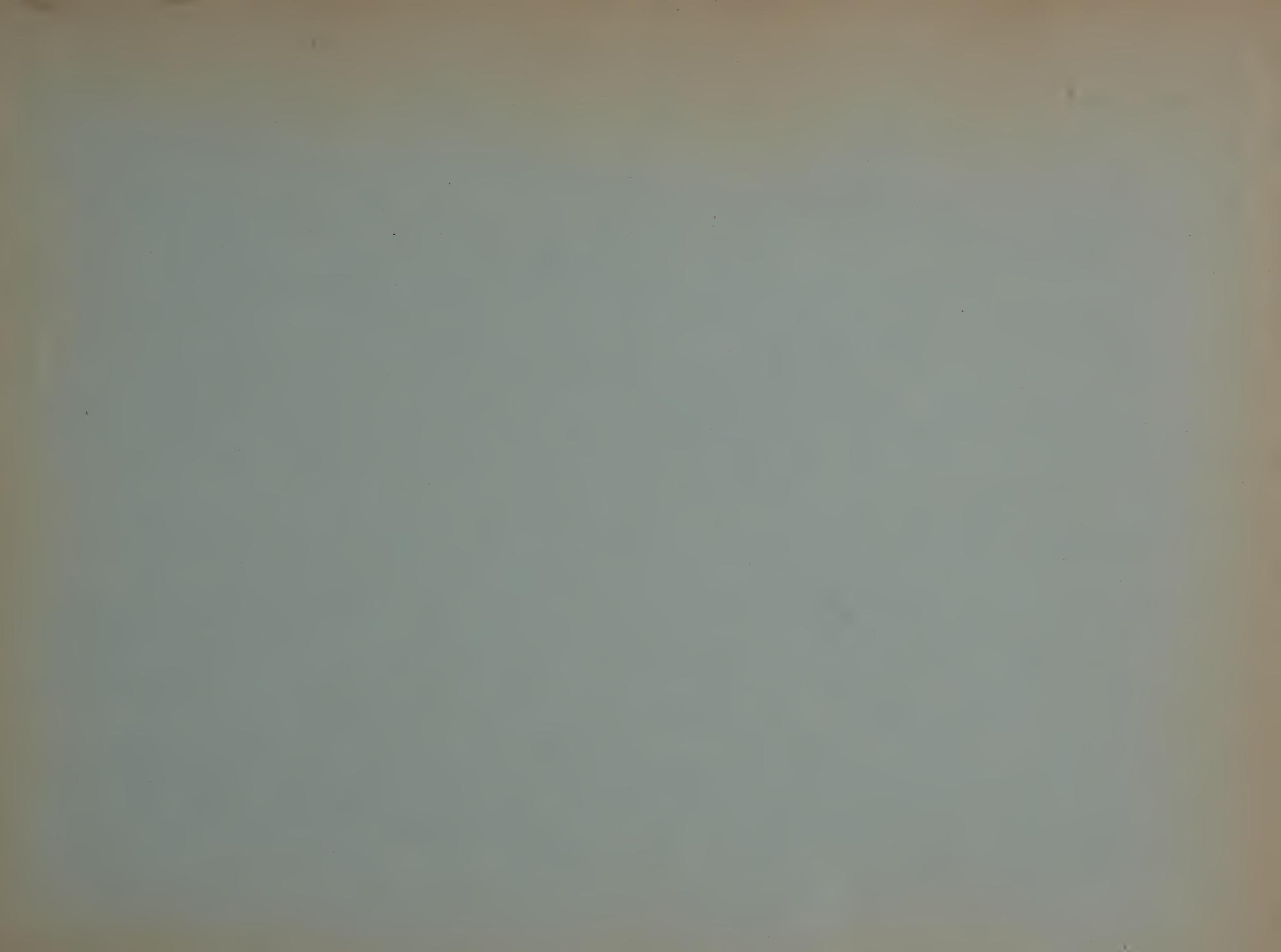




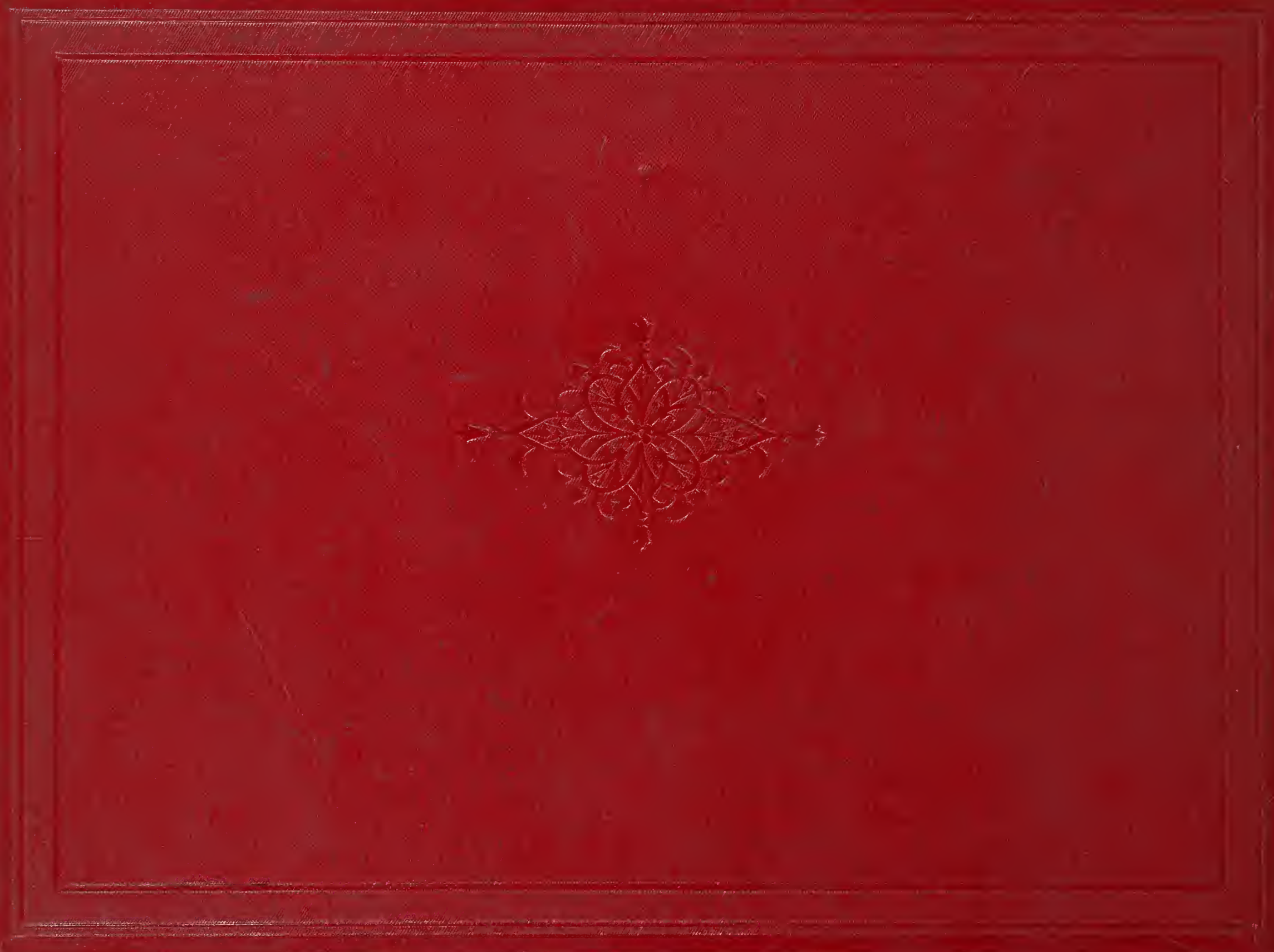

